\author{
UNIVERSIDADE DE SÃO PAULO \\ ESCOLA DE EDUCAÇÃO FÍSICA E ESPORTE
}

\title{
A PRÁTICA CONSTANTE-ALEATÓRIA E A DIVERSIFICAÇÃO DE HABILIDADES MOTORAS
}

João de Paula Pinheiro

SÃO PAULO

2009 
A PRÁTICA CONSTANTE-ALEATÓRIA E A DIVERSIFICAÇÃO DE HABILIDADES MOTORAS

JOÃO DE PAULA PINHEIRO

Dissertação apresentada à Escola de Educação Física e Esporte da Universidade de São Paulo, como requisito parcial para obtenção do grau de Mestre em Educação Física.

ORIENTADOR: PROF.DR. UMBERTO CESAR CORRÊA 


\section{AGRADECIMENTOS}

Ao Prof. Dr. Umberto Cesar Corrêa, pela orientação, confiança e incentivo.

Aos membros da banca, Prof. Dr. Jorge Alberto de Oliveira e Prof. Dr. Rodolfo Novellino Benda, pelas contribuições ao trabalho.

À diretoria e a coordenação pedagógica das instituições de ensino que forneceram as condições necessárias para a realização da coleta de dados. E também, aos professores dessas instituições que auxiliaram esse processo.

À Kika e à Regina do curso "Aprendendo a nadar" da EEFEUSP, por também terem colaborado com a coleta de dados.

Às crianças que participaram da pesquisa como sujeitos.

Aos amigos do LACOM, pelas críticas e sugestões ao trabalho, e pelo apoio.

Ao Ivan, pela ajuda na coleta de dados.

À minha família e a Carol, por todo o apoio e pela compreensão dos momentos em que estive ausente.

À CAPES, pela concessão da bolsa de estudo.

A todos que de alguma forma contribuíram para a realização desta dissertação, meus sinceros agradecimentos.

Obrigado. 
SUMÁRIO

Página

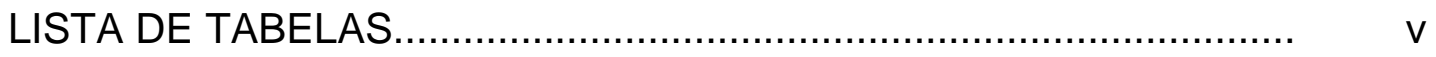

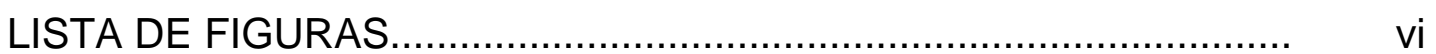

LISTA DE QUADROS.......................................................... ix

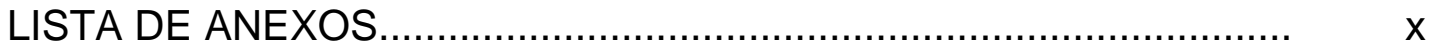

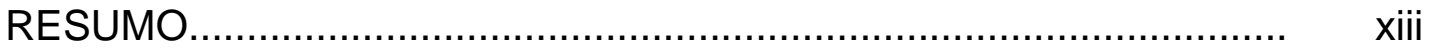

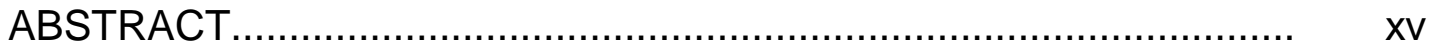

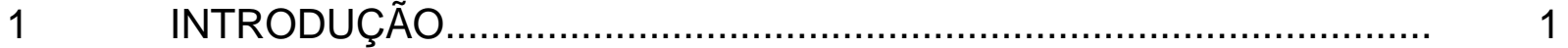

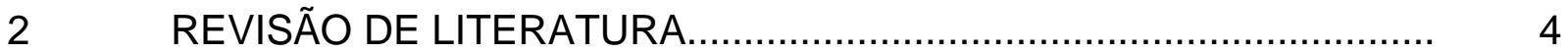

2.1 Processo adaptativo de aprendizagem motora............................... 4

2.2 Estrutura de prática e processo adaptativo de aprendizagem motora. 14

2.3 A prática constante-variada no processo adaptativo de aprendizagem motora................................................................. 22

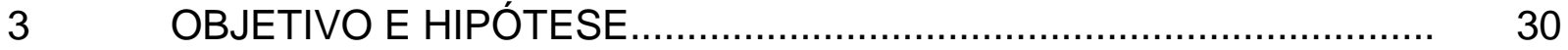

4 EXPERIMENTO 1 - VARIAÇÃO DO ASPECTO PERCEPTIVO........... 30

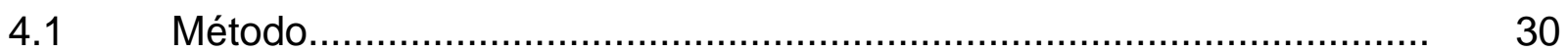

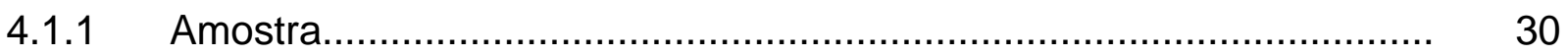

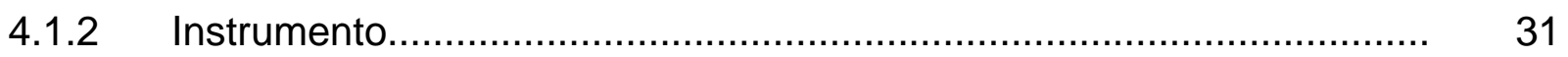

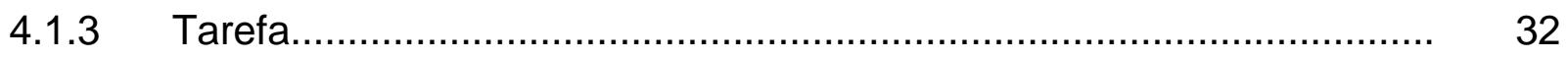

4.1.4 Procedimentos e delineamento.............................................. 32

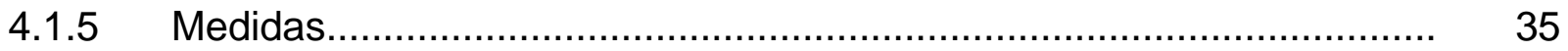

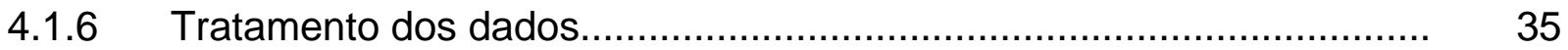

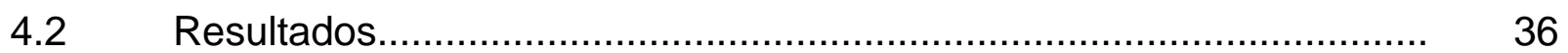

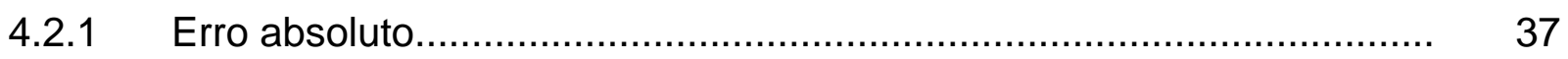

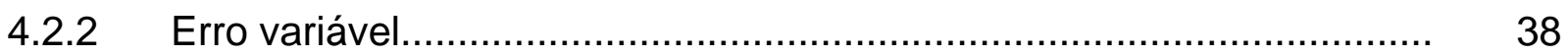


4.2.3 Erro constante................................................................. 39

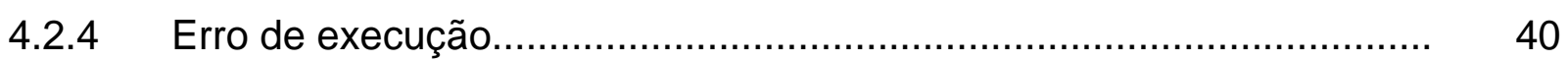

4.3 Síntese dos resultados........................................................ 41

5 EXPERIMENTO 2- VARIAÇÃO DO ASPECTO MOTOR..................... 42

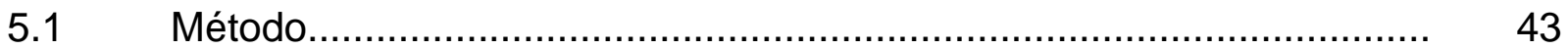

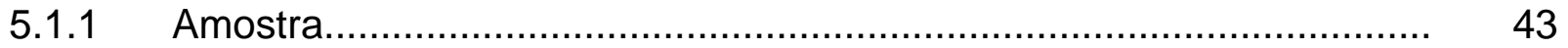

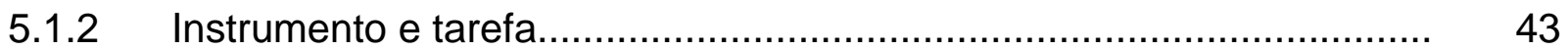

5.1.3 Procedimentos e delineamento.......................................... 43

5.1.4 Medidas e tratamento dos dados................................................ 44

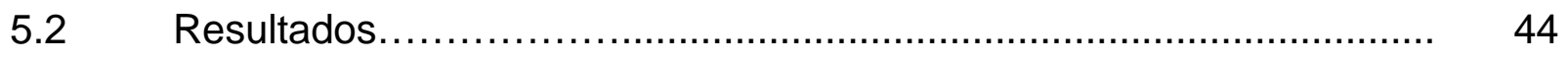

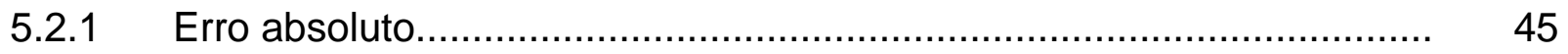

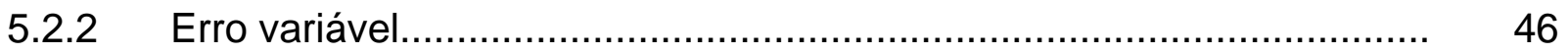

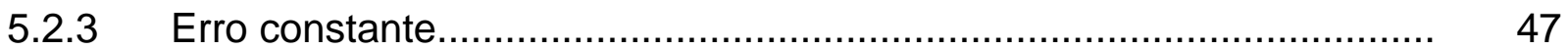

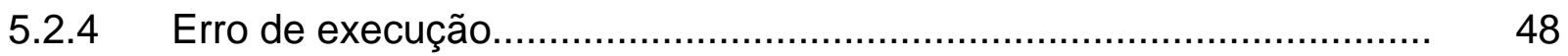

5íntese dos resutados.............................................................. 49

6 EXPERIMENTO 3 - VARIAÇÃO DOS ASPECTOS PERCEPTIVO E MOTOR ....................................................................... 50

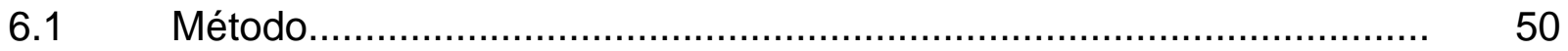

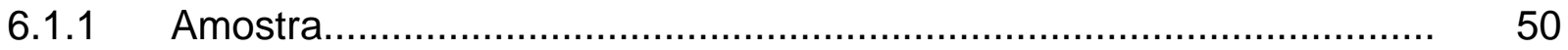

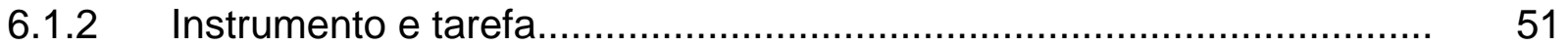

6.1.3 Procedimentos e delineamento................................................. 51

6.1.4 Medidas e tratamento dos dados................................................ 52

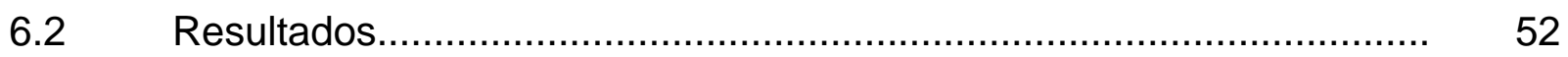

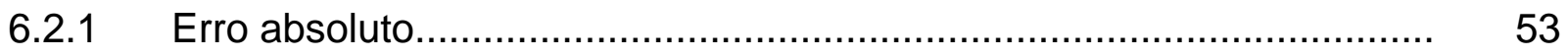

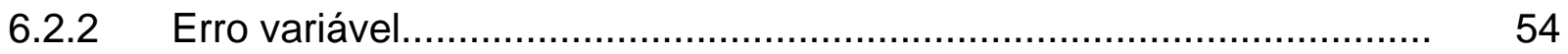

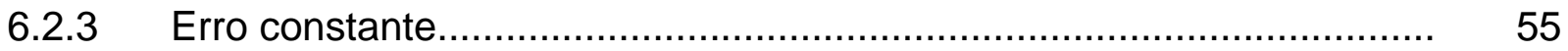

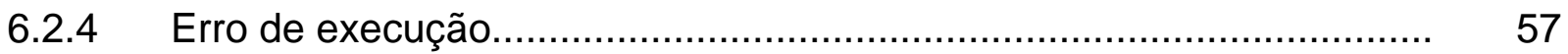

6.3 Síntese dos resultados.............................................................. 58

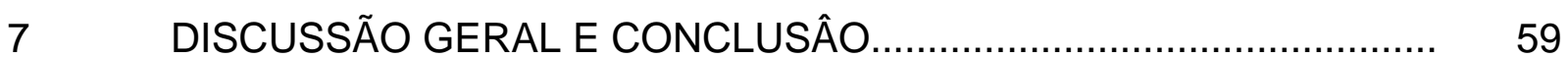

REFERÊNCIAS .................................................................. 62

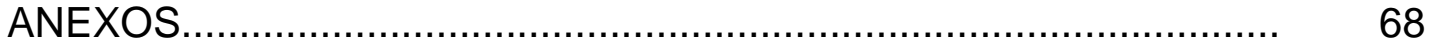


TABELA 1 - Médias dos erros absoluto (EA), variável (EV) e constante (EC) em milissegundos e mediana do erro de execução (EE) dos dois grupos experimentais (CA3 e CA6), no primeiro bloco de tentativas de prática constante (Co1) e nos quatro blocos de tentativas de prática aleatória (Aleat) da fase de estabilização, e nos quatro blocos de tentativas da fase de adaptação (Adap).....

TABELA 2 - Médias dos erros absoluto (EA), variável (EV) e constante (EC) em milissegundos e mediana do erro de execução (EE) dos dois grupos experimentais (CA3 e CA6), no primeiro bloco de tentativas de prática constante (Co1) e nos quatro blocos de tentativas de prática aleatória (Aleat) da fase de estabilização, e nos quatro blocos de tentativas da fase de adaptação (Adap).....

TABELA 3 - Médias dos erros absoluto (EA), variável (EV) e constante (EC) em milissegundos e mediana do erro de execução (EE) dos dois grupos experimentais (CA9 e CA36), no primeiro bloco de tentativas de prática constante (Co1) e nos quatro blocos de tentativas de prática aleatória (Aleat) da fase de estabilização, e nos quatro blocos de tentativas da fase de adaptação (Adap)..... 
LISTA DE FIGURAS

Página

FIGURA 1 - Ilustração do aparelho de timing coincidente em tarefas complexas.

FIGURA 2 - Médias do erro absoluto em milissegundos, no primeiro bloco de tentativas de prática constante (Co1) e nos quatro blocos de tentativas de prática aleatória (Aleat) da fase de estabilização, e nos quatro blocos de tentativas da fase de adaptação (Adap), dos dois grupos experimentais (CA3 e CA6).

FIGURA 3 - Médias do erro variável em milissegundos, no primeiro bloco de tentativas de prática constante (Co1) e nos quatro blocos de tentativas de prática aleatória (Aleat) da fase de estabilização, e nos quatro blocos de tentativas da fase de adaptação (Adap), dos dois grupos experimentais (CA3 e CA6).

FIGURA 4 - Médias do erro constante em milissegundos, no primeiro bloco de tentativas de prática constante (Co1) e nos quatro blocos de tentativas de prática aleatória (Aleat) da fase de estabilização, e nos quatro blocos de tentativas da fase de adaptação (Adap), dos dois grupos experimentais (CA3 e CA6).

FIGURA 5 - Mediana do erro de execução, no primeiro bloco de tentativas de prática constante (Co1) e nos quatro blocos de tentativas de prática aleatória (Aleat) da fase de estabilização, e nos quatro blocos de tentativas da fase de adaptação (Adap), dos dois grupos experimentais (CA3 e CA6) 
FIGURA 6 - Médias do erro absoluto em milissegundos, no primeiro bloco de tentativas de prática constante (Co1) e nos quatro blocos de tentativas de prática aleatória (Aleat) da fase de estabilização, e nos quatro blocos de tentativas da fase de adaptação (Adap), dos dois grupos experimentais (CA3 e CA6)...........................

FIGURA 7 - Médias do erro variável em milissegundos, no primeiro bloco de tentativas de prática constante (Co1) e nos quatro blocos de tentativas de prática aleatória (Aleat) da fase de estabilização, e nos quatro blocos de tentativas da fase de adaptação (Adap), dos dois grupos experimentais (CA3 e CA6)..........................

FIGURA 8 - Médias do erro constante em milissegundos, no primeiro bloco de tentativas de prática constante (Co1) e nos quatro blocos de tentativas de prática aleatória (Aleat) da fase de estabilização, e nos quatro blocos de tentativas da fase de adaptação (Adap), dos dois grupos experimentais (CA3 e CA6).

FIGURA 9 - Mediana do erro de execução, no primeiro bloco de tentativas de prática constante (Co1) e nos quatro blocos de tentativas de prática aleatória (Aleat) da fase de estabilização, e nos quatro blocos de tentativas da fase de adaptação (Adap), dos dois grupos experimentais (CA3 e CA6)....

FIGURA 10 - Médias do erro absoluto em milissegundos, no primeiro bloco de tentativas de prática constante (Co1) e nos quatro blocos de tentativas de prática aleatória (Aleat) da fase de estabilização, e nos quatro blocos de tentativas da fase de adaptação (Adap), dos dois grupos experimentais (CA9 e CA36)............................

FIGURA 11 - Médias do erro variável em milissegundos, no primeiro bloco de tentativas de prática constante (Co1) e nos quatro blocos de tentativas de prática aleatória (Aleat) da fase de estabilização, e nos quatro blocos de tentativas da fase de adaptação (Adap), dos dois grupos experimentais (CA9 e CA36) 
FIGURA 12 - Médias do erro constante em milissegundos, no primeiro bloco de tentativas de prática constante (Co1) e nos quatro blocos de tentativas de prática aleatória (Aleat) da fase de estabilização, e nos quatro blocos de tentativas da fase de adaptação (Adap), dos dois grupos experimentais (CA9 e CA36).

FIGURA 13 - Mediana do erro de execução, no primeiro bloco de tentativas de prática constante (Co1) e nos quatro blocos de tentativas de prática aleatória (Aleat) da fase de estabilização, e nos quatro blocos de tentativas da fase de adaptação (Adap), dos dois grupos experimentais (CA9 e CA36) 


\section{LISTA DE QUADROS}

QUADRO 1 - Delineamento experimental contendo grupos (CA 3 e CA 6), fases (estabilização e adaptação), tipos e quantidades de prática (constante e aleatória) e velocidades manipuladas (V1 a V7).

QUADRO 2 - Delineamento experimental contendo grupos (CA 3 e CA 6), fases (estabilização e adaptação), tipos e quantidades de prática (constante e aleatória) e seqüências de toques manipulados (SQ1 a SQ7).

QUADRO 3 - Delineamento experimental contendo grupos (CA 9 e CA 36), fases (estabilização e adaptação), tipos e quantidades de prática (constante e aleatória) e velocidades do estímulo visual (V1 a V7) seqüências de toques manipuladas (SQ1 a SQ7) 


\section{LISTA DE ANEXOS}

Página

ANEXO I - Termo de consentimento livre e esclarecido

ANEXO II - Média do erro absoluto (EA) em milissegundos, dos participantes dos dois grupos do experimento 1 [CA3 (1) e CA6 (2)], no primeiro bloco de tentativas de prática constante (Co1) e nos quatro blocos de tentativas de prática aleatória (Aleat) da fase de estabilização, e nos quatro blocos de tentativas da fase de adaptação (Adap).

ANEXO III - Média do erro variável (EV) em milissegundos, dos participantes dos dois grupos do experimento 1 [CA3 (1) e CA6 (2)], no primeiro bloco de tentativas de prática constante (Co1) e nos quatro blocos de tentativas de prática aleatória (Aleat) da fase de estabilização, e nos quatro blocos de tentativas da fase de adaptação (Adap).

ANEXO IV - Média do erro constante (EC) em milissegundos, dos participantes dos dois grupos do experimento 1 [CA3 (1) e CA6 (2)], no primeiro bloco de tentativas de prática constante (Co1) e nos quatro blocos de tentativas de prática aleatória (Aleat) da fase de estabilização, e nos quatro blocos de tentativas da fase de adaptação (Adap)

ANEXO V - Mediana do erro de execução (EE), dos participantes dos dois grupos do experimento 1 [CA3 (1) e CA6 (2)], no primeiro bloco de tentativas de prática constante (Co1) e nos quatro blocos de tentativas de prática aleatória (Aleat) da fase de estabilização, e nos quatro blocos de tentativas da fase de adaptação (Adap)..... 
ANEXO VI - Média do erro absoluto (EA) em milissegundos, dos participantes dos dois grupos do experimento 2 [CA3 (1) e CA6 (2)], no primeiro bloco de tentativas de prática constante (Co1) e nos quatro blocos de tentativas de prática aleatória (Aleat) da fase de estabilização, e nos quatro blocos de tentativas da fase de adaptação (Adap)

ANEXO VII - Média do erro variável (EV) em milissegundos, dos participantes dos dois grupos do experimento 2 [CA3 (1) e CA6 (2)], no primeiro bloco de tentativas de prática constante (Co1) e nos quatro blocos de tentativas de prática aleatória (Aleat) da fase de estabilização, e nos quatro blocos de tentativas da fase de adaptação (Adap).

ANEXO VIII - Média do erro constante (EC) em milissegundos, dos participantes dos dois grupos do experimento 2 [CA3 (1) e CA6 (2)], no primeiro bloco de tentativas de prática constante (Co1) e nos quatro blocos de tentativas de prática aleatória (Aleat) da fase de estabilização, e nos quatro blocos de tentativas da fase de adaptação (Adap).

ANEXO IX - Mediana do erro de execução (EE), dos participantes dos dois grupos do experimento 2 [CA3 (1) e CA6 (2)], no primeiro bloco de tentativas de prática constante (Co1) e nos quatro blocos de tentativas de prática aleatória (Aleat) da fase de estabilização, e nos quatro blocos de tentativas da fase de adaptação (Adap).

ANEXO X - Média do erro absoluto (EA) em milissegundos, dos participantes dos dois grupos do experimento 3 [CA9 (1) e CA36 (2)], no primeiro bloco de tentativas de prática constante (Co1) e nos quatro blocos de tentativas de prática aleatória (Aleat) da fase de estabilização, e nos quatro blocos de tentativas da fase de adaptação (Adap) 
ANEXO XI - Média do erro variável (EV) em milissegundos, dos participantes dos dois grupos do experimento 3 [CA9 (1) e CA36 (2)], no primeiro bloco de tentativas de prática constante (Co1) e nos quatro blocos de tentativas de prática aleatória (Aleat) da fase de estabilização, e nos quatro blocos de tentativas da fase de adaptação (Adap)...

ANEXO XII - Média do erro constante (EC) em milissegundos, dos participantes dos dois grupos do experimento 3 [CA9 (1) e CA36 (2)], no primeiro bloco de tentativas de prática constante (Co1) e nos quatro blocos de tentativas de prática aleatória (Aleat) da fase de estabilização, e nos quatro blocos de tentativas da fase de adaptação (Adap)

ANEXO XIII - Mediana do erro de execução (EE), dos participantes dos dois grupos do experimento 3 [CA9 (1) e CA36 (2)], no primeiro bloco de tentativas de prática constante (Co1) e nos quatro blocos de tentativas de prática aleatória (Aleat) da fase de estabilização, e nos quatro blocos de tentativas da fase de adaptação (Adap) 
RESUMO

\title{
A PRÁTICA CONSTANTE-ALEATÓRIA E A DIVERSIFICAÇÃO DE HABILIDADES MOTORAS
}

\author{
Autor: JOÃO DE PAULA PINHEIRO \\ Orientador: PROF.DR. UMBERTO CESAR CORRÊA
}

\begin{abstract}
O objetivo desse trabalho foi investigar os efeitos da quantidade de elementos manipulados na prática variada aleatória, após a prática constante, no processo adaptativo de aprendizagem motora. Participaram do estudo 66 crianças de ambos os gêneros e a tarefa foi de timing coincidente. Foram realizados três experimentos que diferiram no aspecto da tarefa manipulado na prática variada aleatória: velocidade do estímulo visual (experimento 1), padrão seqüencial de resposta (experimento 2) e velocidade do estímulo visual e padrão seqüencial de resposta conjuntamente (experimento 3). Em todos os experimentos, o delineamento envolveu duas quantidades de elementos: três e seis (experimentos 1 e 2); e, nove e trinta e seis (experimento 3). Fez parte do delineamento, também, duas fases de aprendizagem (estabilização e adaptação). As variáveis dependentes foram os erros absoluto, variável, constante e de execução. Os resultados dos três experimentos permitiram concluir que os efeitos das diferentes quantidades de variabilidade na prática aleatória, após a prática constante, no processo adaptativo de aprendizagem motora foram semelhantes.
\end{abstract}

Palavras-chave: Estrutura de prática, diversificação, processo adaptativo, aprendizagem motora. 


\title{
ABSTRACT \\ THE CONSTANT-RANDOM PRACTICE AND THE MOTOR SKILL DIVERSIFICATION
}

\author{
Author: JOÃO DE PAULA PINHEIRO \\ Adviser: PROF.DR. UMBERTO CESAR CORRÊA
}

The objective of this work was to investigate the effect of the amount of elements manipulated in random practice, after the constant practice, in the adaptive process in motor learning. Participants were 66 children of both gender and the task was of coincident timing. Three experiments were carried out manipulating the task aspects in the random practice: visual stimulus speed (experiment 1); sequential response pattern (experiment 2); and visual stimulus speed and sequential response pattern simultaneously (experiment 3 ). In all experiments the design involved two amounts of elements manipulated in random practice: three and six (experiments 1 and 2), nine and thirty six (experiment 3). The design also involved two phases: stabilization and adaptation. The dependent variables were the absolute, variable, constant and execution error. The results of the three experiments allowed concluding that the effects of different quantities of variability in the random practice, after constant practice, in the adaptive process of motor learning were similar.

Keywords: Practice schedule, diversification, adaptive process, motor learning. 


\section{INTRODUÇÃO}

$\mathrm{Na}$ área de Comportamento Motor, os pesquisadores têm procurado entender e explicar basicamente três aspectos: os mecanismos responsáveis pela produção do movimento, o que tem sido abordado na subárea conhecida como Controle Motor; os mecanismos e processos subjacentes às mudanças no comportamento motor que resultam da prática, sendo que isso tem ocorrido na subárea denominada de Aprendizagem Motora; e, as mudanças que ocorrem no comportamento motor ao longo do ciclo de vida, o que tem sido objeto de investigação em Desenvolvimento Motor.

Apesar de o Controle Motor, a Aprendizagem Motora e o Desenvolvimento Motor terem identidades próprias como campos de investigação, os fenômenos por eles estudados devem ser vistos como conectados. Isso porque, segundo TANI (2006), a aprendizagem implica, em última análise, uma melhoria no controle de movimento e é também uma mudança de comportamento que deve ocorrer num processo mais longo denominado desenvolvimento.

Um fenômeno característico do comportamento motor humano, independentemente dele ser focalizado em nível de controle, desenvolvimento ou aprendizagem, é a variabilidade, um aspecto inerente ao comportamento motor humano (NEWELL \& SLIFKIN, 1998) e como tal pode ser analisada em diferentes níveis. Segundo TANI (2000a), podem ser visualizados três tipos de variabilidade. $O$ primeiro tipo diz respeito à variabilidade que surge em razão da inconsistência na macroestrutura da habilidade. Isso produz um excesso de graus de liberdade na microestrutura (componentes da habilidade). Esse tipo de variabilidade está presente durante o processo de estabilização da performance, o qual implica em sua diminuição. O segundo tipo de variabilidade está presente na microestrutura, após a estabilização da performance. Esse tipo de variabilidade, denominado de variabilidade funcional, é necessário para possibilitar a ocorrência de processo adaptativo porque está relacionado com a redundância do sistema e, portanto, deve ser de nível ótimo. E o terceiro tipo de variabilidade é aquele inerente ao sistema motor, denominado de variabilidade de erro. Ela refere-se aos ruídos existentes no caminho desde o envio do comando motor pelo córtex cerebral até a chegada desse 
comando ao grupo muscular correspondente. Entre o ponto inicial e o final, o comando passa por inúmeros intermediários que podem interferir na mensagem inicial. Como conseqüência disso, pode ocorrer uma diferença entre o movimento planejado inicialmente e o movimento realmente executado.

Além desses tipos de variabilidade "internas", há um tipo de variabilidade "externa" denominada de variabilidade de prática. Ela refere-se a mudanças em algum ou alguns aspectos da tarefa durante as execuções sucessivas. Por exemplo, na rebatida do tênis, poderia ser variado a velocidade da bola a cada tentativa, bem como o tipo de rebatida (forehand ou backhand). Esse tipo de variabilidade é o foco do presente trabalho.

Nas últimas décadas, a variabilidade de prática tem sido sugerida promover, entre outros aspectos, a diversificação do comportamento motor. Conforme TANI (1987), entende-se por diversificação, o aumento na quantidade de elementos do comportamento. Retomando o exemplo apresentado anteriormente, da rebatida do tênis, a variação de diferentes velocidades da bola poderia acarretar na incorporação dessas velocidades no comportamento do executante.

A diversificação no comportamento motor tem sido focalizada tanto em termos de desenvolvimento motor quanto de aprendizagem motora. No que concerne ao desenvolvimento motor, segundo TANI, MANOEL, KOKUBUN e PROENÇA (1988), é importante oferecer uma rica experiência de variação de parâmetros numa ampla extensão de tarefas e situações crescentemente complexas nas fases iniciais do desenvolvimento. Segundo CHOSHI (citado por TANI, 1987), o processo de desenvolvimento motor envolve, basicamente, dois processos fundamentais: a diversificação e aumento em complexidade. Por aumento da complexidade entendese o aumento da quantidade de interações entre os elementos do comportamento. TANI (1987) exemplifica o processo de diversificação através do desenvolvimento do andar. Inicialmente, a criança adquire o padrão fundamental de andar e com base nesse padrão desenvolve o andar diversificado em termos de formas, velocidades e direções. A seguir, com base nesses padrões diversificados de andar, desenvolve o correr e pelo mesmo processo desenvolve o correr diversificado. Portanto, o aumento da diversificação implica o surgimento de um novo padrão com base naqueles já existentes. 
Numa etapa posterior, esses elementos do comportamento como o andar, correr, saltar e arremessar interagem para formar estruturas mais complexas. Por exemplo, o correr interage com o quicar uma bola dando origem a uma estrutura mais complexa de comportamento motor chamada drible. Assim, uma grande variedade de combinações pode ser feita, dando origem a estruturas cada vez mais complexas (TANI, 1987). Conforme MANOEL (2005), tanto na diversificação quanto no aumento em complexidade tem-se o processo adaptativo em ação, e, no segundo caso, estaria ocorrendo a reorganização de habilidades já adquiridas em novas habilidades.

No que tange à aprendizagem motora, GENTILE (1972), propôs um modelo de dois estágios. O primeiro estágio é caracterizado por tentativas de o indivíduo adquirir uma idéia do movimento, aprendendo a relação meio/fim com a qual será alcançada a meta. Segundo GENTILE, essa relação poderia ser mais facilmente aprendida através da prática constante. Durante esse estágio, o indivíduo formaria um padrão motor geral que permitiria a ele atingir a meta da tarefa. Tendo adquirido esse padrão motor geral, o indivíduo progrediria para um estágio posterior denominado fixação/diversificação. Nesse segundo estágio, GENTILE relacionou o tipo de prática, a qual os aprendizes deveriam ser submetidos, à natureza da habilidade. Para a aquisição de habilidades motoras fechadas, a prática constante continuaria a ser a mais indicada, pois esta permitiria a fixação do padrão motor adquirido no primeiro estágio. Mas, tratando-se de habilidades motoras abertas, um nível particular de habilidade deveria ser alcançado através da variação sistemática das condições, pois essa variação de condições permitiria que ocorresse a diversificação do padrão motor adquirido no primeiro estágio.

Recentemente, a diversificação do comportamento tem sido focalizada, ora como questão principal, ora como possibilidade de interpretação de resultados (CORREAA \& TANI, 2005). Entretanto, diferentemente do modelo de GENTILE (1972), isso tem ocorrido em uma perspectiva de aprendizagem de habilidade motora de processo adaptativo. Nessa perspectiva, a proposição remete-se à estrutura de prática constante-aleatória possibilitar melhor adaptação, pois, segundo os autores, a prática constante inicial permite formar a estrutura da habilidade e a prática aleatória 
posterior promove a sua diversificação. Isso, por sua vez, possibilita flexibilidade à habilidade e, por conseguinte, adaptabilidade.

A consideração dessas sugestões fez com que os olhares fossem direcionados para a prática variada aleatória, sendo que as investigações passaram a ser realizadas no intuito de entender como a prática variada aleatória poderia ser organizada após a prática constante para otimizar a diversificação.

Foi nesse contexto que a presente dissertação foi desenvolvida. O objetivo do presente trabalho foi investigar os efeitos da quantidade de elementos manipulados na prática variada aleatória, após a prática constante, no processo adaptativo de aprendizagem motora.

\section{REVISÃO DE LITERATURA}

\subsection{Processo adaptativo de aprendizagem motora}

Em Aprendizagem Motora, as principais teorias foram elaboradas sob influência de modelos de regulação e controle baseados em processos de feedback negativo. É o caso, por exemplo, das teorias de circuito fechado (ADAMS, 1971) e de esquema (SCHMIDT, 1975). Em todas, a aprendizagem de habilidades motoras é explicada como um processo de estabilização do desempenho ou de padronização da habilidade, alcançado por meio de feedback negativo.

Processos baseados em feedback negativo ou mecanismo de neutralização do erro são capazes de manter a estrutura ou a ordem estabelecida, mas são incapazes de conduzir a uma nova estrutura. Em termos de aprendizagem motora, esses processos são incapazes de conduzir à formação de novas habilidades a partir daquelas já existentes tal como um processo contínuo de complexidade crescente. De acordo com CORRÊA e TANI (2005), a formação de novas estruturas requer quebra de estabilidade ou da ordem adquirida, portanto, processos baseados em feedback positivo (ampliação do desvio). Conforme esses autores, modelos baseados em processos de feedback negativo são considerados modelos de equilíbrio e modelos baseados em processos de feedback negativo e positivo são considerados modelos de não-equilíbrio termodinâmico. 
Choshi e Tani (CHOSHI, 2000; TANI, 1989; 1995; 2000b; 2005) têm proposto um modelo de não-equilíbrio de aprendizagem de habilidades motoras denominado processo adaptativo. É sob esse modelo de aprendizagem de habilidades motoras que o presente trabalho foi desenvolvido.

Nesse modelo a aprendizagem é explicada considerando-se dois processos fundamentais: estabilização e adaptativo. O processo de estabilização diz respeito à estabilização funcional que resulta na padronização espaço-temporal da habilidade (formação de estrutura). Nessa fase, movimentos inicialmente inconsistentes vão sendo gradativamente refinados até se alcançarem movimentos padronizados e precisos. Nela, o elemento fundamental é o feedback negativo.

O processo adaptativo é aquele em que ocorrem adaptações a novas situações ou tarefas motoras, mediante a reorganização das habilidades já adquiridas. Esse processo refere-se à formação de novas habilidades a partir daquelas existentes, através de uma quebra da estabilidade seguida por outro regime de estabilidade, mas em um nível superior de complexidade. TANI (1995) sugere que a adaptação pode ocorrer de três formas: 1) por meio da própria flexibilidade do sistema, ou seja, via alteração de parâmetros (adaptação paramétrica); 2) por meio da reorganização da estrutura da habilidade (adaptação estrutural); e 3) através da emergência de uma estrutura completamente nova (adaptação auto-organizacional).

Assim, existem perturbações para as quais a adaptação se faz pela flexibilidade inerente à estrutura adquirida, pela mudança de parâmetros da habilidade. Entretanto, existem perturbações de tal envergadura que por mais que haja disponibilidade na estrutura, não há condições de adaptar-se. Nesse caso, exige-se uma reorganização da própria estrutura que, quando concluída, resulta numa mudança qualitativa do sistema (TANI, 2005). Por exemplo, na execução do chute no futebol, a presença de um marcador poderia fazer com que o executante tivesse de realizar o mesmo movimento mais rapidamente (modificação do parâmetro), mudasse a posição do pé no momento do chute (alteração de componente) ou, ainda, executasse um movimento completamente novo (autoorganizacional) como um voleio ou uma bicicleta. 
Em síntese, do ponto de vista da aprendizagem motora, a adaptação ou o processo adaptativo refere-se à reorganização das habilidades já adquiridas para fazer frente a perturbações. Sendo assim, ao visualizar a aprendizagem motora além da estabilização, um importante fator - a perturbação - deve ser levado em consideração. Portanto, é importante esclarecer o conceito de perturbação. Nesse trabalho, uma perturbação está sendo entendida como algo que modifica ou causa mudanças (DORON \& PAROT, 1998), uma incerteza inserida no sistema, a qual ele precisa se adaptar (UGRINOWITSCH, CORRÊA \& TANI, 2005) e, também, um incidente que modifica alguma das propriedades do sistema (NICOLIS \& PRIGOGINE, 1989).

Experimentalmente, o pesquisador pode manipular a perturbação mudando algo na tarefa para verificar se houve alteração no desempenho. Quando o desempenho muda, entende-se que houve perturbação, mas quando não há alteração no desempenho, em nenhum nível, infere-se que não houve perturbação (UGRINOWITSCH \& TANI, 2005).

Em suma, o modelo de processo adaptativo de aprendizagem de habilidades motoras permite compreendê-la como um processo contínuo, de complexidade crescente, em que novas habilidades são formadas a partir da reorganização daquelas já existentes. Esse modelo tem sido investigado em duas linhas de pesquisa, sendo que uma delas tem tido o objetivo de testar o modelo (BENDA, 2001; CATTUZZO, 2007; TANI, 1995; UGRINOWITSCH, 2003), como segue.

Segundo TANI (1995), a adaptação é dependente de dois fatores: a) quanta instabilidade (perturbação) é inserida e b) quando ela é inserida. Esses fatores foram investigados em três experimentos nos quais crianças executaram tarefas seriadas de rastreamento. Os experimentos 1 e 2 apresentaram a mesma tarefa, pressionar cinco chaves de acordo com estímulos visuais correspondentes em um determinado intervalo entre a apresentação dos estímulos. Os experimentos foram conduzidos em duas fases: estabilização e adaptação. $\mathrm{Na}$ fase de estabilização foram realizadas 60 tentativas e na fase de adaptação foram realizadas 40 tentativas com ordem e intervalo entre estímulos diferentes dos realizados na fase anterior. Para acessar o desempenho dos participantes foram utilizadas as respostas omissas, erradas, corretas e antecipatórias. Observou-se uma diminuição do número de respostas 
corretas e um aumento no número de respostas antecipatórias na fase de estabilização, e na fase de adaptação houve uma diminuição no número de respostas antecipatórias, mas o número de respostas corretas se manteve. O autor sugeriu que o aumento do número de respostas antecipatórias na fase de estabilização indica que as crianças compreenderam as características da seqüência de respostas. Durante a fase de adaptação os participantes diminuíram a quantidade de respostas antecipatórias, mas mantiveram a quantidade de respostas corretas. Isso levou a concluir que o maior número de respostas antecipatórias conseguido na fase de estabilização reflete um aumento no grau de redundância do sistema, o qual permitiu aos participantes assegurar a estabilidade em relação à perturbação.

Os resultados permitiram ao autor sugerir uma organização hierárquica, visto que quando o sistema alcançou o nível de respostas antecipatórias, a adaptação à instabilidade foi feita num nível imediatamente inferior na hierarquia, ou seja, no das respostas corretas. Também foi possível sugerir que a adaptação deve ser precedida da estabilização, visto que os grupos de respostas erradas e omissas aumentaram essa medida na adaptação.

Enquanto os experimentos 1 e 2 focaram o momento em que a perturbação deveria ser inserida, o terceiro experimento investigou o nível de perturbação que deveria ser inserido. Considerando que nos experimentos anteriores aspectos temporais e espaciais (intervalo entre estímulos e seqüência de toques) foram manipulados simultaneamente na fase de adaptação, nesse experimento esses aspectos foram alterados separadamente. Observou-se comportamentos diferentes, sendo que o nível de instabilidade foi maior com a modificação dos dois aspectos concomitantemente, seguido pela modificação espacial e pela temporal. Isso sugere uma hierarquia nos níveis de instabilidade.

Em conclusão os resultados desse experimento deram suporte para a proposição de: a) que a adaptação deve ser precedida de estabilização, sendo a redundância alcançada pelo sistema um aspecto crucial; b) uma organização hierárquica no processo de aquisição de habilidades motoras em que a adaptação é feita no nível imediatamente inferior ao alcançado na estabilização; e c) existência de um nível ótimo de instabilidade para a ocorrência de adaptação. 
BENDA (2001) buscou investigar o papel da variabilidade do movimento no processo adaptativo em aprendizagem motora, em função de diferentes níveis de estabilização. Três questões foram investigadas: 1) se a variabilidade observada em diferentes estados do sistema (antes e após a estabilização) é de natureza distinta; 2) se após a estabilização ocorre um aumento da flutuação da variabilidade e 3) se a variabilidade que permanece após a estabilização caracteriza uma flexibilidade que permite adaptação a novas exigências. Três experimentos constituídos de duas fases (estabilização e adaptação) foram realizados.

No primeiro experimento, 90 sujeitos adultos praticaram uma tarefa de arremesso de dardo de salão ao alvo e foram distribuídos em três grupos: préestabilização, estabilização e super-estabilização. Em cada grupo os sujeitos foram divididos conforme a variabilidade do desempenho no último bloco de tentativas da fase de estabilização, resultando em subgrupos de baixa, média e alta variabilidade. Segundo o autor, os resultados mostraram que a variabilidade observada em diferentes estados do sistema não é de natureza distinta, que não ocorre um aumento da flutuação da variabilidade e que a variabilidade que permanece após a estabilização não caracteriza flexibilidade do sistema. Ressalte-se que a tarefa utilizada exigiu precisão. Sendo assim, a variabilidade de resultado no meio ambiente implicaria pior desempenho. Para um bom desempenho seria necessário que a variabilidade de resposta fosse baixa. Entretanto, seria possível apresentar altos níveis de desempenho com baixa variabilidade de resposta e alta variabilidade no padrão de movimento. Assim, novos experimentos foram conduzidos procurando utilizar também a variabilidade no padrão de movimento como critério para divisão dos grupos.

No segundo e terceiro experimentos, BENDA (2001) utilizou um instrumento de timing antecipatório para tarefas complexas, no qual o participante deveria tocar cinco sensores a partir do momento em que os diodos se acendessem e apagassem em seqüência, o que causava a impressão de que o estímulo luminoso vinha em sua direção. Assim, o participante deveria tocar o último sensor simultaneamente ao acendimento do último diodo, sincronizando seu movimento ao estímulo luminoso. Os experimentos envolveram duas fases: primeiro a fase de estabilização; e depois a fase de adaptação, na qual a tarefa foi modificada com o intuito de perturbar o 
sistema. No segundo experimento, a modificação limitou-se ao tempo total de movimento e, no terceiro experimento, foram modificados o tempo total de movimento e a disposição espacial dos sensores. Considerou-se, então, a perturbação do terceiro experimento mais severa que a do segundo.

No segundo experimento conduzido por BENDA (2001), participaram 90 sujeitos adultos seguindo um delineamento semelhante ao do primeiro experimento e tomando o erro variável como critério para a divisão dos grupos, não foram observadas diferenças estatísticas no desempenho dos grupos após a alteração na tarefa. Ambos os grupos foram perturbados pela mudança e recuperaram-se em seguida. Esse resultado, segundo o autor, sugere que a variabilidade de resposta que permanece após a estabilização, não caracteriza flexibilidade do sistema, sendo contrário às predições do estudo.

No terceiro experimento participaram 90 sujeitos adultos seguindo o mesmo delineamento do segundo experimento e com o erro variável como critério para divisão dos grupos, porém envolvendo na adaptação, além do aumento na velocidade do estímulo, uma alteração na configuração espacial das chaves de resposta. Segundo o autor, os resultados mostraram que a variabilidade relacionada a microestrutura do programa de ação (tempo total de movimento) tem um efeito distinto conforme o estado do sistema e que a variabilidade relacionada a macroestrutura (timing relativo) deve ser reduzida na fase de estabilização. E também que a variabilidade relacionada à microestrutura não interferiu no desempenho sendo, de certa forma, benéfica para a adaptação.

No seu conjunto, os resultados sugeriram que: a) a variabilidade pode ter um papel diferenciado conforme o estado de organização do sistema; b) há um aumento da amplitude da variabilidade após a estabilização; c) a variabilidade pode ter um papel facilitador na adaptação.

UGRINOWITSCH (2003) pesquisou como o nível de estabilização do desempenho e o tipo de perturbação exercem influência no processo adaptativo em aprendizagem motora. Foram realizados três experimentos constituídos de duas fases: estabilização e adaptação. Foi utilizada uma tarefa complexa de timing coincidente, semelhantemente àquela utilizada por BENDA (2001). Três grupos foram formados em cada experimento de acordo com três níveis relacionados ao 
grau de estabilização do desempenho: pré-estabilização, estabilização e superestabilização. O critério para estabilização foi de três tentativas consecutivas com erro na faixa de $30 \mathrm{~ms}$. No primeiro experimento, os participantes não estabilizaram o desempenho (pré-estabilização), e foram submetidos a diferentes tipos de perturbação: perturbação perceptiva, motora e perceptivo-motora. Os resultados mostraram que os participantes dos três grupos não conseguiram se adaptar. Esses resultados corroboram a proposição de TANI (1995), de que sem a estabilização do desempenho não é possível haver adaptação. No entanto, o experimento possibilitou identificar uma hierarquia na perturbação, pois mesmo sem atingir a meta da tarefa, o desempenho dos grupos foi diferente na segunda fase do experimento. A perturbação perceptiva parece ser a menos exigente e a perceptivo-motora parece ser a mais exigente das três.

Seguindo o mesmo raciocínio de testar a adaptação frente a diferentes tipos de perturbação em diferentes níveis de estabilização, no segundo experimento todos os grupos foram levados à estabilização do desempenho, para então verificar como ocorreria a adaptação. Assim que era atingido o nível de estabilização (três execuções consecutivas com erro absoluto igual ou inferior a 30ms) era inserido um diferente tipo de perturbação, caracterizando os três grupos experimentais: grupo estabilização perceptiva, grupo estabilização motora e grupo estabilização perceptivo-motora. Como a quantidade de prática de cada sujeito foi diferente em função da medida qualitativa de estabilização do desempenho, para efeito de análise foram utilizados somente o primeiro e o último bloco de tentativas da fase de estabilização, juntamente com todos os blocos da fase de adaptação. De acordo com os resultados, ao final da fase de estabilização, os três grupos melhoraram o desempenho em relação ao primeiro bloco de tentativas, sem existir diferença entre os mesmos. Ao ser inserida a perturbação, os grupos adaptaram-se de forma diferente, pois o grupo estabilização perceptiva e o grupo estabilização motora apresentaram o mesmo desempenho, mas o grupo estabilização perceptivo-motora só atingiu o mesmo desempenho dos outros dois grupos no quinto bloco de tentativas da fase de adaptação. Segundo o autor esses resultados indicaram que a adaptação não depende somente do nível de estabilização, mas também do tipo de perturbação. 
No terceiro experimento, todos os grupos foram levados à super-estabilização do desempenho, definida como seis blocos de três execuções consecutivas, com o erro absoluto igual ou inferior a $30 \mathrm{~ms}$, para então ser inserida diferentes tipos de perturbação, caracterizando a formação dos três grupos experimentais: grupo superestabilização com perturbação perceptiva, grupo super-estabilização com perturbação motora e grupo super-estabilização com perturbação perceptivo-motora. Da mesma forma que no segundo experimento, foram utilizados somente o primeiro e o último bloco da fase de estabilização para análise comparativa.

Os resultados mostraram que o erro absoluto diminuiu do primeiro para o último bloco de tentativas da fase de estabilização sem diferença intergrupos, mostrando que todos os grupos atingiram o mesmo nível de estabilização do desempenho ao final da primeira fase do experimento. Com a inserção da perturbação houve um aumento do erro no primeiro bloco de tentativas da fase de adaptação, entretanto, no segundo ele já voltou ao nível da fase anterior. De acordo com o autor, esses resultados indicaram que, ao ser atingida a super-estabilização do desempenho, o sistema ficou sensível a qualquer alteração mostrando aumento do erro. Contudo, o retorno ao nível de desempenho anterior, demonstrou capacidade de adaptação.

Ao observar a variabilidade do desempenho, foi possível identificar que não houve queda da variabilidade do primeiro para o último bloco de tentativas da fase de estabilização. Apesar de manter a mesma variabilidade da fase inicial do experimento, o desempenho na fase da adaptação voltou ao nível da fase anterior logo no segundo bloco. Além disso, essa variabilidade foi diminuindo ao longo da fase de adaptação, chegando a ser menor que a da fase de estabilização no último bloco. Esses resultados corroboram as proposições de BENDA (2001) e TANI (2000b) de que a variabilidade presente no início da aprendizagem é diferente daquela presente após a estabilização do desempenho. A variabilidade alta na superestabilização do desempenho parece ser uma fonte de adaptação, ou seja, a variabilidade é alta porque o sistema já adquiriu redundância (TANI, 1995). A redundância no domínio motor é entendida como uma reserva de capacidade que permite ao ser humano responder a uma perturbação (TANI, 2000b). O conjunto dos resultados do terceiro experimento indica que com o nível de super-estabilização do 
desempenho seria possível enfrentar qualquer uma das três perturbações, uma vez que tanto o desempenho quanto a variabilidade não apresentaram diferença entre grupos.

Analisando o conjunto de resultados dos três experimentos apresentados por UGRINOWITSCH (2003), pode-se concluir que: 1) a estabilização é um pré-requisito para adaptação, mas que essa adaptação depende de quando a perturbação é inserida e de quanta perturbação é introduzida; 2) independente do nível de estabilização, a mudança perceptivo-motora constitui uma perturbação maior que a motora e a perceptiva, assim como a motora caracteriza maior perturbação que a perceptiva.

CATTUZZO (2007) investigou a aquisição de habilidades motoras testando dois ciclos de instabilidade-estabilidade-instabilidade. Para isso, foram realizados 2 experimentos. A tarefa utilizada foi a mesma tarefa de rastreamento de um padrão luminoso utilizada por TANI (1995). As medidas utilizadas também foram as mesmas medidas utilizadas por TANI (1995): respostas antecipatórias (RA), respostas corretas $(R C)$, respostas erradas (RE) e respostas omissas (RO).

O primeiro experimento teve como objetivo conhecer o nível de exigência de cada intervalo inter-estímulos, sendo que esse nível está associado à análise da incerteza que deve estar presente no sistema, assim como da análise dos recursos que o sistema tem para suplantar tal incerteza. Foi composto de uma única fase, na qual os participantes foram divididos em 6 grupos de acordo com o intervalo interestímulos $(300,400,500,600,700$ e 800 ms) e praticaram 100 tentativas de uma única seqüência de acendimento das lâmpadas. Os resultados mostraram que os intervalos de 300 e $400 \mathrm{~ms}$ foram intervalos muito exigentes, pois davam pouca oportunidade para suplantar a incerteza que eles geravam, e que os intervalos de 700 e 800 ms foram pouco exigentes, pois permitiram desde o início da prática que o sistema utilizasse todos os tipos de resposta, optando pelas respostas que mais atendiam à meta de aprender a ordem da seqüência ao responder correta e antecipadamente. O intervalo de $600 \mathrm{~ms}$ também pareceu ter gerado pouco desafio levando à manutenção do nível alto de respostas corretas do início ao fim da prática e não modificou os outros tipos de respostas. O intervalo de $500 \mathrm{~ms}$ foi considerado o mais adequado para o início do processo de aprendizagem dessa tarefa. 
Com base nos resultados do primeiro experimento, o segundo experimento teve o propósito de investigar a aquisição de habilidades motoras, no modelo do processo adaptativo, testando dois ciclos de instabilidade-estabilidade-instabilidade. A tarefa e medidas utilizadas foram as mesmas do primeiro experimento, entretanto, o delineamento envolveu uma fase de estabilização com 100 tentativas seguida pelas fases de adaptação I, com 100 tentativas também, e adaptação II com 20 tentativas. Os participantes foram divididos em 6 grupos de acordo com a combinação dos intervalos inter-estímulos (ms) manipulados nas fases de adaptação I e II: G1 - 500/400/300; G2 - 500/400/500; G3 - 500/400/600; G4 - 500/600/400; G5 - 500/600/500; e G6 - 500/600/700. Também foi realizada outra análise na qual foi feito um reagrupamento dos dados com o objetivo de separar os sujeitos que atingiram precocemente ou tardiamente um critério de desempenho, por entender que isso poderia se constituir uma característica que retratava a redundância no sistema. O critério de desempenho utilizado para os sujeitos precoces foi a realização de três séries completas de respostas corretas até o terceiro bloco de dez tentativas da fase de estabilização e o dos sujeitos tardios foi a realização ou não desse critério a partir do sétimo bloco de dez tentativas também da fase de estabilização. Assim, foram reunidos os sujeitos que tiveram os mesmos tratamentos de intervalos entre estímulos nas fases de estabilização e adaptação l e, dentre eles, foram discriminados os precoces e os tardios, o que resultou em quatro novos grupos: GA - precoces do G1, G2 e G3; GB - tardios do G1, G2 e G3; GC precoces do G4, G5 e G6; e GD - tardios do G4, G5 e G6.

Os resultados encontrados permitiram a autora concluir que: a) o processo de aprendizagem ocorreu mediante sucessivos ciclos de estabilização-adaptação, que não tem um fim definido. O comportamento motor humano adaptou-se a partir da alternância desses momentos de instabilidade-estabilidade-instabilidade, pois isso garante o aumento da sua complexidade; b) existe efeito do nível de estabilização alcançado no primeiro ciclo para o segundo ciclo de instabilidade-estabilidadeinstabilidade, mas isso depende também da magnitude da perturbação; c) a redundância inicial na estrutura tem efeito no desempenho ao longo dos ciclos, o que significa que no processo contínuo de aquisição, garantir recursos excedentes é vantajoso para o sistema. 
Em síntese, os resultados têm mostrado que a adaptação é dependente do estado do sistema e, portanto, do momento em que a perturbação é inserida. Nesse caso, as evidências mostram que o processo de estabilização é um pré-requisito para aquele de adaptação e que a adaptação é dependente do tipo/nível de perturbação. As evidências têm mostrado, também, que a perturbação é maior quando parâmetros temporais e espaciais da tarefa são alterados simultaneamente e menor quando apenas o parâmetro temporal é alterado, estando a alteração do parâmetro espacial no nível intermediário.

\subsection{Estrutura de prática e processo adaptativo de aprendizagem motora}

A segunda linha de pesquisa refere-se à investigação da aquisição de habilidades motoras em função da manipulação dos fatores feedback (MEIRA JÚNIOR, 2005; TANI, MEIRA JÚNIOR \& GOMES, 2005; UGRINOWITSCH, TERTULIANO, COCA, PEREIRA \& GIMENEZ, 2003), prática (BARROS, 2006; CORRÊA, 2001; 2007; CORRÊA, BENDA \& TANI, 2001; CORRÊA, BENDA, MEIRA JÚNIOR \& TANI, 2003; CORRÊA, GONÇALVES, BARROS \& MASSIGLI, 2006; CORRÊA, BARROS, MASSIGLI, GONÇALVES, \& TANI, 2007; FIALHO, 2007; MASSIGLI, GONÇALVES, BARROS, SOUZA JÚNIOR \& CORRÊA, 2004; PAROLI, 2004, PINHEIRO \& CORREAA, 2007; TANI, 1989; WALTER, BASTOS, ARAUJO, SILVA \& CORRÊA, 2008) e ambos (TERTULIANO, SOUZA JÚNIOR, SILVA FILHO \& CORRÊA, 2008). Em relação ao fator feedback, o conjunto de resultados ainda é inconclusivo. $\mathrm{E}$, concernente à prática, os resultados permitem sugerir que o processo adaptativo é favorecido pela prática constante seguida da prática variada, mais especificamente, pela estrutura constante-aleatória.

TANI (1989) realizou estudo com o objetivo de investigar o efeito da variabilidade de resposta no processo adaptativo em aprendizagem motora. $O$ estudo constou de dois experimentos que envolveram duas fases: estabilização e adaptação. $O$ autor formulou a seguinte hipótese: para que estruturas flexíveis na organização do movimento sejam adquiridas é preciso que durante a fase de estabilização, seja permitido ao executante variabilidade nas respostas. Para isso utilizou uma tarefa de coordenação bi-manual. Em cada experimento, os sujeitos 
foram divididos em dois grupos: prática constante e prática variada em blocos. $\mathrm{Na}$ fase de estabilização de ambos os experimentos, os sujeitos do grupo de prática constante executaram um determinado padrão de coordenação bi-manual, ao passo que os sujeitos do grupo de prática variada realizaram o mesmo número de tentativas, porém, em quatro padrões diferentes. Na fase de adaptação, os grupos executaram um padrão de coordenação diferente daquele praticado na fase de estabilização. O primeiro experimento foi realizado com sujeitos universitários e a prática variada foi manipulada em relação ao ponto de início da resposta, enquanto que o segundo experimento foi realizado com crianças e a prática variada foi manipulada em relação às seqüências de movimentos.

No primeiro experimento, as medidas utilizadas foram o tempo de execução das tentativas e o número de erros. Os resultados não mostraram diferença significativa entre os grupos de prática constante e variada. No segundo experimento, as medidas utilizadas foram as mesmas do primeiro experimento, acrescentando-se a medida do número de erros direcionais. Os resultados mostraram que houve diferença significativa entre os grupos em relação ao tempo de execução no final da fase de estabilização, quando o grupo de prática constante mostrou desempenho superior ao grupo de prática variada. Não houve diferenças significativas entre os grupos na fase de adaptação. Os resultados desses dois experimentos foram interpretados pelo autor como evidências que apoiaram a hipótese formulada. Sendo assim, a repetição de um único padrão de movimento poderia acarretar numa diminuição da variabilidade de respostas e contribuiria para formação de padrões motores rígidos. Segundo o autor, essa perda de flexibilidade no padrão motor poderia causar dificuldades para o aprendiz, tendo em vista que ele caminha no sentido de alcançar novos objetivos e enfrentar novas situações, ou seja, no processo adaptativo presente no desenvolvimento hierárquico de habilidades motoras.

CORREAA (2001) investigou os efeitos de diferentes estruturas de prática no processo adaptativo na aquisição de habilidades motoras em três experimentos, os quais diferiram quanto à prática variada. $O$ delineamento constou de quatro grupos (prática constante, prática aleatória, prática constante-aleatória, e prática aleatóriaconstante) e de duas fases de aprendizagem (estabilização e adaptação). Nos três 
experimentos crianças praticaram uma tarefa que consistia em tocar alvos de forma seqüencial em integração a um estímulo visual. Utilizou-se um aparelho de timing antecipatório em tarefas complexas. O estudo teve como medidas de desempenho o erro absoluto, o erro variável e o erro de execução; o timing relativo (variável e absoluto) serviu de medida da macroestrutura da habilidade e o tempo de movimento (variabilidade), de medida da microestrutura. Nesse trabalho, macro e microestruturas foram entendidas, respectivamente, como características invariantes e variantes de habilidades motoras.

No primeiro experimento, a prática variada referiu-se ao componente perceptivo da tarefa, isto é, à velocidade de apresentação do estímulo visual. Na fase de estabilização, enquanto a prática era constante, as crianças executaram a tarefa em uma única velocidade do estímulo visual e, quando a prática era aleatória, a tarefa era executada variando-se aleatoriamente três velocidades do estímulo visual. $\mathrm{Na}$ fase de adaptação, os grupos executaram as tentativas em uma única velocidade do estímulo visual, porém, diferente daquelas praticadas na fase anterior e sem conhecimento de resultados (CR). Nesse experimento, todos os grupos executaram a tarefa numa mesma seqüência de toques nas duas fases do experimento. Conforme os resultados, o desempenho foi semelhante para todos os grupos na fase de adaptação, mas o grupo de prática constante-aleatória adaptou-se sem modificação da estrutura e os demais grupos adaptaram-se pela modificação de um componente da macroestrutura da habilidade. Para esse autor, a estrutura macroscópica da tarefa referia-se à relação entre os componentes da tarefa e, portanto, aos aspectos invariantes acessados via média e desvio-padrão do timing relativo.

No segundo experimento, a prática variada foi manipulada quanto a diferentes padrões seqüenciais de resposta. $O$ instrumento, a tarefa, as medidas e o delineamento experimental foram semelhantes ao do primeiro experimento, considerando que a variabilidade de prática referiu-se a três seqüências de toques na fase de estabilização e uma nova seqüência na fase de adaptação, sendo que nesta última não foi fornecido CR. Todas as tentativas foram executadas com a mesma velocidade do estímulo visual. Os resultados indicaram melhor desempenho na fase de adaptação para o grupo de prática constante-aleatória. Ele foi mais preciso que os 
grupos de prática aleatória e aleatória-constante e foi o grupo mais consistente na fase de adaptação.

No terceiro experimento, a prática foi variada nos aspectos perceptivo e motor da tarefa de aquisição, respectivamente, diferentes velocidades de estímulo visual e diferentes padrões de resposta. Novamente, instrumento, tarefa, medidas e delineamento experimental foram semelhantes aos dos experimentos anteriores. De acordo com os resultados, houve melhor desempenho na fase de adaptação do grupo de prática constante-aleatória. Além disso, esse grupo, diferentemente dos demais, foi capaz de modificar a estrutura (macroscópica) da tarefa em relação a dois componentes. E, semelhantemente aos demais grupos, modificou a microestrutura (tempo de movimento) da tarefa, contudo, foi capaz de reorganizá-la com mais consistência do que os outros grupos.

Os resultados desses três experimentos levaram o autor a concluir que prática constante-aleatória foi aquela mais eficaz no processo adaptativo na aquisição de habilidades motoras. Segundo ele, isso ocorreu porque em um primeiro momento a prática aleatória possibilitou a formação de um padrão e, em um segundo momento, a prática aleatória possibilitou a sua diversificação. Uma outra conclusão que o conjunto de resultados possibilitou referiu-se à existência de uma hierarquia relacionada à adaptação. Esse autor inferiu que, quando a modificação na tarefa referiu-se à modificação na velocidade do estímulo visual e padrão seqüencial de resposta em conjunto, houve um nível superior de perturbação comparado com aquele gerado pela modificação apenas no padrão seqüencial de resposta que, por sua vez, causou superior perturbação em comparação com a modificação na velocidade do estímulo visual.

Também preocupados com os efeitos de diferentes estruturas de prática no processo adaptativo na aquisição de habilidades motoras, CORRÊA, BENDA e TANI (2001) investigaram os efeitos das práticas variada e constante e suas combinações, durante o processo de estabilização, no processo adaptativo na aquisição de uma tarefa com validade ecológica. A tarefa motora consistiu em arremessar um dardo de salão num alvo circular, com o objetivo de acertar o seu centro. O alvo continha 11 áreas que assumiam pontuação de um a 11 , da extremidade para o centro. 0 delineamento, semelhante ao do estudo anterior, constou de quatro grupos 
experimentais - prática constante, prática aleatória, prática constante-aleatória e prática aleatória-constante - e de duas fases: estabilização e adaptação. Nesse estudo foram utilizados dois tipos de arremesso: com empunhadura comum ou do tipo caneta (fase de estabilização), e com empunhadura profissional (fase de adaptação). Na fase de estabilização, a prática variada foi manipulada em termos de três distâncias de arremesso ao alvo $(2,00 ; 2,60 ; 3,20 \mathrm{~m})$. E, quando a prática era constante, os participantes executavam as tentativas de uma única distância do alvo. $\mathrm{Na}$ fase de adaptação, todos os grupos executaram as tentativas com empunhadura e distância do alvo diferentes daquelas praticadas na fase anterior e sem CR.

Os resultados, analisados com base na média e no desvio padrão dos pontos, não permitiram inferir da ocorrência de aprendizagem, pois os grupos mantiveram-se no mesmo nível durante toda a fase de estabilização. Além do mais, não houve diferença entre os grupos em nenhuma das fases do experimento. As explicações para esses resultados referiram-se a: a) variações na tarefa não serem suficientes a ponto de causar diferenças entre grupos; b) complexidade da tarefa, pois os sujeitos mantiveram um baixo nível de desempenho durante toda fase de estabilização; c) instruções referentes ao padrão de movimento a ser alcançado, pois não foi informado aos sujeitos o padrão de arremesso de precisão e, como conseqüência, eles executaram o padrão de arremesso à distância, prejudicando seu desempenho.

CORREA et al. (2003) realizaram estudo com o objetivo de verificar os efeitos de diferentes estruturas de prática no processo adaptativo na aprendizagem de uma tarefa de controle de força manual. Para isso, os participantes foram divididos em quatro grupos experimentais: prática constante, prática aleatória, prática constantealeatória e prática aleatória-constante. A tarefa motora consistiu no controle de força manual para alcançar metas de performance pré-estabelecidas. Foi manipulada a quantidade de força de preensão $(20 \%, 40 \%, 60 \%$ e $80 \%$ da força máxima), de acordo com as quatro situações de prática. Essa pesquisa envolveu duas fases experimentais: estabilização e adaptação, com trinta e vinte execuções, respectivamente. Na fase de estabilização, quando a prática era constante, os participantes realizavam as tentativas em uma única quantidade de força de preensão e, quando a prática era aleatória, as tentativas eram realizadas em três quantidades de força. Na fase de adaptação, além da ausência de CR, a quantidade 
de força de preensão foi modificada para um valor diferente daqueles da fase anterior.

Os resultados desse estudo indicaram que, em termos de precisão, os grupos de prática constante e constante-aleatória obtiveram melhor desempenho na fase de adaptação do que aqueles de prática aleatória e aleatória-constante. Em relação à consistência do desempenho, observou-se que o grupo de prática constante foi superior aos demais grupos. Esses resultados levaram os autores a inferir que a flexibilidade do sistema que permite a adaptação pode ser alcançada por meio de prática constante, ou de prática constante seguida pela prática aleatória.

Como se pôde notar, foram realizados inicialmente cinco experimentos (CORRÊA, 2001; CORRÊA et al., 2001; 2003) com o mesmo delineamento em termos de grupos (prática constante, aleatória, constante-aleatória e aleatóriaconstante) e fases (estabilização e adaptação). Esses experimentos diferiram em relação à tarefa de aprendizagem. No estudo em que foi utilizada a tarefa de controle de força manual os resultados foram favoráveis à adaptação via prática constante. Já nos estudos com a tarefa de timing coincidente, os resultados mostraram melhor adaptação para os grupos de prática constante-aleatória. E, no experimento com a tarefa de arremesso de dardo de salão, os resultados apontaram para a adaptação equivalente para as diferentes estruturas de prática. Os resultados inicialmente apresentados induziram à elaboração da seguinte pergunta: já que a tarefa foi a única diferença entre aqueles experimentos, seria esse o aspecto determinante dos efeitos das práticas constante, aleatória, aleatória-constante e constante-aleatória?

Assim, a partir do exposto, BARROS (2006) investigou os efeitos de diferentes estruturas de prática no processo adaptativo em aprendizagem motora em função da especificidade da tarefa. Foram realizados três experimentos nos quais as exigências de aprendizagem e a variabilidade de prática foram em termos de controle temporal, de força e espacial, respectivamente, experimentos 1, 2 e 3 . Os três experimentos envolveram um delineamento com quatro grupos de prática (constante, aleatória, constante-aleatória e aleatória-constante) e de duas fases (estabilização e adaptação). A tarefa consistiu em tocar três alvos (sensores) metálicos em uma ordem pré-estabelecida com determinados tempos de movimento para cada toque (experimento 1) e com determinadas forças de toques (experimento 2). No 
experimento 3, a tarefa foi tocar, de olhos vendados, três sensores metálicos, na seqüência proposta pelo experimentador. Os resultados indicaram que, nos experimentos 1 e 2 (controle temporal e de força, respectivamente) a estrutura de prática constante-aleatória possibilitou melhor adaptação. No entanto, no experimento 3 (controle espacial) a estrutura de prática aleatória-constante possibilitou a melhor adaptação, o que levou o autor a concluir que houve complementaridade de especificidade/generalidade da tarefa nos efeitos da estruturação da prática no processo adaptativo em aprendizagem motora.

PINHEIRO e CORRÊA (2007) investigaram a aprendizagem de habilidades motoras em diferentes estruturas de prática utilizando-se de tarefas de timing coincidente, porém, manipulando-se o estímulo visual em termos de diferentes desacelerações. Isso porque em situações reais não se observam estímulos que se deslocam em velocidade constante. $O$ instrumento utilizado foi o aparelho de timing coincidente em tarefas complexas e a tarefa foi tocar cinco alvos em uma ordem préestabelecida integrada a um estímulo visual, da mesma forma que nos experimentos de CORREAA (2001). Os participantes foram distribuídos aleatoriamente em quatro grupos, conforme a estrutura de prática: constante, aleatória, constante-aleatória e aleatória-constante, similarmente a outros experimentos (BARROS, 2006; CORREAA, 2001; CORRÊA et al., 2001; 2003). O estudo foi realizado em duas fases: estabilização, na qual foram realizadas 72 tentativas de acordo com a situação experimental de cada grupo e, adaptação, com 36 tentativas em uma mesma situação para todos os grupos. Todos os grupos executaram a tarefa numa mesma ordem de toques nos sensores em ambas as fases do experimento.

$\mathrm{Na}$ fase de estabilização as crianças do grupo de prática constante executaram todas as tentativas em apenas uma desaceleração do estímulo visual ($0,87 \mathrm{~m} / \mathrm{s}^{2}$ ); as crianças do grupo de prática aleatória executaram todas as tentativas com a variação aleatória de três desacelerações do estímulo visual $\left(-0,87 \mathrm{~m} / \mathrm{s}^{2},-0,73\right.$ $\mathrm{m} / \mathrm{s}^{2}$, e $\left.-0,89 \mathrm{~m} / \mathrm{s}^{2}\right)$; as crianças do grupo de prática constante-aleatória executaram a primeira metade das tentativas da mesma forma que o grupo de prática constante ($\left.0,87 \mathrm{~m} / \mathrm{s}^{2}\right)$, e as tentativas posteriores em três desacelerações do estímulo $(-0,87$ $\mathrm{m} / \mathrm{s}^{2},-0,73 \mathrm{~m} / \mathrm{s}^{2},-0,89 \mathrm{~m} / \mathrm{s}^{2}$ ) aleatoriamente, ou seja, semelhante ao grupo de prática aleatória; e, ao contrário do grupo de prática constante-aleatória, as crianças do 
grupo de prática aleatória-constante executaram a primeira metade das tentativas variando aleatoriamente a desaceleração do estímulo $\left(-0,87 \mathrm{~m} / \mathrm{s}^{2},-0,73 \mathrm{~m} / \mathrm{s}^{2},-0,89\right.$ $\mathrm{m} / \mathrm{s}^{2}$ ), e as tentativas posteriores em apenas uma desaceleração do estímulo visual ($0,87 \mathrm{~m} / \mathrm{s}^{2}$ ). Na fase de adaptação, todos os grupos executaram as tentativas em uma mesma desaceleração do estímulo visual $\left(-0,86 \mathrm{~m} / \mathrm{s}^{2}\right)$, diferente daquelas praticadas na fase de estabilização e sem CR. Foram utilizadas como medidas de desempenho os erros absolutos, variável e constante e, como medidas relacionadas ao padrão de execução, o timing relativo e o tempo total de movimento.

Os resultados mostraram que, na fase de adaptação, os grupos de prática aleatória e aleatória-constante tiveram desempenhos mais consistentes do que o grupo de prática constante. Quando se analisou o comportamento de cada grupo em termos do padrão de execução, verificou-se que quando foi introduzido um novo valor de desaceleração (fase de adaptação), o grupo de prática constante alterou dois componentes $\left(3^{\circ}\right.$ e $\left.5^{\circ}\right)$ de sua macro-estrutura. Já os grupos de prática aleatória e aleatória-constante alteraram, respectivamente, cinco e quatro componentes. Esses resultados permitem inferir que os grupos de prática aleatória e aleatóriaconstante foram capazes de "sacrificar" mais o seu padrão de movimento em termos da macro-estrutura, em prol da manutenção do desempenho. Portanto, eles foram mais flexíveis do que o grupo de prática constante.

TERTULIANO et al. (2008) buscaram investigar os efeitos de diferentes estruturas de prática e freqüências de fornecimento de feedback extrínseco na aprendizagem de habilidades motoras. Os participantes foram distribuídos em oito grupos que resultaram da combinação das práticas constante, aleatória, constantealeatória e aleatória-constante com as freqüências de fornecimento de feedback $100 \%$ e $33 \%$. A tarefa foi o saque por cima do voleibol, executada com o objetivo de fazer com que a bola acertasse o centro de um alvo redondo localizado no lado oposto da quadra. O feedback extrínseco manipulado foi o conhecimento de performance (CP), sendo que o mesmo foi baseado em uma lista de hierarquia de fornecimento de CP. O estudo envolveu duas fases experimentais: estabilização e adaptação, com a execução de 130 e 30 tentativas, respectivamente. $\mathrm{Na}$ fase de estabilização a prática aleatória foi manipulada em termos de diferentes regiões do saque. As medidas utilizadas referiram-se à pontuação relativa à meta do saque e ao 
padrão de movimento. Os resultados mostraram que não houve melhora no desempenho durante a fase de estabilização e que na fase de adaptação o desempenho de todos os grupos piorou, em relação à fase anterior. Assim, segundo o autor, os resultados não permitiram concluir sobre os efeitos de diferentes estruturas de prática e freqüências de feedback extrínseco, uma vez que não foi constatada ocorrência de aprendizagem.

Como se pôde notar, dos experimentos apresentados, em seis verificou-se maior eficácia da combinação da prática constante seguida pela prática aleatória no processo adaptativo na aquisição de habilidades motoras. As explicações para esses resultados têm sido no sentido de que a prática constante, primeiramente, seria responsável pela formação de uma estrutura da habilidade e que posteriormente, a prática variada aleatória seria responsável pela diversificação dessa estrutura.

Contudo, um aspecto que chamou a atenção nos experimentos apresentados anteriormente é que em todos eles a estrutura constante-aleatória foi organizada em $50 \%$ das tentativas de forma constante e 50\% das tentativas de forma aleatória. Com base nesse dado, surgiu a seguinte pergunta: até que momento, no processo de estabilização, a prática constante deveria ser conduzida? Essa pergunta foi o foco de investigações que serão apresentadas no tópico seguinte.

\subsection{A prática constante-variada no processo adaptativo de aprendizagem motora}

O fato de a prática constante-aleatória ter possibilitado melhores resultados do que as demais estruturas de prática em boa parte dos experimentos tornou-se fonte de especulações, entre as quais se encontram aquela relativa à existência de uma quantidade "ótima" de prática constante antes da introdução da prática aleatória e aquela relativa aos efeitos de prática constante combinada com outro tipo de prática variada, a prática por blocos.

Considerando as explicações de que a prática constante anteriormente à aleatória possibilitaria a padronização da habilidade, a pergunta que se fez foi: o quanto de prática constante seria suficiente para que isso ocorresse? Para responder a essa pergunta, três experimentos (CORRÊA et al., 2006; 2007; MASSIGLI et al., 
2004) foram realizados objetivando verificar os efeitos de diferentes quantidades de prática constante anteriormente à prática aleatória, no processo adaptativo em aprendizagem motora.

A tarefa utilizada nos três experimentos foi de timing coincidente. $O$ delineamento foi similar nos três experimentos: duas fases (estabilização e adaptação) e três grupos de prática constante-aleatória. O primeiro grupo executou a prática constante até o alcance de determinado desempenho critério; o segundo grupo executou a prática constante $33 \%$ além do desempenho critério; e o terceiro grupo executou $66 \%$ de prática constante adicional. A porcentagem de prática adicional foi relativa à quantidade de prática para o alcance do desempenho critério, o qual se referiu à execução de três tentativas consecutivas com erro menor que 50 ms. A prática aleatória envolveu a realização de 36 tentativas.

As pesquisas diferiram em termos dos aspectos manipulados durante a prática aleatória. No trabalho de MASSIGLI et al. (2004) foi manipulada a velocidade do estímulo visual. No trabalho de CORRÊA et al. (2006) foi manipulada a seqüência de toques. E, em CORREA et al. (2007), ambos os aspectos foram manipulados simultaneamente.

Também similar aos três trabalhos foram as medidas: erros absoluto e variável, picos relativo e absoluto de força e tempo total e timing relativo. Os resultados, nos três experimentos, não indicaram diferenças entre os grupos, o que fez com que os autores sugerissem que a prática constante poderia ser conduzida suficientemente até a formação de uma estrutura, inferida por meio do alcance do desempenho critério, não havendo necessidade de estender a quantidade de prática constante.

No seu conjunto, esses resultados foram interpretados em termos da existência de uma quantidade ótima de prática constante para o início da diversificação da habilidade motora (prática aleatória), sendo tal nível relativo ao alcance de um desempenho-critério. A partir disso, outras perguntas foram feitas: se há uma quantidade ótima de prática constante, haveria também, uma quantidade ótima de prática aleatória? Em outras palavras, o quanto de prática aleatória seria suficiente para promover a diversificação da habilidade? 
Contudo, paralelamente à realização desses estudos, outras especulações foram realizadas, porém, questionando o tipo de prática variada a ser executado após a prática constante. Assim, considerando os efeitos superiores da prática constante-aleatória e, também, a existência de outros tipos de prática variada, como a "por blocos", PAROLI (2004) investigou se os efeitos da prática constante seguida por prática aleatória seriam os mesmos da prática constante seguida por prática em blocos. A tarefa foi de timing coincidente (tocar cinco sensores em uma seqüência predeterminada de forma que o último toque coincidisse com o acendimento de um diodo alvo). Nesse caso, participaram estudantes universitários voluntários, que foram divididos em dois grupos de prática (constante-por blocos e constantealeatória). Os experimentos constaram de duas fases: estabilização e adaptação. $\mathrm{Na}$ fase de estabilização os participantes realizavam a prática constante até a obtenção de um desempenho critério (três tentativas consecutivas com erro menor que $30 \mathrm{~ms}$ ). $\mathrm{E}$, então, realizavam 36 tentativas de prática aleatória ou por blocos de acordo com o grupo experimental. Na fase de adaptação os grupos realizavam 27 tentativas em uma condição diferente daquelas experimentadas na fase anterior.

Foram realizados três experimentos que diferiram no aspecto da tarefa manipulado nas práticas variadas: no experimento 1, a prática foi variada em relação a três velocidades do estímulo visual; no experimento 2 a prática foi variada em termos de três seqüências de toques; e, no experimento 3, ambos os aspectos foram variados. Os resultados indicaram que, nos experimentos 1 e 2 os dois tipos de prática apresentaram resultados semelhantes. No entanto, no experimento 3 a prática constante seguida da prática por blocos possibilitou a melhor adaptação, 0 que levou a autora a concluir que a imprevisibilidade não favoreceu a exploração de alternativas de resposta.

Partindo do pressuposto de que a adaptação depende do nível/tipo de perturbação e, também, que existe uma hierarquia dos tipos de perturbação, FIALHO (2007) investigou o efeito da prática constante-aleatória, com manipulação dos diferentes aspectos da habilidade, na adaptação a diferentes tipos de perturbação. Foram realizados três experimentos, constituídos de duas fases (estabilização e adaptação). A fase de estabilização foi dividida em duas etapas: uma de prática constante e outra de prática aleatória, que orientou a formação dos três grupos 
experimentais com variação do aspecto perceptivo, motor e perceptivo-motor da habilidade, respectivamente. Em seguida, foi iniciada a fase de adaptação, que teve um tipo de perturbação em cada experimento. No primeiro experimento foi inserida uma perturbação perceptiva, no segundo uma perturbação motora e no terceiro uma perturbação perceptivo-motora. A tarefa utilizada foi de timing coincidente, semelhante aquela utilizada por CORRÊA (2001). As medidas utilizadas nesse estudo foram divididas em medidas de desempenho (erro absoluto, erro variável, erro constante e magnitude e variabilidade do tempo de reação), medidas sobre a microestrutura da habilidade (magnitude e variabilidade do tempo total de movimento), medidas sobre a macroestrutura da habilidade (magnitude $\mathrm{e}$ variabilidade do tempo relativo dos cinco componentes da habilidade e tentativas erradas) e medidas complementares (tentativas para atingir o critério de desempenho e sujeitos eliminados).

Os resultados dos três experimentos permitiram o autor concluir que: a) existe uma hierarquia de dificuldade em relação ao aspecto da habilidade manipulado na prática aleatória, com a prática variando o aspecto perceptivo-motor sendo mais difícil do que a prática variando o aspecto motor, e a prática variando o aspecto motor sendo mais difícil do que a prática variando o aspecto perceptivo; b) existe uma hierarquia em relação ao tipo de perturbação, com a perturbação perceptiva sendo menor do que a perturbação motora e a perceptivo-motora, e a perturbação motora sendo menor do que a perceptivo-motora; c) parece haver uma relação de especificidade entre a capacidade de adaptação a uma perturbação e o aspecto da habilidade manipulado na prática aleatória.

Um aspecto que chama a atenção é que em todos os trabalhos citados anteriormente a prática foi totalmente determinada pelo pesquisador. Isso levou WALTER et al. (2008) a realizar um estudo com o objetivo de investigar os efeitos de diferentes estruturas de prática com liberdade de escolha na aprendizagem de habilidades motoras. Para isso foi realizado um experimento em que as estruturas de prática constante e constante seguida de variada aleatória foram associadas a diferentes liberdades de escolha. O estudo foi composto de seis grupos experimentais: um grupo de prática constante; um grupo de prática constante seguida de variada aleatória; um grupo de prática constante com liberdade na 
escolha da seqüência; um grupo de prática constante com liberdade na escolha da seqüência seguida de liberdade na escolha da(s) seqüência(s); um grupo de prática constante com liberdade na escolha de alguns componentes para formar uma seqüência; e um grupo de prática constante com liberdade na escolha de alguns componentes para formar uma seqüência seguida de liberdade na escolha de alguns componentes para formar uma ou mais seqüências.

O experimento foi realizado em duas fases: estabilização, na qual a prática foi conduzida até a obtenção de um desempenho critério, mais 36 tentativas de acordo com a situação experimental de cada grupo, todas com CR. E, a fase de adaptação, na qual foram executadas 36 tentativas em uma mesma situação para todos os grupos, sem CR. A utilização de um critério de desempenho foi adotada para assegurar que os aprendizes atingissem um mesmo estado na fase de estabilização, amenizando as diferenças individuais, além de servir como controle de possíveis experiências anteriores com tarefas similares. Esse critério foi de três tentativas consecutivas com erro de até \pm 30 milissegundos. A tarefa consistiu em tocar cinco sensores em uma seqüência que variou de acordo com o grupo experimental, de forma que o último toque coincidisse com o acendimento de um diodo alvo. Foi utilizado o aparelho de timing coincidente em tarefas complexas (CORREAA \& TANI, 2004). As medidas utilizadas nesse estudo foram divididas em medidas de desempenho (erro absoluto, erro variável, erro constante), medidas sobre a microestrutura da habilidade (magnitude e variabilidade do tempo total de movimento), medida sobre a macroestrutura da habilidade (variabilidade de seqüenciamento) e medidas complementares (erro de execução).

Com base nos resultados obtidos a autora concluiu que o grupo que teve a prática constante com liberdade na escolha dos componentes intermediários para formar uma seqüência foi aquele que alcançou melhores resultados na adaptação a uma nova tarefa, assim, foi o grupo mais eficiente no processo adaptativo em aprendizagem motora. Os resultados deste estudo demonstram que a efetividade da estrutura de prática constante é aumentada quando se oferece ao aprendiz liberdade na escolha da resposta motora, especificamente no que se refere à escolha dos componentes que formam a seqüência, para a aprendizagem motora. 
Os resultados dos trabalhos descritos até aqui induziram CORRÊA (2007) à elaboração das seguintes perguntas: haveria um nível "ótimo" de prática variada após a prática constante? O quanto de prática variada seria correspondente a esse nível e, portanto, suficiente para promover a diversificação da habilidade? O nível "ótimo" seria dependente do tipo de prática variada (por blocos ou aleatória)?

Para tentar responder essas questões, CORRÊA (2007) realizou um estudo cujo objetivo foi investigar os efeitos de diferentes quantidades das práticas variada aleatória e por blocos, após a prática constante, no processo adaptativo na aprendizagem de habilidades motoras. Para isso foram realizados três experimentos que diferiram no componente da tarefa manipulado nas práticas variada aleatória e por blocos. No primeiro experimento, as práticas variadas foram manipuladas em relação ao componente perceptivo da tarefa de aquisição, ou seja, diferentes velocidades do estímulo visual. No segundo experimento, as práticas variadas foram manipuladas em relação ao componente motor, variando-se o padrão seqüencial de resposta. E, no terceiro experimento, as práticas variadas por blocos e aleatória foram manipuladas em relação aos componentes perceptivo e efetor da tarefa de aquisição, isto é, velocidade do estímulo visual e padrão seqüencial de resposta conjuntamente. A tarefa de aprendizagem foi de timing coincidente. O experimento envolveu duas fases de aprendizagem: estabilização e adaptação. Na fase de estabilização, as crianças executaram as primeiras tentativas sob prática constante até o alcance do desempenho-critério, que foi executar três tentativas consecutivas dentro de um patamar de $50 \mathrm{~ms}$ de erro. Em seguida, elas executavam as tentativas sob prática variada aleatória ou por blocos. Foram formados seis grupos em função da quantidade de prática variada (18, 36 e 63 tentativas) e do tipo de prática variada (por blocos ou aleatória). Na fase de adaptação foram realizadas 36 tentativas em uma condição diferente da fase anterior e sem CR.

No primeiro experimento, a prática variada foi manipulada em termos de diferentes velocidades do estímulo visual. A seqüência de toques nos sensores foi a mesma durante todo o experimento, e foram utilizadas três velocidade do estímulo visual na fase de estabilização, de acordo com o tipo de prática. $\mathrm{Na}$ fase de adaptação foi utilizada uma nova velocidade do estímulo visual. Os resultados mostraram que não houve diferença entre os grupos, na fase de adaptação, no que 
concerne à quantidade de prática. Contudo, observou-se que os grupos de prática variada por blocos foram aqueles mais perturbados na referida fase. Pôde-se concluir, dessa forma que neste experimento a prática constante-variada aleatória foi aquela que mais favoreceu o processo adaptativo na aprendizagem de habilidades motoras.

No segundo experimento, as práticas variadas por blocos e aleatória foram manipuladas em relação ao padrão de resposta. Na fase de estabilização, enquanto a prática foi constante os participantes executaram as tentativas em uma única seqüência de toques nos sensores e velocidade do estímulo visual. As tentativas posteriores foram executadas variando-se três padrões seqüenciais de resposta, de acordo com o tipo de prática. Na fase de adaptação todos os grupos executaram a tarefa em um novo padrão seqüencial de resposta. Os resultados permitiram o autor inferir que não houve diferença entre os grupos, na fase de adaptação, em relação ao fator quantidade de prática. Entretanto, pôde-se observar que os grupos de prática variada por blocos, novamente, foram aqueles mais perturbados. Assim, concluiu-se que a prática constante-variada aleatória foi aquela que mais favoreceu o processo adaptativo na aprendizagem de habilidades motoras.

No terceiro experimento, as práticas variadas por blocos e aleatória foram manipuladas em relação aos componentes perceptivo e motor da tarefa de aprendizagem, ou seja, diferentes velocidades do estímulo visual e diferentes padrões seqüenciais de resposta (toques). Na fase de estabilização a prática constante envolveu a execução de tentativas em uma única seqüência de toques e velocidade do estímulo visual, e a prática variada envolveu a execução de tentativas variando a combinação de três diferentes velocidades do estímulo visual e três padrões seqüenciais de resposta, de acordo com o tipo de prática (aleatória ou por blocos). A fase de adaptação envolveu a execução da tarefa em uma velocidade do estímulo visual e um padrão seqüencial de resposta diferentes daqueles da fase anterior. Os resultados do presente experimento não mostraram efeitos da quantidade de tentativas, tampouco do tipo de prática variada. $\mathrm{O}$ autor sugeriu que, nesse experimento, a prática variada por blocos, após a prática constante, também pode ter possibilitado às crianças a capacidade de lidar com a incerteza e a instabilidade produzida pela introdução de um novo padrão seqüencial de reposta. 
Isso teria sido possível em virtude da quantidade de variações na tarefa. Enquanto nos experimentos 1 e 2 houve a manipulação de, respectivamente, três velocidades do estímulo visual e três padrões seqüenciais de resposta, no terceiro experimento as variações envolveram a combinação de ambos os aspectos resultando em nove condições e, portanto, em nove blocos de tentativas. Sendo assim, embora a prática tivesse sido variada por blocos, as variações entre os blocos foram aleatórias, o que pode ter gerado incerteza e instabilidade nas execuções. No mesmo sentido, a prática envolvendo as citadas nove condições pode ter possibilitado que as crianças explorassem diferentes alternativas.

Considerando os resultados dos três experimentos, o autor concluiu que: a) há um nível ótimo de prática variada após a prática constante; b) esse nível corresponde à quantidade de dezoito tentativas aleatórias envolvendo três velocidades do estímulo visual, dezoito tentativas aleatórias envolvendo três padrões seqüenciais de resposta e dezoito tentativas aleatórias ou por blocos envolvendo a combinação de três velocidades do estímulo visual e três padrões seqüenciais de resposta; c) o nível ótimo é dependente do tipo de prática variada (por blocos ou aleatória) apenas quando ela se refere à manipulação de aspectos perceptivo e motor da tarefa em separado.

Os três experimentos realizados por CORREAA (2007) tiveram, além do aspecto da tarefa manipulada na prática variada, diferenças relativas à quantidade de condições manipuladas na referida prática. Enquanto nos dois primeiros experimentos a prática foi variada em relação a três condições, respectivamente, três velocidades do estímulo visual e três padrões seqüenciais de resposta, a combinação desses aspectos no terceiro experimento fez com que a prática variada envolvesse nove condições. E, verificou-se, justamente, diferenças na adaptação entre os mesmos. Isso nos levou a perguntar: a diversificação de habilidades motoras adquirida via diferentes quantidades de variações na prática aleatória, após a prática constante, afetaria o processo adaptativo? Essa foi a questão do presente projeto.

A consideração de dois aspectos implicou na necessidade de realização de três experimentos. O primeiro diz respeito às habilidades motoras poderem ser variadas em relação a diferentes aspectos. Pôde-se observar na revisão dos estudos 
que em tarefas que envolvem exigências perceptivas e motoras, ambos os aspectos podem ser variados separadamente e conjuntamente. O segundo aspecto refere-se à existência de hierarquia na adaptação em função de modificações na tarefa relativas às exigências supracitadas (perceptivas, motoras e perceptivas e motoras em conjunto).

Assim, no primeiro experimento, a prática variada aleatória foi manipulada em relação ao aspecto perceptivo da tarefa de aquisição. No segundo experimento, a prática variada aleatória foi manipulada em relação ao aspecto motor. $E$, no terceiro experimento, a prática variada aleatória foi manipulada em relação aos aspectos perceptivo e motor da tarefa de aquisição, como segue.

\section{OBJETIVO E HIPÓTESE}

O objetivo desse trabalho foi investigar os efeitos da quantidade de elementos manipulados na prática variada aleatória, após a prática constante, no processo adaptativo de aprendizagem motora.

Esperava-se melhor adaptação dos grupos cuja prática variada envolvesse maior variabilidade em termos da quantidade. Isso porque era esperado que a maior quantidade de variabilidade implicasse em uma habilidade mais diversificada ou com mais redundância.

\section{EXPERIMENTO 1 - VARIAÇÃO DO ASPECTO PERCEPTIVO}

\subsection{Método}

Neste experimento, a prática variada aleatória foi referente ao aspecto perceptivo da tarefa, ou seja, a diferentes velocidades do estímulo visual.

\subsubsection{Amostra}

Participaram desse experimento 22 crianças voluntárias de ambos os gêneros, com média de idade de $9,7( \pm 0,7)$ anos, sem experiência prévia na tarefa utilizada, 
distribuídas aleatoriamente em dois grupos experimentais $(n=11)$. A participação no experimento foi condicionada ao consentimento livre e esclarecido assinado pelo responsável pela criança (ANEXO I). Esse experimento, bem como aqueles 2 e 3 foram aprovados pelo Comitê de Ética em Pesquisa da Escola de Educação Física e Esporte da Universidade de São Paulo (protocolo n²008/04).

\subsubsection{Instrumento}

Foi utilizado um aparelho de timing coincidente em tarefas complexas (CORREAA \& TANI, 2004) descrito a seguir e ilustrado na FIGURA 1.

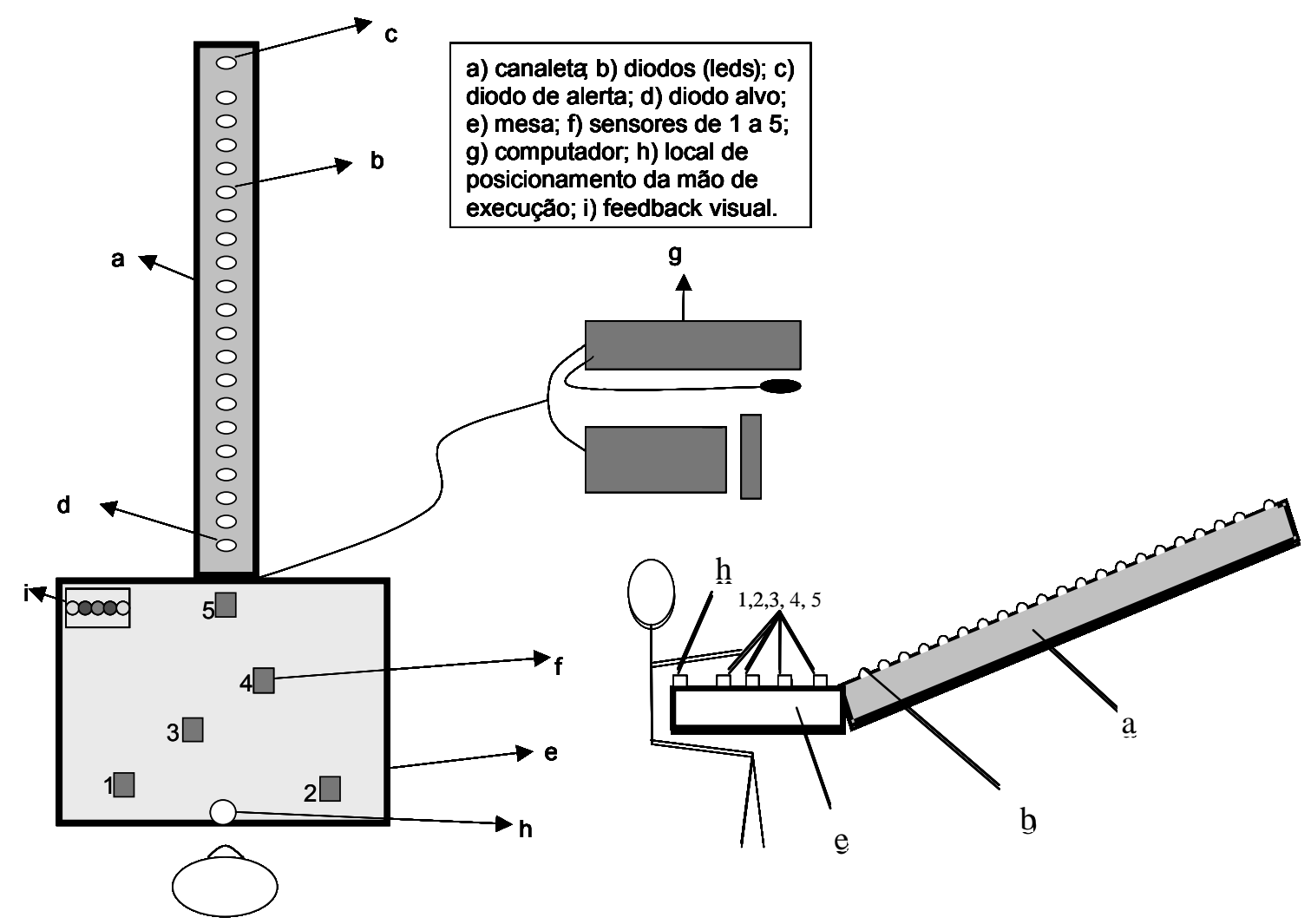

FIGURA 1 - lustração do aparelho de timing coincidente em tarefas complexas.

O aparelho era composto por uma canaleta de 200 centímetros de comprimento, 10 centímetros de largura e 10 centímetros de altura. Sobre a canaleta estavam dispostos, em linha reta, 100 diodos (leds) distantes 1 centímetro uns dos 
outros. O equipamento era composto, também, de uma mesa de madeira de 70 centímetros de comprimento, 90 centímetros de largura e 6 centímetros de altura, sobre a qual estavam dispostos cinco alvos medindo 5 centímetros de largura e 15 centímetros de comprimento. Além desses aspectos, o aparelho envolvia uma caixa de 10 centímetros de comprimento, 20 centímetros de largura e 2 centímetros de altura com cinco leds que informavam o erro referente ao timing coincidente ao executante (feedback). E, por final, o aparelho envolvia um computador com um software que, na presente pesquisa, possibilitava o controle das velocidades e do início e fim de cada tentativa, o registro dos dados e o fornecimento de feedback.

\subsubsection{Tarefa}

A tarefa foi tocar com a mão dominante cinco alvos (sensores) em uma ordem pré-estabelecida em integração a um estímulo visual.

\subsubsection{Procedimentos e delineamento}

O experimento envolveu duas fases: estabilização e adaptação. Na fase de estabilização, as crianças executaram as primeiras tentativas sob prática constante até o alcance do seguinte desempenho-critério: executar três tentativas consecutivas dentro de um patamar de $50 \mathrm{~ms}$ de erro. Em seguida, elas executaram as tentativas sob prática variada aleatória.

Conforme mostra o QUADRO 1, as crianças executaram as tentativas da prática constante até o alcance do desempenho-critério e, em seguida, 36 tentativas em forma de prática variada aleatória - na qual foram manipuladas três velocidades do estímulo visual para um grupo (CA3), e seis velocidades do estímulo visual para o outro (CA6).

Assim, na fase de estabilização, enquanto a prática era constante as crianças executaram as tentativas em uma única seqüência de toques nos sensores (SQ1=12-4-3-5, FIGURA 1) e velocidade do estímulo visual (V1=144,3 cm/s). As tentativas posteriores foram executadas variando-se aleatoriamente três velocidades do estímulo visual para o grupo CA3 (V1=144,3 cm/s, V2=168,4 cm/s, e V3=126,3 
$\mathrm{cm} / \mathrm{s})$, e seis velocidades do estímulo visual para o grupo CA6 (V1=144,3 cm/s, $\mathrm{V} 2=168,4 \mathrm{~cm} / \mathrm{s}, \mathrm{V} 3=126,3 \mathrm{~cm} / \mathrm{s}, \mathrm{V} 4=155,4 \mathrm{~cm} / \mathrm{s}, \mathrm{V} 5=137,7 \mathrm{~cm} / \mathrm{s}, \mathrm{e} V 6=118,9 \mathrm{~cm} / \mathrm{s})$

QUADRO 1 - Delineamento experimental contendo grupos (CA3 e CA6), fases (estabilização e adaptação), tipos e quantidades de prática (constante e aleatória) e velocidades manipuladas (V1 a V7).

\begin{tabular}{|c|c|c|c|}
\hline FASES $\rightarrow$ & \multicolumn{2}{|c|}{ ESTABILIZAÇÃO } & ADAPTAÇÃO \\
\hline GRUPOS $\downarrow$ & $\begin{array}{c}\text { Prática Constante } \\
\text { (Até o DC) }\end{array}$ & $\begin{array}{c}\text { Prática Aleatória } \\
(36 \text { tentativas })\end{array}$ & (36 tentativas) \\
\hline CA3 & V1 & V1, V2, V3 & V7 \\
\hline CA6 & V1 & V1, V2, V3, V4, V5, V6 & V7 \\
\hline
\end{tabular}

$\mathrm{DC}=$ desempenho-critério $( \pm 50 \mathrm{~ms}$ de erro $)$

Embora se considere as diferenças individuais relativas à quantidade de prática constante, para a prática aleatória isso não pode ser feito porque, ao fazê-lo, não se poderia garantir a todas as crianças a execução de igual quantidade de tentativas nas diferentes condições manipuladas. Portanto, como no estudo de CORRÊA (2007), optou-se por determinar uma quantidade de tentativas na prática aleatória que envolvesse igualmente as condições experimentais.

A fase de adaptação envolveu uma modificação na tarefa relativa ao componente manipulado na prática aleatória, portanto, uma mudança na velocidade do estímulo visual. Nessa fase, todos os grupos executaram as tentativas utilizandose da mesma seqüência de toques nos sensores e em uma mesma velocidade do estímulo visual, porém essa última foi diferente daquelas praticadas na fase de estabilização (V7=106,4 cm/s).

Sobre os procedimentos, o experimentador explicava o experimento, e em seguida verificava o interesse do indivíduo em participar. Feito isso, o experimento foi iniciado. O indivíduo era posicionado de frente para o aparelho, em uma cadeira regulável, de forma que seu abdômen ficasse à altura da mesa, e que ele pudesse tocar todos os sensores sem restrições. Também era verificada a possibilidade de o indivíduo tocar os alvos sem apoiar-se, ou debruçar-se sobre a mesa. 
Considerados esses aspectos, eram dadas explicações sobre o aparelho e a tarefa. Primeiramente, eram dadas explicações sobre a canaleta, posicionada à frente da criança, num ângulo de $30^{\circ}$, e foi mostrado o seu funcionamento (diodo de alerta, diodo alvo, etc.). Também eram dadas informações sobre os sensores e o computador. Em seguida, a tarefa era explicada: o experimentador informava à criança que ela deveria colocar sua mão dominante sobre a mesa, numa marca determinada, e dirigir seu olhar para o diodo de alerta, e que ela deveria tocar os sensores com a ponta dos dedos, a partir do momento que o estímulo luminoso começasse a correr, fazendo com que o último toque (alvo $n^{\circ} 5$ ) coincida com o acendimento da lâmpada alvo. Para todos os indivíduos eram apresentadas analogias com ações esportivas, como por exemplo, a rebatida no tênis, o saque e a cortada no voleibol. Novamente, após essas informações, o indivíduo era consultado sobre seu interesse em participar do estudo.

Após essas explicações, o experimentador verificava a compreensão da tarefa por parte da criança, e permitia que elas executassem a seqüência de toques até cinco vezes, para reforçar seu entendimento. A seqüência de alvos a ser tocada era posicionada em cima da mesa, à frente e à direita da criança, de modo que sua visualização ficasse facilitada. Além disso, o experimentador apontava para a criança os alvos a serem tocados. Pensou-se em no máximo cinco execuções para se evitar efeitos de aprendizagem.

O experimentador informava à criança que após cada tentativa ela deveria colocar sua mão novamente na marca determinada, e que the seriam dadas informações sobre o seu desempenho (conhecimento de resultados - CR) por meio do aparelho de feedback (item i da FIGURA 1).

O CR fornecido foi: muito antes ou depois (a partir de $101 \mathrm{~ms}$ de erro), um pouco antes ou depois (de $51 \mathrm{~ms}$ a $100 \mathrm{~ms}$ de erro), certo (até $50 \mathrm{~ms}$ de erro). O intervalo entre cada execução foi de aproximadamente 6 segundos. Ao término da fase de estabilização, o experimentador explicava à criança que na próxima fase 0 seu desempenho não iria ser informado. Em seguida a fase de adaptação era iniciada. 
Ao final do experimento, o experimentador agradecia à criança por sua participação, sanava-lhe eventuais dúvidas, e a acompanhava até seu local de atividade. O tempo para cada indivíduo foi de no máximo 40 minutos.

\subsubsection{Medidas}

O estudo teve como variáveis dependentes os erros absoluto, variável e constante, respectivamente, medidas que permitiram inferir a precisão, consistência e direção do desempenho. Essas medidas possibilitaram analisar o desempenho em relação à meta da tarefa (coincidência). Também foi utilizado o erro de execução, o qual se referiu às tentativas cuja seqüência era executada errada ou de forma incompleta. Elas foram calculadas da seguinte forma:

- Erro absoluto - média do erro absoluto em blocos de nove tentativas.

- Erro variável - desvio-padrão do erro em blocos de nove tentativas.

- Erro constante - média do erro em blocos de nove tentativas.

- Erro de execução - somatória dos erros de execução em blocos de nove tentativas.

\subsubsection{Tratamento dos dados}

Os dados foram analisados em blocos de nove tentativas. $\mathrm{Na}$ fase de estabilização, foram considerados para análise o primeiro bloco de tentativas de prática constante e os quatro blocos de tentativas de prática variada aleatória. Para as medidas de desempenho (erros absoluto, variável e constante), foi conduzida para cada grupo uma análise de variância (ANOVA one-way) para verificar o comportamento de cada grupo na sua situação experimental. $E$, na fase de adaptação foi realizada uma análise de variância a dois fatores ( 2 grupos $\mathrm{x} 5$ blocos de tentativas), com medidas repetidas no segundo fator (ANOVA two-way), para comparar os efeitos das diferentes quantidades de variações da prática. Para essa análise foram considerados o último bloco da fase de estabilização e os quatro 
blocos de tentativas da fase de adaptação. A localização das diferenças encontradas foi efetuada pelo teste de Tukey HSD.

Para o erro de execução, foram realizados testes estatísticos nãoparamétricos por se tratar de valores discretos. Foi conduzida uma análise de variância (ANOVA de Friedman) para verificar o comportamento de cada grupo na sua situação experimental. Em caso de diferenças, a localização das mesmas foi efetuada a partir da análise dos postos. E, foi realizado o Teste $U$ de Mann-Whitney para comparar os efeitos das diferentes quantidades de variações da prática.

\subsection{Resultados}

Os resultados das medidas de desempenho relacionadas ao alcance da meta da tarefa (timing coincidente) - erros absoluto, variável e constante - e do erro de execução são apresentados na TABELA 1 e ilustrados, respectivamente, nas FIGURAS 2, 3, 4 e 5.

TABELA 1 - Médias dos erros absoluto (EA), variável (EV) e constante (EC) em milissegundos e mediana do erro de execução (EE) dos dois grupos experimentais (CA3 e CA6), no primeiro bloco de tentativas de prática constante (Co1) e nos quatro blocos de tentativas de prática aleatória (Aleat) da fase de estabilização, e nos quatro blocos de tentativas da fase de adaptação (Adap).

\begin{tabular}{ccccccccccc}
\hline Medida & Grupos & Co1 & Aleat1 & Aleat2 & Aleat3 & Aleat4 & Adap 1 & Adap 2 & Adap 3 & Adap 4 \\
\hline EA & CA3 & 418,83 & 174,75 & 173,93 & 179,58 & 128,27 & 162,18 & 126,86 & 102,16 & 106,87 \\
& CA6 & 325,46 & 128,06 & 148,31 & 171,25 & 132,88 & 165,72 & 178,49 & 178,71 & 174,43 \\
EV & CA3 & 246,55 & 236,14 & 184,02 & 200,06 & 131,57 & 154,40 & 117,23 & 88,37 & 93,49 \\
& CA6 & 249,63 & 151,03 & 201,96 & 210,92 & 179,76 & 150,99 & 136,26 & 115,47 & 121,20 \\
EC & CA3 & 404,26 & 89,20 & 127,92 & 121,96 & 58,68 & $-102,39$ & $-72,17$ & $-67,85$ & $-74,79$ \\
& CA6 & 304,04 & 39,03 & 49,94 & 78,92 & 1,69 & $-108,85$ & $-136,59$ & $-126,32$ & $-144,81$ \\
EE & CA3 & 4 & 1 & 0 & 1 & 2 & 1 & 1 & 1 & 0 \\
& CA6 & 4 & 1 & 0 & 1 & 2 & 1 & 1 & 1 & 1 \\
\hline
\end{tabular}




\subsubsection{Erro absoluto}

Conforme se pode observar na FIGURA 2, ambos os grupos diminuíram o erro absoluto durante a fase de estabilização. Essa observação foi confirmada pelas ANOVAS one-way. Para o grupo CA3 foi encontrado $F(4 ; 40)=4,43$, $p<0,05$ e para 0 grupo CA6, $F(4 ; 36)=5,80, p<0,01$, sendo que o teste de Tukey ${ }_{\text {HSD }}$ mostrou que o primeiro bloco de tentativas de prática constante foi diferente dos demais blocos desta fase em ambos os grupos $(p<0,05)$.

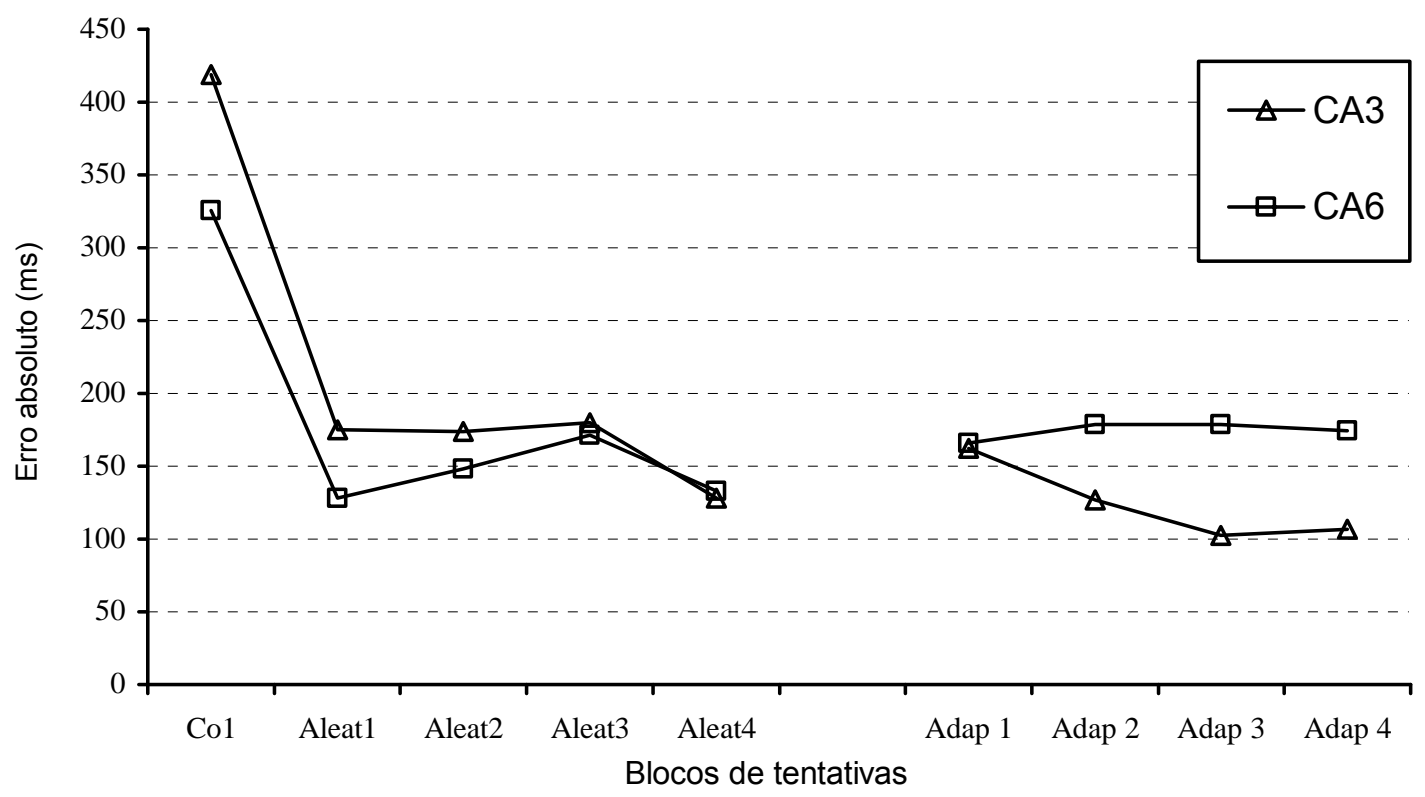

FIGURA 2 - Médias do erro absoluto em milissegundos, no primeiro bloco de tentativas de prática constante (Co1) e nos quatro blocos de tentativas de prática aleatória (Aleat) da fase de estabilização, e nos quatro blocos de tentativas da fase de adaptação (Adap), dos dois grupos experimentais (CA3 e CA6).

Na fase de adaptação, os grupos mantiveram o mesmo desempenho do último bloco de tentativas da fase de estabilização. Apesar de haver uma diferença entre os grupos de aproximadamente $70 \mathrm{~ms}$ no valor do erro absoluto nos dois últimos blocos da fase de adaptação, a ANOVA two-way não detectou diferenças estatisticamente significantes. Foram encontrados os seguintes resultados: grupos $[F(1 ; 20)=2,23$, 
$p>0,05]$; blocos de tentativas $[F(4 ; 80)=1,29, p>0,05]$; e interação entre grupos e blocos de tentativas $[F(4 ; 80)=2,34, p>0,05]$.

Esses resultados permitem inferir que os grupos conseguiram melhorar e manter o nível de desempenho durante a fase de estabilização. $E$, que além de não serem perturbados com a mudança de velocidade, os grupos obtiveram o mesmo desempenho na fase de adaptação.

\subsubsection{Erro variável}

A pesar de se observar certa diminuição do erro variável na fase de estabilização (FIGURA 3), a análise estatística não encontrou diferenças significantes. A ANOVA one-way encontrou para o grupo CA3 $[F(4 ; 40)=0,83, p>0,05]$ e para o grupo CA6 $[F(4 ; 32)=1,11, p>0,05]$.

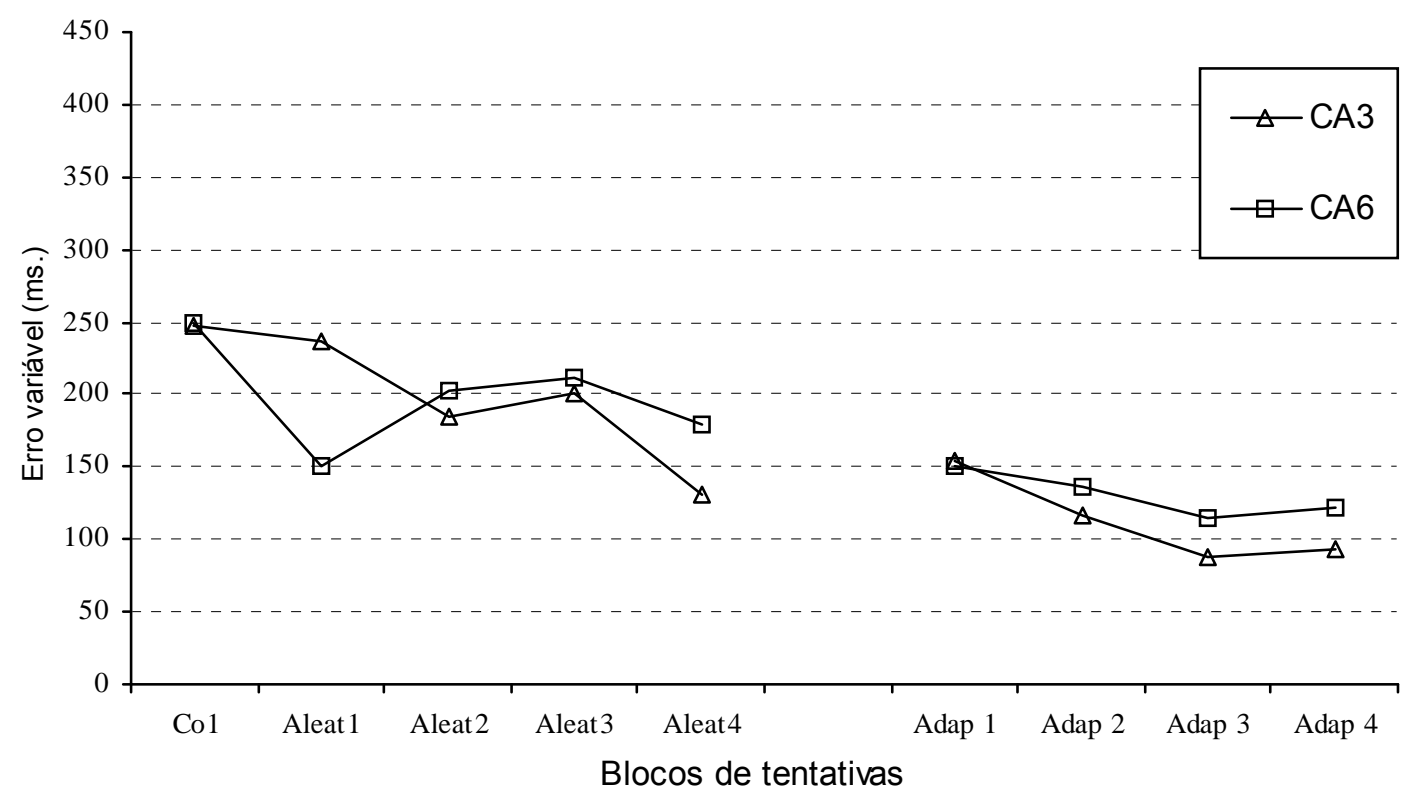

FIGURA 3 - Médias do erro variável em milissegundos, no primeiro bloco de tentativas de prática constante (Co1) e nos quatro blocos de tentativas de prática aleatória (Aleat) da fase de estabilização, e nos quatro blocos de tentativas da fase de adaptação (Adap), dos dois grupos experimentais (CA3 e CA6). 
$\mathrm{Na}$ fase de adaptação, a ANOVA two-way encontrou diferenças estatisticamente significantes apenas no fator blocos de tentativas $[F(4 ; 80)=3,69$, $p<0,01]$. O teste de Tukey ${ }_{H S D}$ indicou tais diferenças entre o último bloco de tentativas da fase de estabilização e o terceiro bloco de tentativas da fase de adaptação $(p<0,03)$. Para os demais fatores foram encontrados: grupos $[F(1 ; 20)=1,35, p>0,05]$; e, interação entre grupos e blocos de tentativas $[F(4,80)=0,51, p>0,05]$.

Os resultados sugerem que ambos os grupos mantiveram o mesmo nível de consistência durante a fase de estabilização e houve uma melhora da consistência do último bloco de tentativas da fase de estabilização para o penúltimo bloco da fase de adaptação.

\subsubsection{Erro constante}

Pode-se notar que ambos os grupos tiveram uma tendência a atrasar a resposta durante a fase de estabilização (FIGURA 4).

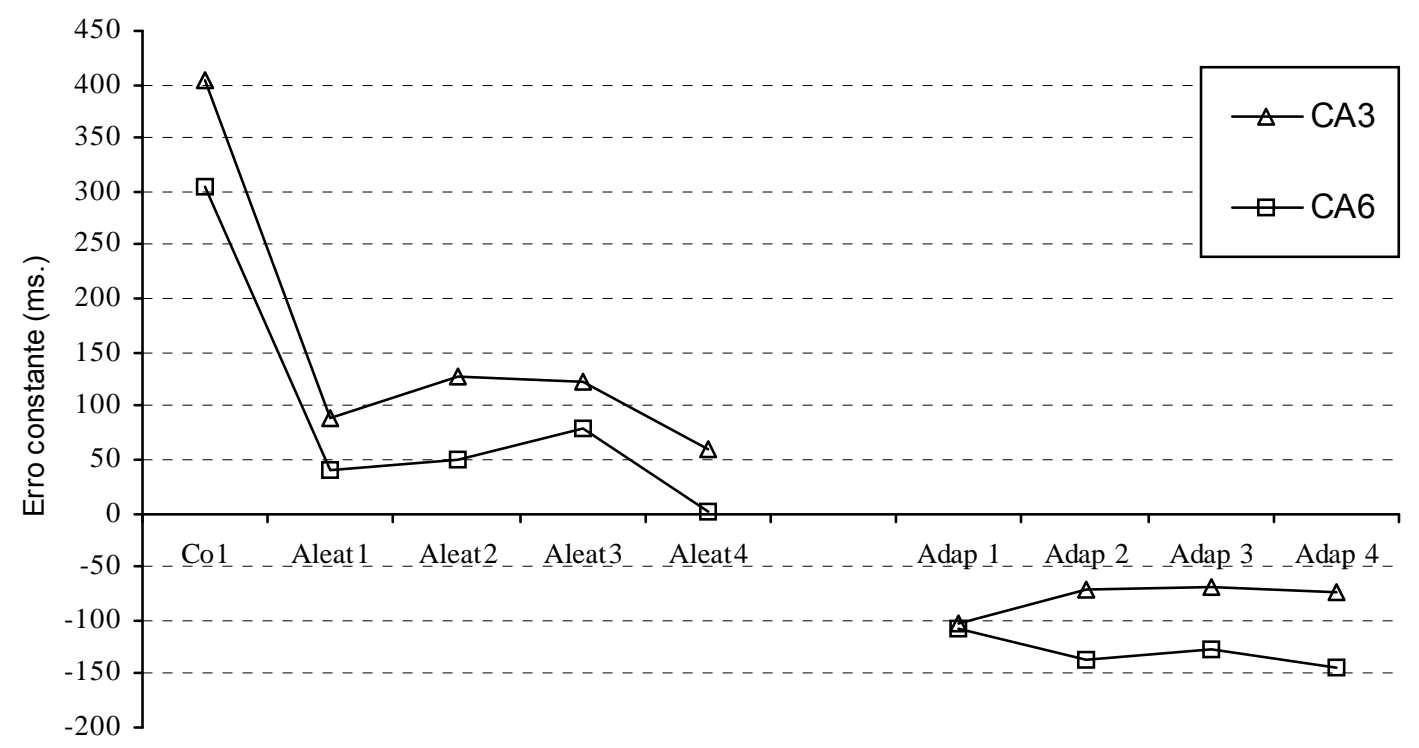

Blocos de tentativas

FIGURA 4 - Médias do erro constante em milissegundos, no primeiro bloco de tentativas de prática constante (Co1) e nos quatro blocos de tentativas de prática aleatória (Aleat) da fase de estabilização, e nos quatro blocos de tentativas da fase de adaptação (Adap), dos dois grupos experimentais (CA3 e CA6). 
A ANOVA one-way encontrou para o grupo CA3 $[F(4 ; 40)=6,06, p<0,01]$ e para o grupo CA6 $[F(4 ; 36)=9,26, p<0,01]$. O teste de Tukey ${ }_{\text {HSD }}$ mostrou que o primeiro bloco de tentativas de prática constante foi diferente dos demais blocos desta fase em ambos os grupos ( $p<0,01)$.

Ao contrário da fase anterior, na fase de adaptação ambos os grupos tiveram uma tendência a adiantar a resposta (FIGURA 4). A ANOVA two-way encontrou os seguintes resultados: grupos $[F(1 ; 20)=1,89, p>0,05]$; blocos de tentativas $[F(4$; $80)=20,28, p>0,05]$; e, interação entre grupos e blocos de tentativas $[F(4 ; 80)=0,91$, $p>0,05]$.

Esses resultados possibilitam inferir que a mudança de desempenho atrasado para adiantado não foi significante e que os grupos mantiveram o mesmo desempenho na fase de adaptação.

\subsubsection{Erro de execução}

A medida de erro de execução mostra quantas tentativas no bloco de nove foram executadas de forma incompleta ou na seqüência incorreta. A FIGURA 5, associada às medidas da TABELA 1, permite observar que ambos os grupos diminuíram a quantidade de execuções erradas na fase de estabilização. A ANOVA de Friedman apontou diferenças estatisticamente significantes para ambos os grupos, sendo que foi encontrado para o grupo CA3 $x^{2}(N=11, g l=4)=21,51, p<0,01$ e para o grupo CA6 $x^{2}(\mathrm{~N}=11, \mathrm{gl}=4)=22,09, \mathrm{p}<0,01$.

Na fase de adaptação, concernente às comparações intragrupo, a ANOVA de Friedman não apontou diferenças estatisticamente significantes para nenhum dos grupos, sendo que foi encontrado para o grupo CA3 $x^{2}(N=11, g l=4)=1,57, p>0,05$ e para o grupo CA6 $x^{2}(\mathrm{~N}=11, \mathrm{gl}=4)=1,56, \mathrm{p}>0,05$. 


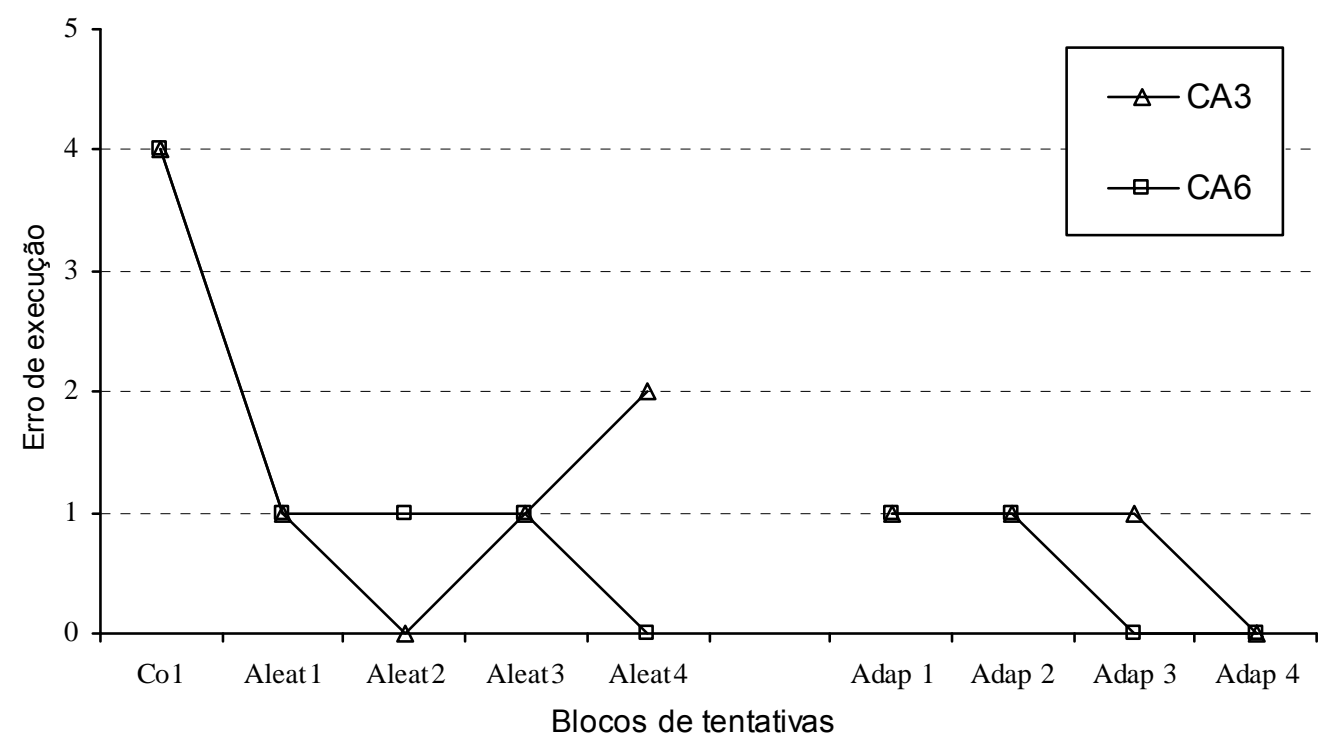

FIGURA 5 - Mediana do erro de execução, no primeiro bloco de tentativas de prática constante (Co1) e nos quatro blocos de tentativas de prática aleatória (Aleat) da fase de estabilização, e nos quatro blocos de tentativas da fase de adaptação (Adap), dos dois grupos experimentais (CA3 e CA6).

Na comparação entre os grupos, o teste $U$ de Mann-Whitney não encontrou diferenças, sendo que para o último bloco de tentativas da fase de estabilização foi encontrado $Z$ ajustado=1,30, $p=0,19$; para o primeiro bloco de tentativas da fase de adaptação foi encontrado $Z$ ajustado $=0,21, p=0,84$; para o segundo bloco foi encontrado $Z$ ajustado $=-0,25, p=0,80$; para o terceiro bloco foi encontrado $Z$ ajustado=0,51, $p=0,61$; e para o quarto bloco foi encontrado $Z$ ajustado=0,43, $p=0,66$.

Esses resultados mostram que houve diminuição na quantidade de execuções erradas na fase de estabilização e que o desempenho alcançado foi mantido e sem diferenças entre os grupos.

\subsection{Síntese dos resultados}

As análises dos resultados permitiram verificar que, na fase de estabilização, os grupos melhoraram a precisão, mantiveram o nível de consistência, diminuíram o atraso na resposta e a quantidade de execuções erradas. 
$\mathrm{Na}$ fase de adaptação não foram verificadas diferenças entre os grupos. Verificou-se que, com a introdução da nova velocidade, o nível de precisão foi mantido e houve um aumento da consistência do último bloco de tentativas da fase de estabilização para o penúltimo bloco da fase de adaptação. A quantidade de execuções erradas foi mantida.

Esses resultados permitem entender que as práticas variadas aleatórias com variação de três e seis elementos, após a prática constante, possibilitaram similar processo adaptativo. Por um lado, poderia ser pensado que a diversificação conseguida com a variação em três velocidades teria sido suficiente para dar conta da perturbação inserida por meio de uma nova velocidade. Por outro lado, a nova velocidade pode não ter causado perturbação ou, no caso de ter causado, ela pode não ter sido "robusta" o suficiente para exigir do sistema uma maior capacidade de adaptação.

Outros estudos que utilizaram tarefa semelhante à utilizada no presente trabalho também não encontraram diferenças entre o desempenho dos grupos experimentais quando o aspecto manipulado na prática variada e modificado na fase de adaptação foi o componente perceptivo (CORRÊA, 2001; 2007; MASSIGLI et al., 2004; PAROLI, 2004). Um aspecto que parece ter sido essencial para isso diz respeito ao estímulo visual ter sido manipulado em termos de velocidade constante, pois quando a aceleração foi modificada, no estudo de PINHEIRO e CORRÊA (2007), foram encontradas diferenças em relação à consistência, sendo que os grupos de prática aleatória e aleatória-constante foram mais consistentes que os grupos de prática constante e constante-aleatória.

Em suma, não houve diferença entre os grupos na fase de adaptação. Podese concluir que a diversificação conseqüente do aumento na quantidade de elementos manipulados na prática aleatória (de três para seis elementos) não implicou em melhor adaptação.

\section{EXPERIMENTO 2 - VARIAÇÃO DO ASPECTO MOTOR}

Nesse experimento, a prática variada aleatória foi manipulada em termos do padrão seqüencial de resposta (seqüência de toques). 


\subsection{Método}

\subsubsection{Amostra}

Participaram desse experimento 22 crianças voluntárias de ambos os gêneros, com média de idade de 9,8 $( \pm 0,6)$ anos, sem experiência prévia na tarefa utilizada, distribuídas aleatoriamente em dois grupos experimentais $(n=11)$. A participação no experimento foi condicionada ao consentimento livre e esclarecido assinado pelo responsável pela criança (ANEXO I).

\subsubsection{Instrumento e tarefa}

Foram similares aos do experimento 1.

\subsubsection{Procedimentos e delineamento}

$\mathrm{Na}$ fase de estabilização do presente experimento, enquanto a prática foi constante as crianças executaram as tentativas em uma única seqüência de toques nos sensores (SQ1=1-2-4-3-5, FIGURA 1) e velocidade do estímulo visual (V1=144,3 $\mathrm{cm} / \mathrm{s}$ ). Contudo, como mostra o QUADRO 2, as tentativas posteriores foram executadas variando-se aleatoriamente três padrões seqüenciais de resposta para 0 grupo CA3 (SQ1=1-2-4-3-5, SQ2=1-3-2-4-5 e SQ3=1-4-2-3-5, FIGURA 1), e seis padrões seqüenciais de resposta para o grupo CA6 (SQ1=1-2-4-3-5, SQ2=1-3-2-4-5, SQ3=1-4-2-3-5, SQ4=1-4-2-4-5, SQ5=1-4-3-4-5 e SQ6=1-3-4-2-5, FIGURA 1).

QUADRO 2 - Delineamento experimental contendo grupos (CA3 e CA6), fases (estabilização e adaptação), tipos e quantidades de prática (constante e aleatória) e seqüências de toques manipuladas (SQ1 a SQ7).

\begin{tabular}{|c|c|c|c|}
\hline FASES $\rightarrow$ & \multicolumn{2}{|c|}{ ESTABILIZAÇÃO } & ADAPTAÇÃO \\
\hline GRUPOS $\downarrow$ & $\begin{array}{c}\text { Prática Constante } \\
\text { (Até DC) }\end{array}$ & $\begin{array}{c}\text { Prática Aleatória } \\
\text { (36 tentativas) }\end{array}$ & (36 tentativas) \\
\hline CA3 & SQ1 & SQ1, SQ2, SQ3 & SQ7 \\
\hline CA6 & SQ1 & SQ1, SQ2, SQ3, SQ4, SQ5, SQ6 & SQ7 \\
\hline
\end{tabular}

$\mathrm{DC}=$ desempenho-critério $( \pm 50 \mathrm{~ms}$ de erro $)$ 
$\mathrm{Na}$ fase de adaptação, todos os grupos executaram a tarefa em um novo padrão seqüencial de resposta (SQ7=1-4-3-2-5, FIGURA 1).

\subsubsection{Medidas e tratamento dos dados}

Também foram semelhantes àqueles do experimento 1.

\subsection{Resultados}

Os resultados das medidas de desempenho relacionadas ao alcance da meta da tarefa (timing coincidente) - erros absoluto, variável e constante - e do erro de execução são apresentados na TABELA 2 e ilustrados, respectivamente, nas FIGURAS 6, 7, 8 e 9.

TABELA 2 - Médias dos erros absoluto (EA), variável (EV) e constante (EC) em milissegundos e mediana do erro de execução (EE) dos dois grupos experimentais (CA3 e CA6), no primeiro bloco de tentativas de prática constante (Co1) e nos quatro blocos de tentativas de prática aleatória (Aleat) da fase de estabilização, e nos quatro blocos de tentativas da fase de adaptação (Adap).

\begin{tabular}{ccccccccccc}
\hline Medida & Grupos & Co1 & Aleat1 & Aleat2 & Aleat3 & Aleat4 & Adap 1 & Adap 2 & Adap 3 & Adap 4 \\
\hline EA & CA3 & 339,78 & 95,46 & 133,45 & 106,62 & 90,90 & 132,65 & 152,01 & 174,88 & 114,84 \\
& CA6 & 356,60 & 472,32 & 377,94 & 465,34 & 342,82 & 182,81 & 164,09 & 116,54 & 119,59 \\
EV & CA3 & 249,45 & 104,65 & 160,04 & 105,84 & 102,27 & 102,07 & 132,91 & 138,25 & 84,29 \\
& CA6 & 211,63 & 432,03 & 257,97 & 317,61 & 266,87 & 110,47 & 135,40 & 78,95 & 137,55 \\
EC & CA3 & 285,68 & 24,29 & 89,33 & 65,52 & 44,29 & 71,27 & 104,86 & 123,34 & 71,46 \\
& CA6 & 350,40 & 456,26 & 368,58 & 444,88 & 290,04 & 170,20 & 134,46 & 95,29 & 99,51 \\
EE & CA3 & 4 & 2 & 2 & 1 & 1 & 3 & 2 & 3 & 1 \\
& CA6 & 5 & 4 & 3 & 3 & 4 & 2 & 1 & 2 & 1 \\
\hline
\end{tabular}




\subsubsection{Erro absoluto}

Ao observar a FIGURA 6, nota-se que o grupo CA3 diminuiu o erro absoluto durante a fase de estabilização; enquanto o grupo CA6 não diminui. A ANOVA oneway encontrou diferenças estatisticamente significantes para o grupo CA3 $[F(4$; $40)=7,04, p<0,01]$, sendo que o teste de Tukey ${ }_{\text {HSD }}$ mostrou que o primeiro bloco de tentativas de prática constante foi diferente dos demais blocos desta fase $(p<0,01)$. Para o grupo CA6, não foram encontradas diferenças $[F(4 ; 36)=0,49, p>0,05]$.

$\mathrm{Na}$ fase de adaptação, apesar do grupo CA6 ter diminuído o erro absoluto do último bloco de tentativas da fase de estabilização para o primeiro bloco da fase de adaptação, a ANOVA two-way não detectou diferenças estatisticamente significantes. Foram encontrados os seguintes resultados: grupos $[F(1 ; 20)=0,96, p>0,05]$; blocos de tentativas $[F(4 ; 80)=0,83, p>0,05]$; e interação entre grupos e blocos de tentativas $[F(4 ; 80)=2,20, p>0,05]$.

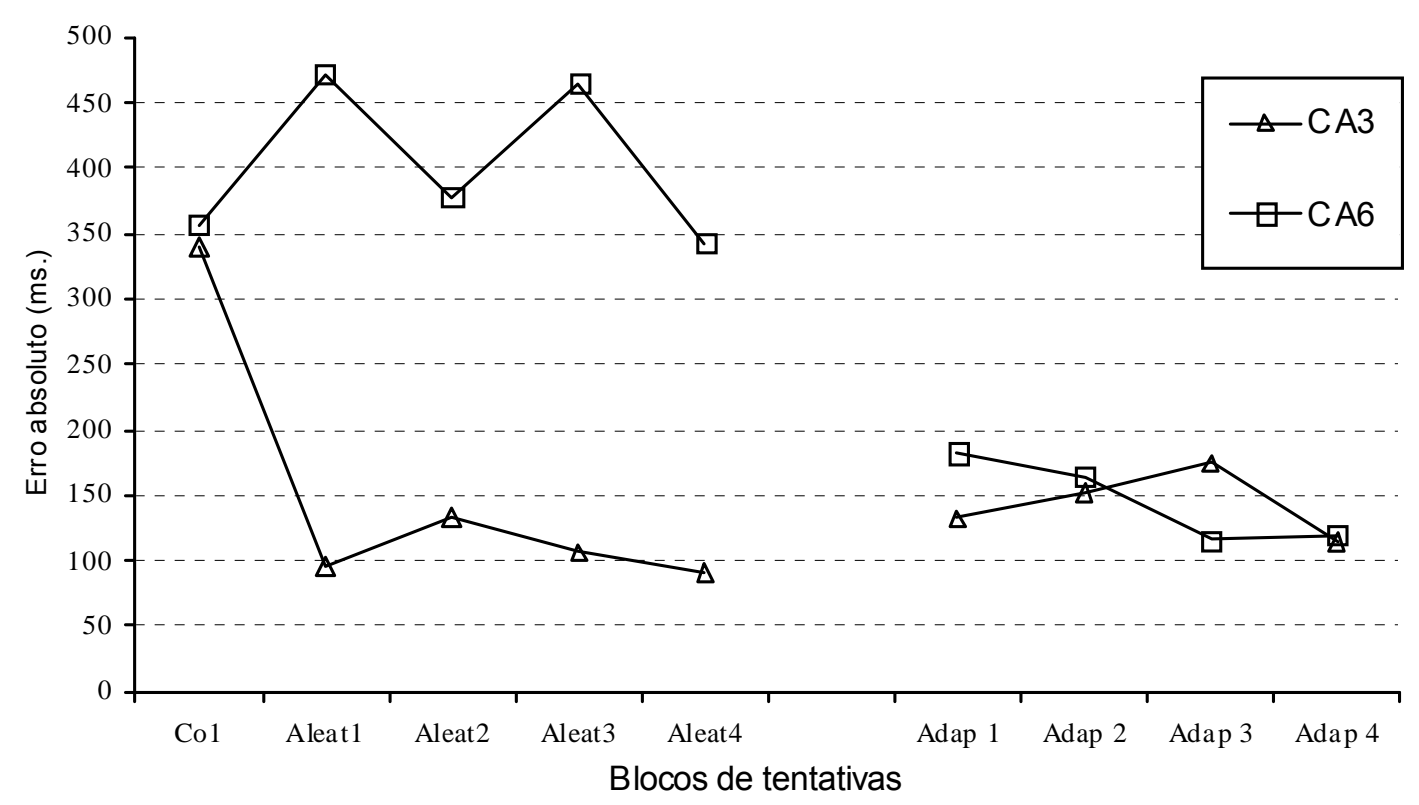

FIGURA 6 - Médias do erro absoluto em milissegundos, no primeiro bloco de tentativas de prática constante (Co1) e nos quatro blocos de tentativas de prática aleatória (Aleat) da fase de estabilização, e nos quatro blocos de tentativas da fase de adaptação (Adap), dos dois grupos experimentais (CA3 e CA6). 
Esses resultados indicam que o grupo com três variações da prática aleatória (CA3) conseguiu melhorar e manter o nível de desempenho em termos de precisão durante a fase de estabilização; enquanto o grupo com seis variações da prática aleatória (CA6) não melhorou o seu desempenho do primeiro bloco de tentativas de prática constante para os blocos de tentativas de prática aleatória. Entretanto, é importante ressaltar que se trata de um comportamento esperado, ou seja, que com a introdução da prática aleatória o desempenho piore. Apesar disso, a fase seguinte (adaptação) não implicou em perturbação, tampouco em diferenças entre os grupos.

\subsubsection{Erro variável}

$\mathrm{Na}$ fase de estabilização, apesar de o grupo CA3 ter apresentado diminuição do erro variável e o grupo CA6 apresentado aumento (FIGURA 7), a análise estatística não encontrou diferenças significantes. A ANOVA one-way encontrou $F$ (4; $32)=2,28, p>0,05$ para o grupo $\mathrm{CA} 3$ e $F(4 ; 20)=0,19, p>0,05$ para o grupo CA6.

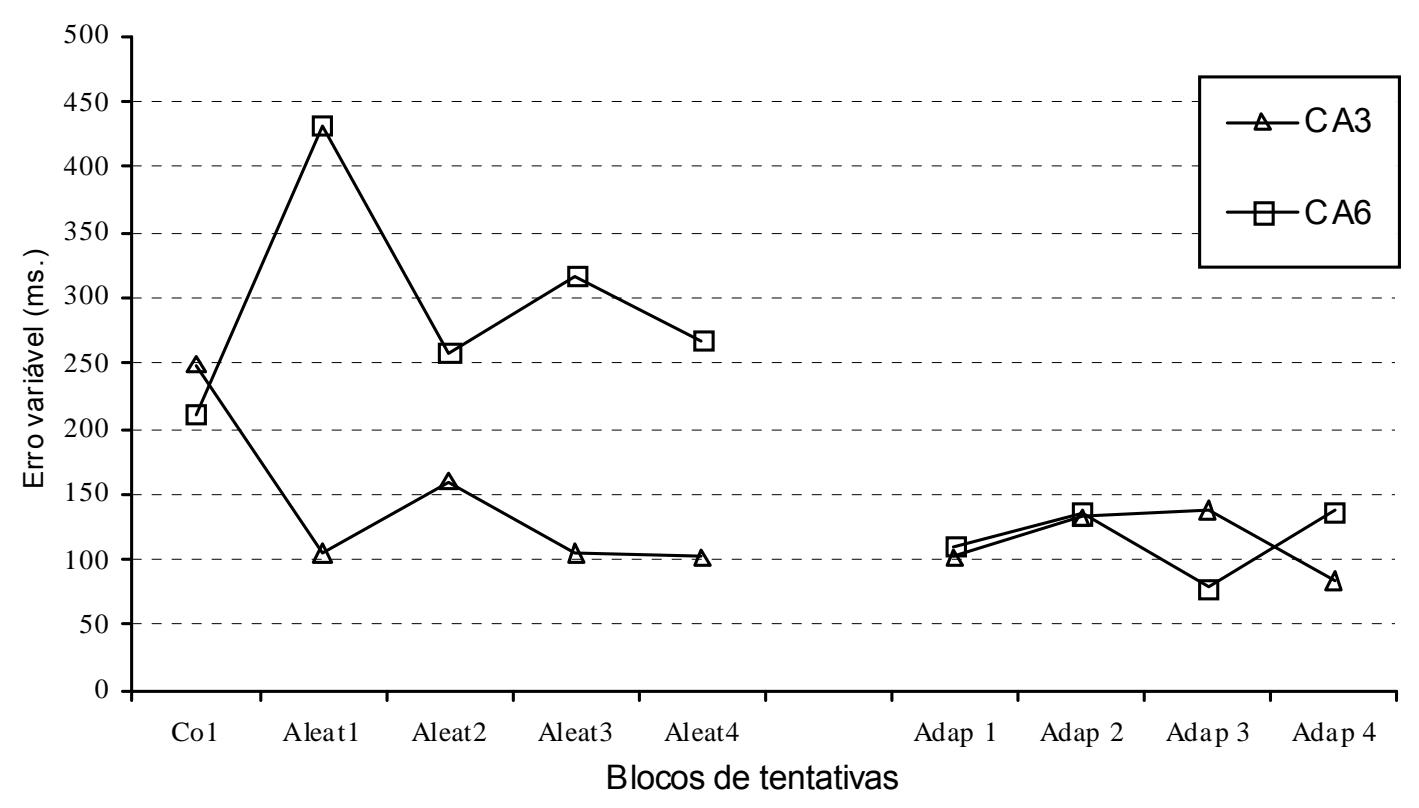

FIGURA 7 - Médias do erro variável em milissegundos, no primeiro bloco de tentativas de prática constante (Co1) e nos quatro blocos de tentativas de prática aleatória (Aleat) da fase de estabilização, e nos quatro blocos de tentativas da fase de adaptação (Adap), dos dois grupos experimentais (CA3 e CA6). 
$\mathrm{Na}$ fase de adaptação, a ANOVA two-way não encontrou diferenças estatisticamente significantes para nenhum fator. Foram encontrados os seguintes resultados: blocos de tentativas $[F(4 ; 72)=1,17, p>0,05]$; grupos $[F(1 ; 18)=2,28$, $p>0,05]$; e, interação grupos e blocos de tentativas $[F(4 ; 72)=0,86, p>0,05]$.

Os resultados sugerem que ambos os grupos mantiveram o mesmo nível de consistência durante a fase de estabilização e adaptação.

\subsubsection{Erro constante}

Pode-se notar na FIGURA 8 que ambos os grupos tiveram uma tendência a atrasar a resposta durante a fase de estabilização. A ANOVA one-way encontrou para o grupo CA3 $[F(4 ; 40)=5,37, p<0,01]$, sendo que o teste de Tukey ${ }_{H S D}$ mostrou que o primeiro bloco de tentativas de prática constante foi diferente dos demais blocos desta fase $(p<0,01)$;. e para o grupo CA6 $[F(4 ; 36)=0,52, p>0,05]$.

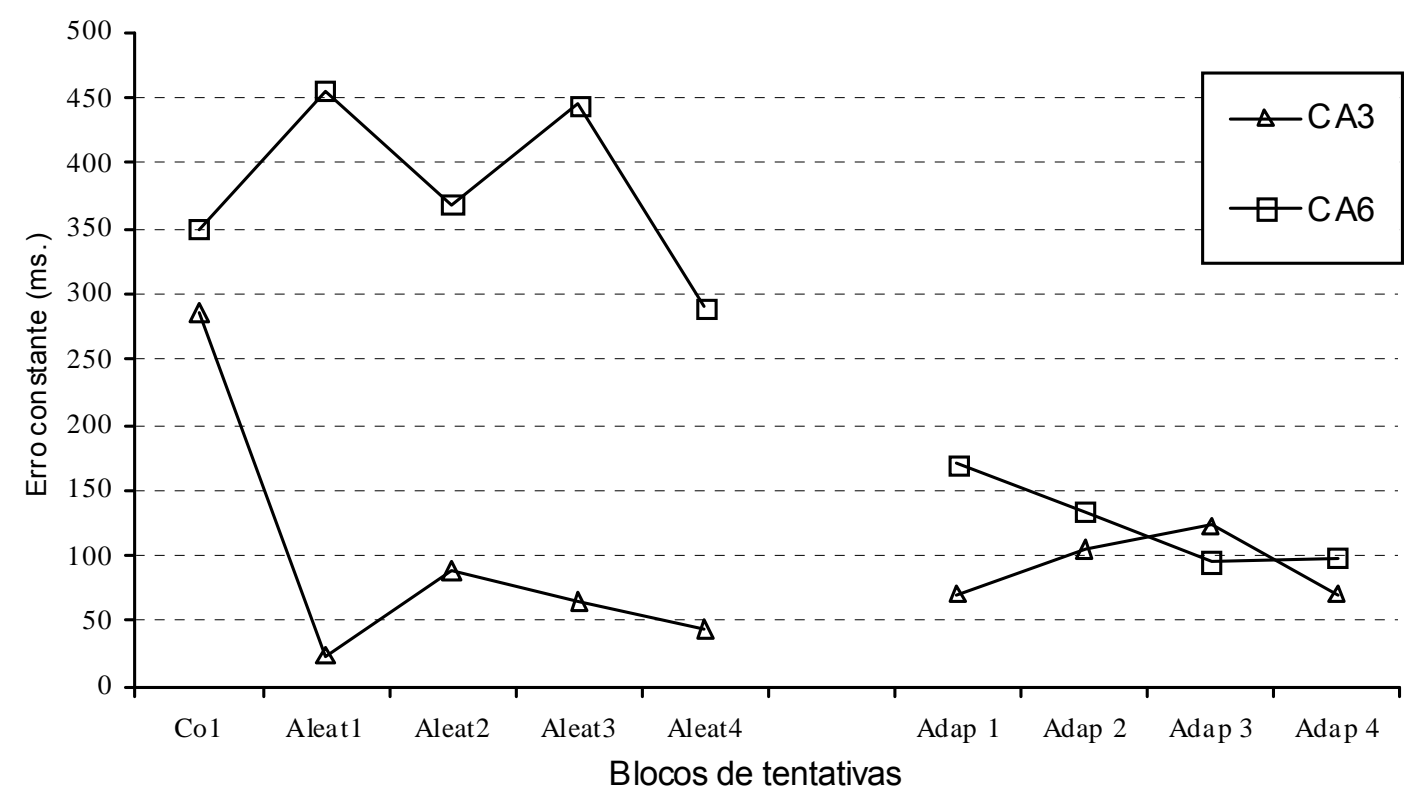

FIGURA 8 - Médias do erro constante em milissegundos, no primeiro bloco de tentativas de prática constante (Co1) e nos quatro blocos de tentativas de prática aleatória (Aleat) da fase de estabilização, e nos quatro blocos de tentativas da fase de adaptação (Adap), dos dois grupos experimentais (CA3 e CA6). 
Ao contrário do experimento anterior, no qual ambos os grupos tiveram uma tendência a adiantar a resposta na fase de adaptação, nesse experimento os grupos continuaram a atrasar a resposta. A ANOVA two-way não encontrou diferenças estatisticamente significantes para nenhum fator. Foram encontrados os seguintes resultados: blocos de tentativas $[F(4 ; 80)=0,83, p>0,05]$; grupos $[F(1 ; 20)=0,96$, $p>0,05]$; e, interação grupos e blocos de tentativas $[F(4 ; 80)=2,20, p>0,05]$.

Sendo assim, os resultados possibilitam inferir que os grupos não foram perturbados com a modificação na tarefa e mantiveram o mesmo desempenho na fase de adaptação.

\subsubsection{Erro de execução}

A FIGURA 9, associada às medidas da TABELA 2, permite observar que ambos os grupos diminuíram a quantidade de execuções erradas na fase de estabilização. No entanto, a ANOVA de Friedman apontou diferenças estatisticamente significantes apenas para o grupo CA6 $x^{2}(N=11, g l=4)=10,26$, $p<0,03$. Para o grupo CA3 foi encontrado $x^{2}(N=11, g l=4)=8,73, p>0,05$.

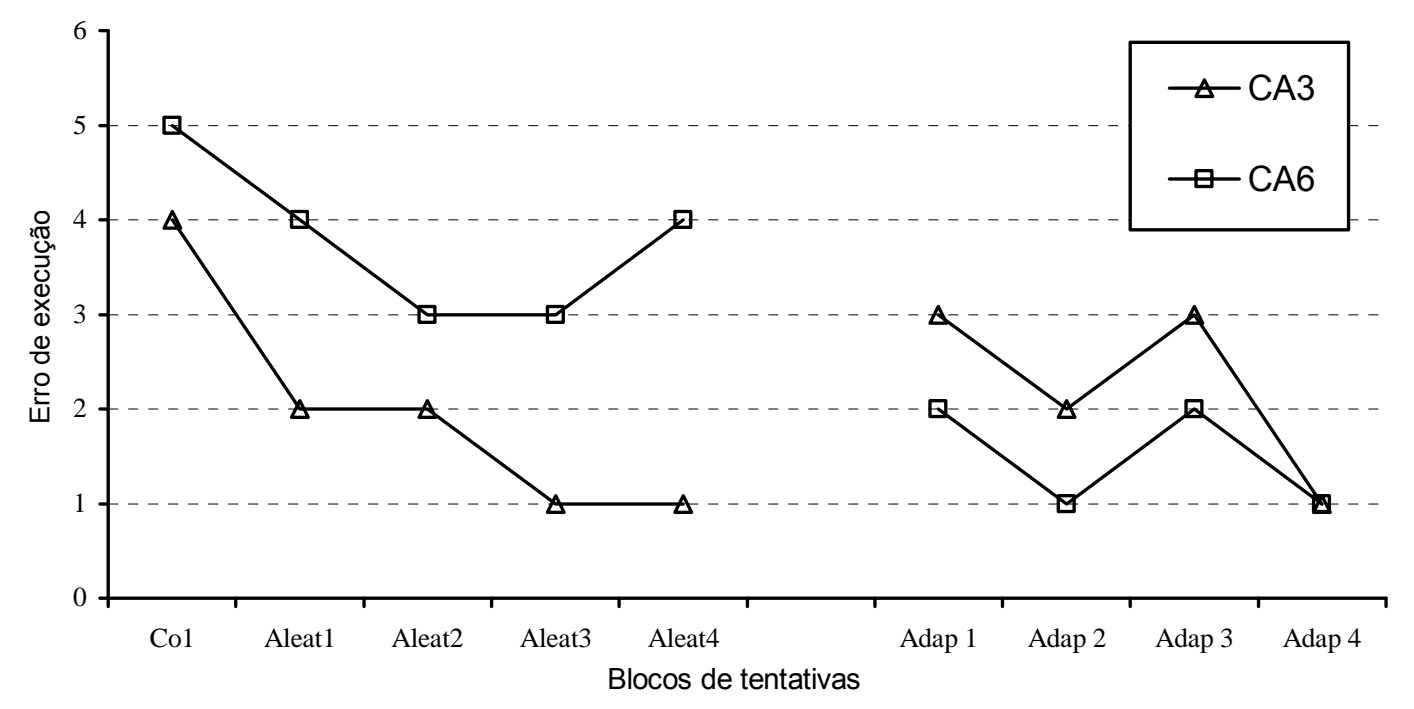

FIGURA 9 - Mediana do erro de execução, no primeiro bloco de tentativas de prática constante (Co1) e nos quatro blocos de tentativas de prática aleatória (Aleat) da fase de estabilização, e nos quatro blocos de tentativas da fase de adaptação (Adap), dos dois grupos experimentais (CA3 e CA6). 
Na fase de adaptação, concernente às comparações intragrupo, a ANOVA de Friedman apontou diferenças estatisticamente significantes para ambos os grupos, sendo que foi encontrado para o grupo $C A 3 x^{2}(N=11, g l=4)=12,90, p<0,01$ e para o grupo CA6 $x^{2}(N=11, g l=4)=10,07, p<0,04$.

$\mathrm{Na}$ comparação entre os grupos, o teste $U$ de Mann-Whitney encontrou diferenças estatisticamente significantes apenas no último bloco de tentativas da fase de estabilização ( $Z$ ajustado=-3,01, $p=0,00$ ). Para o primeiro bloco de tentativas da fase de adaptação foi encontrado $Z$ ajustado=0,84, $p=0,40$; para o segundo bloco foi encontrado $Z$ ajustado $=0,54, p=0,59$; para o terceiro bloco foi encontrado $Z$ ajustado=0,23, $p=0,82$; e para o quarto bloco foi encontrado $Z$ ajustado=0,35, $p=0,73$.

Em síntese, uma das inferências que se pode fazer relativa aos resultados da fase de estabilização é que houve diminuição da quantidade de execuções erradas em ambos os grupos. É possível sugerir, também, que os desempenhos de ambos os grupos flutuou com a introdução do novo padrão seqüencial de resposta (fase de adaptação), mas, também, que foram similares.

\subsection{Síntese dos resultados}

As análises dos resultados possibilitaram notar que, na fase de estabilização, o grupo com três elementos na prática variada aleatória melhorou a precisão e diminuiu o atraso do desempenho. Com relação às outras medidas, os grupos tiveram desempenho semelhante: o nível de consistência foi mantido, houve atraso da resposta e diminuição da quantidade de execuções erradas.

Com relação à fase de adaptação, pode-se concluir que os grupos desempenharam semelhantemente, uma vez que não houve diferenças entre eles no que diz respeito à precisão, à variabilidade e à direção do desempenho. Entretanto, ambos os grupos foram perturbados em termos de erro de execução.

Similarmente ao experimento anterior, esses resultados permitem entender que as práticas variadas aleatórias com variação de três e seis elementos, após a prática constante, possibilitaram similar processo adaptativo. Entretanto, diferentemente do experimento 1 , esses resultados não permitem sugerir que a 
perturbação não tenha sido robusta o suficiente para exigir adaptação da habilidade adquirida. Isso porque ambos os grupos foram perturbados com a modificação na tarefa (introdução de uma nova seqüência de toques). Na verdade, esse resultado era esperado uma vez que a literatura tem mostrado que a modificação em aspectos motores implica em maior perturbação do que aquela de aspectos perceptivos da tarefa (CORREAA, 2001; TANI, 1995; UGRINOWITSCH, 2003).

Por outro lado, da mesma forma que no experimento 1, pode-se sugerir que a diversificação resultante da variabilidade de três elementos e, consequentemente, o nível de redundância alcançado, tenham sido suficientes para dar conta da perturbação.

Em suma, o fato de não ter havido diferenças entre os grupos na fase de adaptação possibilita a conclusão de que a diversificação conseqüente do aumento na quantidade de elementos manipulados na prática aleatória (de três para seis elementos) não implicou em melhor adaptação.

\section{EXPERIMENTO 3 - VARIAÇÃO DOS ASPECTOS PERCEPTIVO E MOTOR}

No terceiro experimento, a prática foi variada em termos dos aspectos perceptivo e motor da tarefa de aquisição, respectivamente, diferentes velocidades do estímulo visual e diferentes padrões seqüenciais de resposta (toques).

\subsection{Método}

\subsubsection{Amostra}

Participaram desse experimento 22 crianças voluntárias de ambos os gêneros, com média de idade de 9,8 $( \pm 0,7)$ anos, sem experiência prévia na tarefa utilizada, distribuídas aleatoriamente em dois grupos experimentais $(n=11)$. A participação no experimento foi condicionada ao consentimento livre e esclarecido assinado pelo responsável pela criança (ANEXO I). 


\subsubsection{Instrumento e tarefa}

Foram semelhantes aos dos experimentos 1 e 2.

\subsubsection{Procedimentos e delineamento}

Na fase de estabilização desse experimento, como mostra o QUADRO 3, após a prática constante, a prática aleatória foi manipulada em relação aos componentes da tarefa variados nos experimentos 1 e 2, portanto, em relação à combinação de diferentes velocidades do estímulo visual e de diferentes padrões seqüenciais de reposta.

QUADRO 3 - Delineamento experimental contendo grupos (CA9 e CA36), fases (estabilização e adaptação), tipos e quantidades de prática (constante e aleatória) e velocidades do estímulo visual (V1 A V7) seqüências de toques manipuladas (SQ1 a SQ7).

\begin{tabular}{|c|c|c|c|}
\hline $\begin{array}{c}\text { FASES } \\
\rightarrow\end{array}$ & \multicolumn{2}{|c|}{ ESTABILIZAÇÃO } & ADAPTAÇÃO \\
\hline $\begin{array}{c}\text { GRUPOS } \\
\downarrow\end{array}$ & $\begin{array}{c}\text { Prática } \\
\text { Constante } \\
\text { (Até DC) }\end{array}$ & $\begin{array}{c}\text { Prática Aleatória } \\
\text { (36 tentativas) }\end{array}$ & (36 tentativas) \\
\hline \multirow{2}{*}{ CA9 } & V1/SQ1 & $\begin{array}{r}\text { V1/SQ1, V1/SQ2, V1/SQ3, } \\
\text { V2/SQ1, V2/SQ2, V2/SQ3, } \\
\text { V3/SQ1, V3/SQ2, V3/SQ3 }\end{array}$ & V7/SQ7 \\
& & V1/SQ1, V1/SQ2, V1/SQ3, V1/SQ4, V1/SQ5, V1/SQ6, & \\
& & V2/SQ1, V2/SQ2, V2/SQ3, V2/SQ4, V2/SQ5, V2/SQ6, & \\
CA36 & V3/SQ1, V3/SQ2, V3/SQ3, V3/SQ4, V3/SQ5, V3/SQ6, & V7/SQ7 \\
& & V4/SQ1, V4/SQ2, V4/SQ3, V4/SQ4, V4/SQ5, V4/SQ6, & \\
& & V5/SQ1, V5/SQ2, V5/SQ3, V5/SQ4, V5/SQ5, V5/SQ6, & \\
& V6/SQ1, V6/SQ2, V6/SQ3, V6/SQ4, V6/SQ5, V6/SQ6 & \\
\hline
\end{tabular}

$\mathrm{DC}=$ desempenho-critério $( \pm 50 \mathrm{~ms}$ de erro $)$

$\mathrm{Na}$ fase de estabilização a prática constante envolveu a execução de tentativas em uma única seqüência de toques (SQ1=1-2-4-3-5, FIGURA 1) e velocidade do estímulo visual (V1=144,3 cm/s), e a prática aleatória envolveu a execução de tentativas variando aleatoriamente a combinação de três diferentes velocidades do estímulo visual e três padrões seqüenciais de resposta para o grupo CA9 (V1=144,3 cm/s, V2=168,4 cm/s, e V3=126,3 cm/s - SQ1=1-2-4-3-5, SQ2=1-3-2- 
4-5 e SQ3=1-4-2-3-5, FIGURA 1), e de seis diferentes velocidades do estímulo visual e seis padrões seqüenciais de resposta para o grupo CA36 (V1=144,3 cm/s, $\mathrm{V} 2=168,4 \mathrm{~cm} / \mathrm{s}, \mathrm{V} 3=126,3 \mathrm{~cm} / \mathrm{s}, \mathrm{V} 4=155,4 \mathrm{~cm} / \mathrm{s}, \mathrm{V} 5=137,7 \mathrm{~cm} / \mathrm{s}$, e V6=118,9 cm/s SQ1=1-2-4-3-5, SQ2=1-3-2-4-5, SQ3=1-4-2-3-5, SQ4=1-4-2-4-5, SQ5=1-4-3-4-5 e SQ6=1-3-4-2-5, FIGURA 1).

A fase de adaptação envolveu a execução da tarefa em uma velocidade do estímulo visual e um padrão seqüencial de resposta diferentes daqueles da fase anterior (V7=106,4 cm/s - SQ7=1-4-3-2-5).

\subsubsection{Medidas e tratamento dos dados}

Também foram os mesmos utilizados nos experimentos 1 e 2 .

\subsection{Resultados}

Os resultados das medidas de desempenho relacionadas ao alcance da meta da tarefa (timing coincidente) - erros absoluto, variável e constante - e do erro de execução são apresentados na TABELA 3 e ilustrados, respectivamente, nas FIGURAS 10, 11, 12 e 13.

TABELA 3 - Médias dos erros absoluto (EA), variável (EV) e constante (EC) em milissegundos e mediana do erro de execução (EE) dos dois grupos experimentais (CA9 e CA36), no primeiro bloco de tentativas de prática constante (Co1) e nos quatro blocos de tentativas de prática aleatória (Aleat) da fase de estabilização, e nos quatro blocos de tentativas da fase de adaptação (Adap).

\begin{tabular}{ccccccccccc}
\hline Medida & Grupos & Co1 & Aleat1 & Aleat2 & Aleat3 & Aleat4 & Adap 1 & Adap 2 & Adap 3 & Adap 4 \\
\hline EA & CA9 & 496,05 & 488,49 & 466,41 & 349,25 & 400,96 & 582,46 & 572,03 & 322,26 & 300,71 \\
& CA36 & 356,97 & 884,65 & 619,67 & 622,13 & 546,87 & 558,80 & 313,05 & 660,40 & 366,74 \\
EV & CA9 & 436,20 & 586,77 & 608,96 & 485,65 & 578,38 & 691,72 & 705,44 & 530,02 & 433,05 \\
& CA36 & 249,70 & 850,86 & 772,35 & 797,03 & 644,90 & 657,07 & 387,07 & 649,71 & 444,72 \\
\hline
\end{tabular}


TABELA 3 - continuação.

\begin{tabular}{ccccccccccc}
\hline EC & CA9 & 451,49 & $-209,54$ & $-219,46$ & $-168,49$ & $-155,97$ & $-508,60$ & $-523,73$ & $-275,84$ & $-258,63$ \\
& CA36 & 327,55 & $-605,86$ & $-342,97$ & $-256,52$ & $-276,09$ & $-370,23$ & $-264,63$ & $-630,99$ & $-338,45$ \\
EE & CA9 & 4 & 2 & 1 & 1 & 2 & 2 & 1 & 0 & 0 \\
& CA36 & 3 & 4 & 1 & 2 & 1 & 1 & 0 & 2 & 0 \\
\hline
\end{tabular}

\subsubsection{Erro absoluto}

Conforme se pode notar na FIGURA 10, o grupo CA9 manteve o nível do erro absoluto durante a fase de estabilização, enquanto o grupo CA36 aumentou e depois diminuiu esse erro. Isso foi confirmado pelas ANOVAS one-way, visto que não foram encontradas diferenças significantes para o grupo CA9 $[F(4 ; 36)=0,58, p>0,05]$, mas, foram pra o grupo $\mathrm{CA} 36[\mathrm{~F}(4 ; 40)=7,91, p<0,01]$. Para esse grupo o teste de Tukey ${ }_{\text {HSD }}$ mostrou que o primeiro bloco de tentativas de prática aleatória foi diferente do primeiro bloco de prática constante e do último bloco de prática aleatória $(p<0,01)$.

Concernente à fase de adaptação, a ANOVA two-way encontrou diferenças significantes no fator blocos de tentativas $[F(4 ; 80)=2,89, p<0,03]$ e na interação entre grupos e blocos de tentativas $[F(4 ; 80)=4,72, p<0,01]$. No tocante às diferenças entre os blocos de tentativas, o teste de Tukey ${ }_{\text {HSD }}$ identificou diferenças entre o primeiro e o último blocos de tentativas da fase de adaptação $(p<0,02)$, mostrando superioridade do primeiro em relação ao segundo. $E$, em relação à interação entre grupos e blocos de tentativas, o teste de Tukey ${ }_{\text {HSD }}$ identificou diferenças entre os grupos no terceiro bloco de tentativas da fase de adaptação $(p<0,04)$. Para o fator grupos foi encontrado $F(1 ; 20)=0,26, p>0,05$.

Esses resultados indicam que o grupo com nove variações da prática aleatória (CA9) manteve o nível de desempenho em termos de precisão durante a fase de estabilização; enquanto o grupo com 36 variações da prática aleatória (CA36) piorou o seu desempenho, conseguindo recuperá-lo só no último bloco desta fase. Na fase seguinte (adaptação), também houve diferença no comportamento dos grupos. $O$ grupo CA9 foi mais preciso que o grupo CA36 no terceiro bloco de tentativas desta fase. 


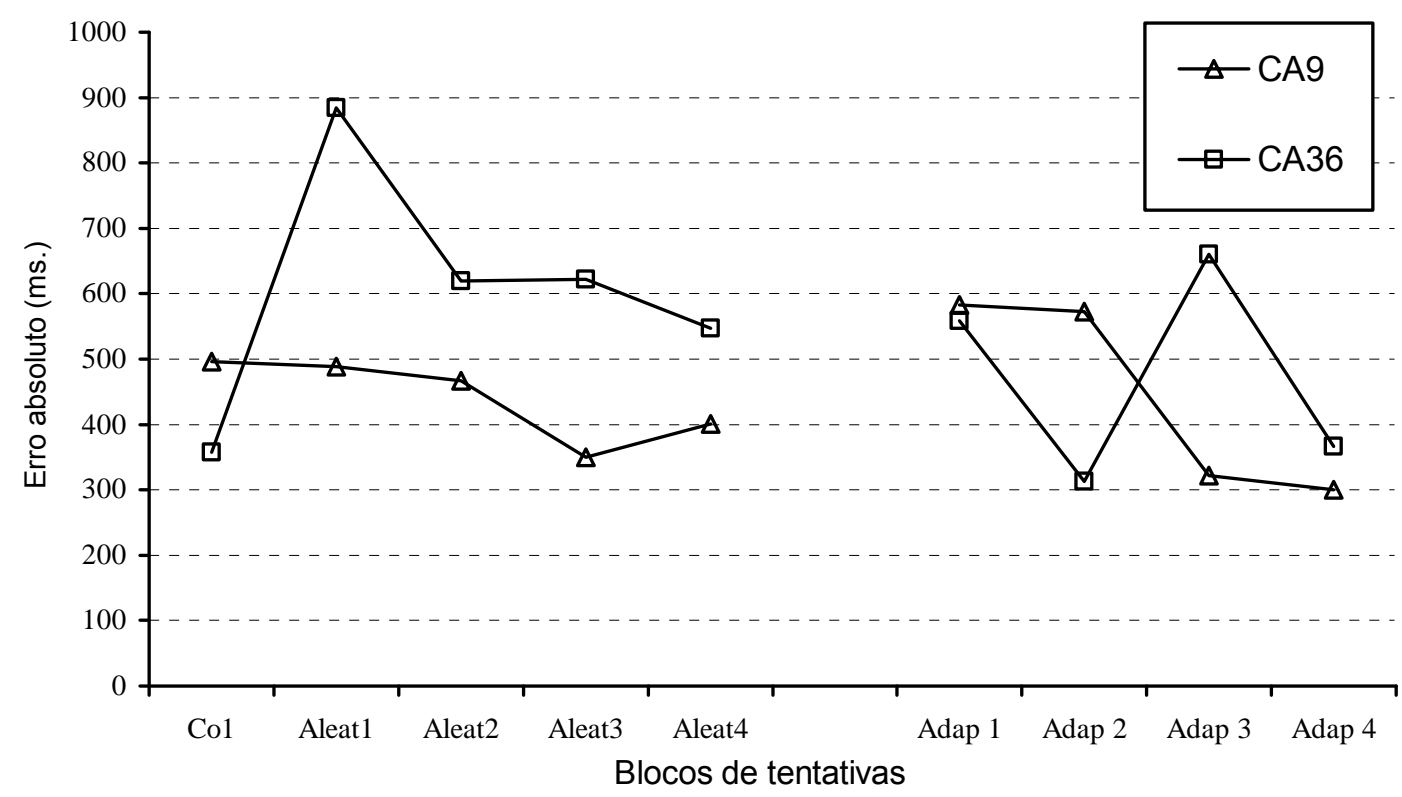

FIGURA 10 - Médias do erro absoluto em milissegundos, no primeiro bloco de tentativas de prática constante (Co1) e nos quatro blocos de tentativas de prática aleatória (Aleat) da fase de estabilização, e nos quatro blocos de tentativas da fase de adaptação (Adap), dos dois grupos experimentais (CA9 e CA36).

\subsubsection{Erro variável}

Similarmente ao erro absoluto, pode-se notar que na fase de estabilização o grupo CA9 apresentou um aumento com posterior manutenção do nível do erro variável, enquanto o grupo CA36 apresentou diminuição após o aumento inicial (FIGURA 11). Essas observações foram parcialmente confirmadas pelas análises estatísticas, pois a ANOVA one-way não encontrou diferenças significantes para o grupo CA9 $[F(4 ; 28)=1,13, p>0,05]$; enquanto que para o grupo CA36 foram encontradas diferenças $[F(4 ; 40)=17,29, p<0,05]$, sendo que o teste de Tukey ${ }_{H S D}$ mostrou que o primeiro bloco de tentativas de prática constante foi diferente (inferior) dos demais blocos $(p<0,01)$.

$\mathrm{Na}$ fase de adaptação, a ANOVA two-way não encontrou diferenças significantes em nenhum dos fatores analisados: grupos $[F(1 ; 20)=0,09 ; p>0,05]$; 
blocos de tentativas $[F(4 ; 80)=2,36, p>0,05]$ e interação entre grupos e blocos de tentativas $[F(4 ; 80)=2,24, p>0,05]$.

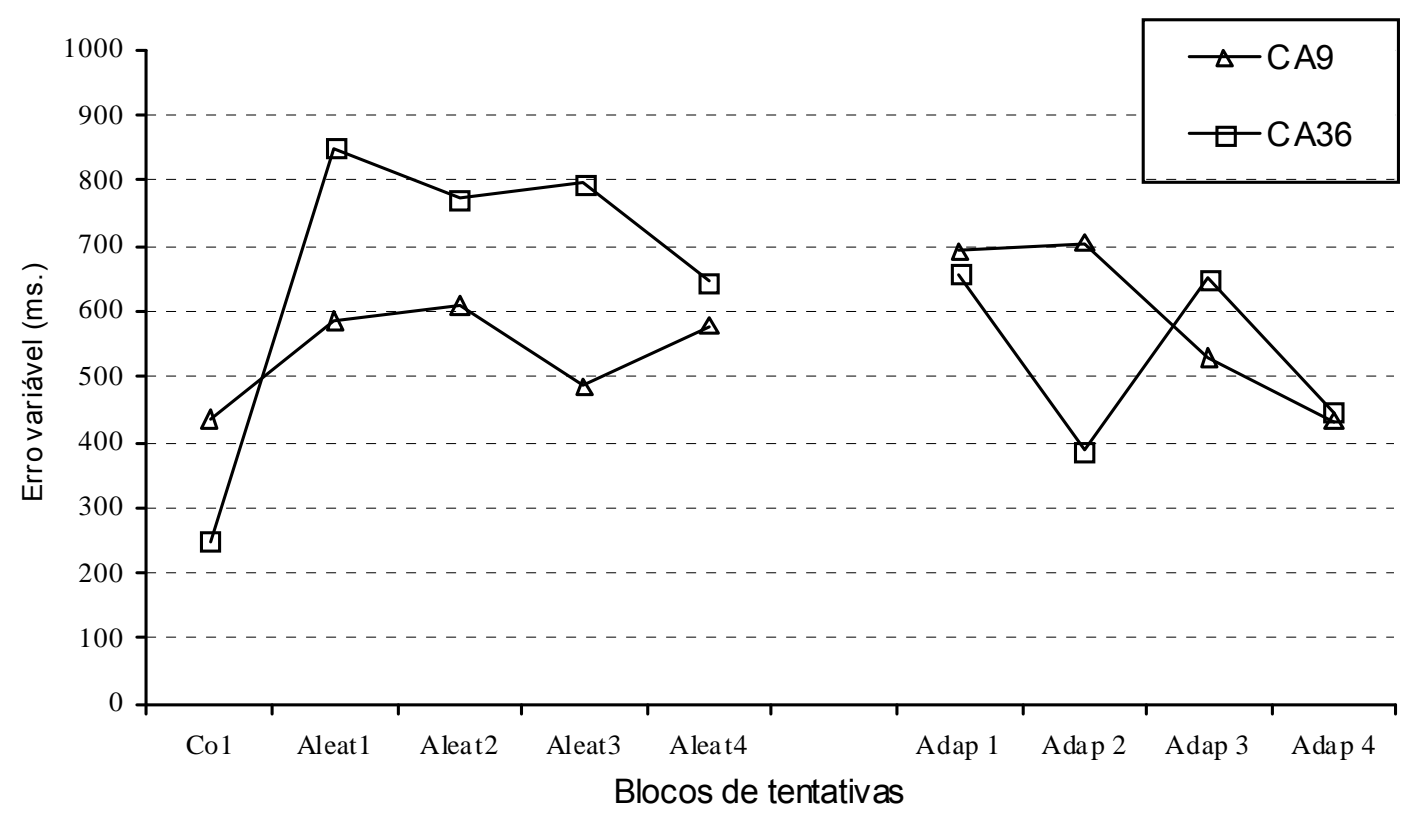

FIGURA 11 - Médias do erro variável em milissegundos, no primeiro bloco de tentativas de prática constante (Co1) e nos quatro blocos de tentativas de prática aleatória (Aleat) da fase de estabilização, e nos quatro blocos de tentativas da fase de adaptação (Adap), dos dois grupos experimentais (CA9 e CA36).

Dessa forma, pode-se inferir que no final da fase de estabilização os grupos estavam com o desempenho em um mesmo nível de consistência e assim se mantiveram após as modificações na tarefa (fase de adaptação).

\subsubsection{Erro constante}

Ao observar a FIGURA 12 nota-se que ambos os grupos tiveram uma tendência a atrasar a resposta durante a prática constante da fase de estabilização. Já durante a prática variada aleatória, os grupos passaram a adiantar a resposta. Isso foi confirmado pela ANOVA one-way que encontrou diferenças significantes para ambos os grupos. Para o grupo CA9 foi encontrado $F(4 ; 36)=6,23, p<0,01$ e para 0 grupo CA36, $F(4 ; 40)=14,80, p<0,01$, sendo que o teste de Tukey ${ }_{\text {HSD }}$ mostrou que, 
em ambos os grupos, o primeiro bloco de tentativas de prática constante foi diferente dos demais blocos $(p<0,01)$.

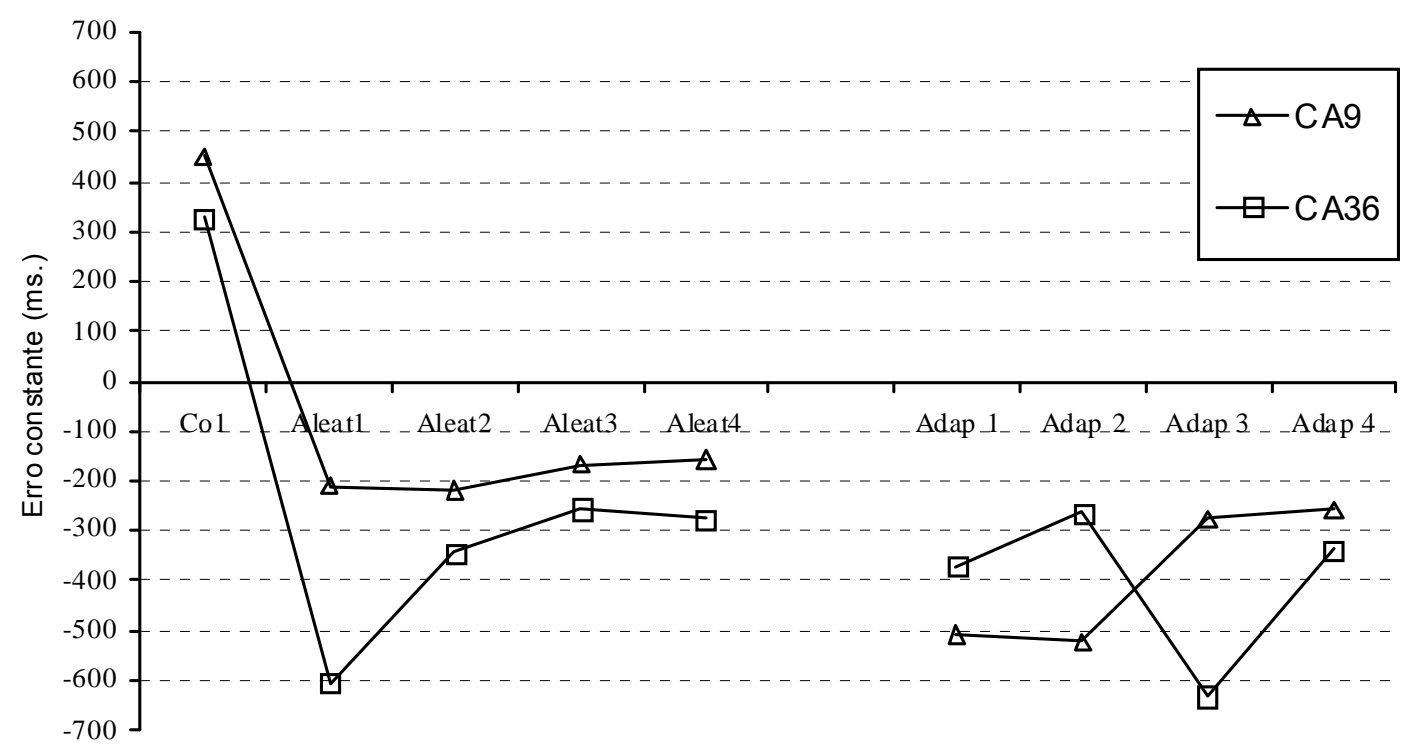

Blocos de tentativas

FIGURA 12 - Médias do erro constante em milissegundos, no primeiro bloco de tentativas de prática constante (Co1) e nos quatro blocos de tentativas de prática aleatória (Aleat) da fase de estabilização, e nos quatro blocos de tentativas da fase de adaptação (Adap), dos dois grupos experimentais (CA9 e CA36).

Na fase de adaptação a ANOVA two-way encontrou diferenças significantes no fator blocos de tentativas $[F(4 ; 80)=3,54, p<0,01]$ e na interação entre grupos e blocos de tentativas $[F(4 ; 80)=4,97, p<0,01]$. No tocante às diferenças no fator blocos de tentativas, o teste de Tukey ${ }_{\text {HSD }}$ identificou diferenças entre o último bloco da fase de estabilização e o primeiro e terceiro blocos da fase de adaptação $(p<0,04)$, indicando que os grupos aumentaram o erro constante a partir do último bloco da fase de estabilização. Em relação à interação entre grupos e blocos de tentativas, o teste de TukeyнSD identificou diferenças entre os grupos no terceiro bloco de tentativas da fase de adaptação $(p<0,05)$, indicando maior antecipação do grupo CA36. Para o fator quantidade de elementos manipulados na prática aleatória foi encontrado $[F(1 ; 20)=0,10, p>0,05]$. 
Sendo assim, pode-se inferir que ambos os grupos apresentaram desempenhos com sentido de atraso durante a prática constante e, durante a prática variada aleatória, os grupos passaram a adiantar a resposta. Com as modificações na tarefa, ambos os grupos continuaram a executar o último toque anteriormente ao acendimento do diodo-alvo, embora o CA36 o tenha feito mais acentuadamente.

\subsubsection{Erro de execução}

A FIGURA 13, associada à TABELA 3, permite observar que ambos os grupos diminuíram a quantidade de execuções erradas na fase de estabilização. Essa observação foi confirmada pela ANOVA de Friedman, a qual apontou diferenças estatisticamente significantes para ambos os grupos: CA9 $x^{2}(N=11, g l=4)=12,91$, $p<0,02$ e CA36 $x^{2}(N=11, g l=4)=11,42, p<0,03$.

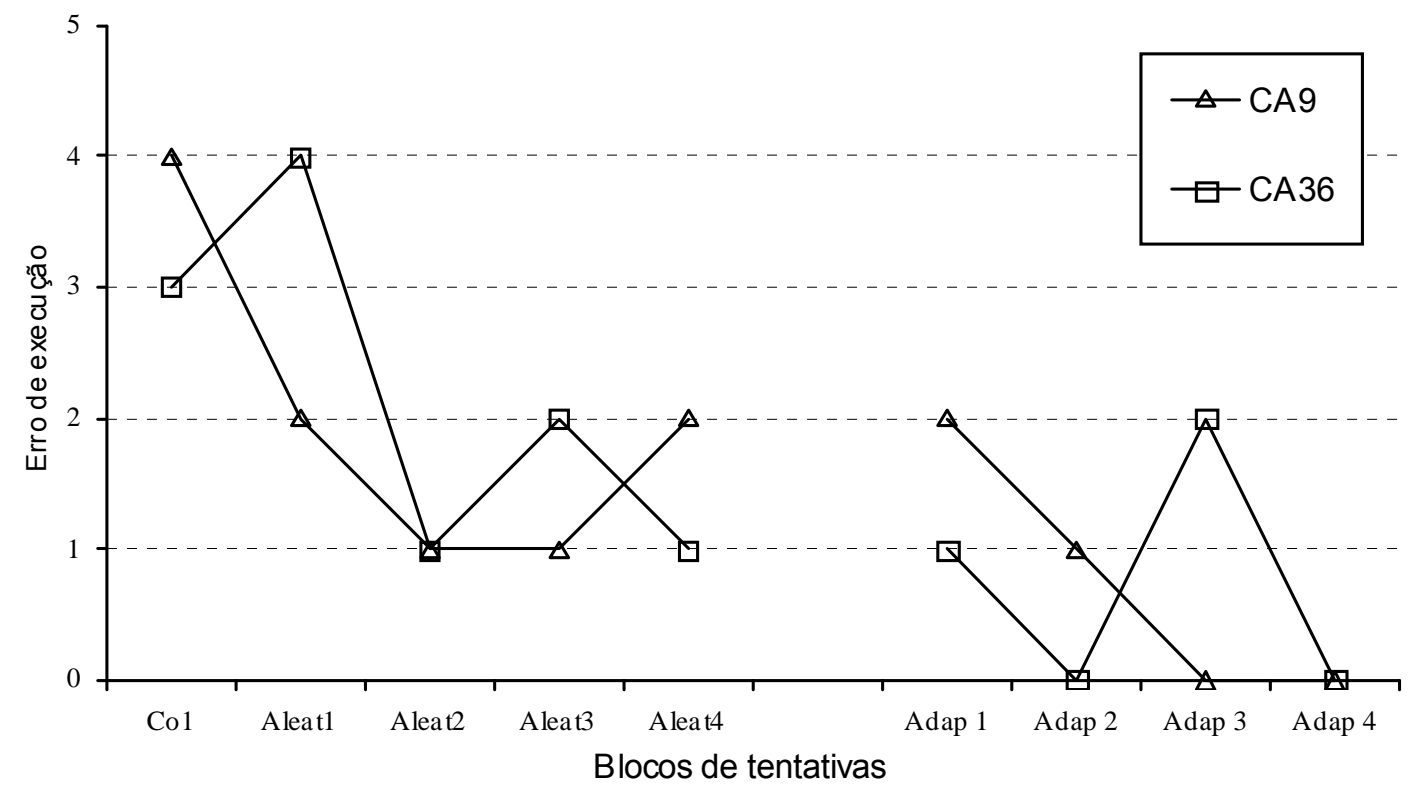

FIGURA 13 - Mediana do erro de execução, no primeiro bloco de tentativas de prática constante (Co1) e nos quatro blocos de tentativas de prática aleatória (Aleat) da fase de estabilizacão, e nos quatro blocos de tentativas da fase de adaptação (Adap), dos dois grupos experimentais (CA9 e CA36). 
$\mathrm{Na}$ fase de adaptação, concernente às comparações em cada grupo, a ANOVA de Friedman apontou diferenças estatisticamente significantes para ambos os grupos, sendo que foi encontrado para o grupo CA9 $x^{2}(N=11, g l=4)=10,05$, $p<0,04$ e $x^{2}(N=11, g l=4)=18,11, p<0,01$ para o grupo CA36. Com isso sugere-se que - CA9 tenha diminuído a quantidade de erro e que isso pode ter ocorrido com o CA36, mas com um aumento no decorrer da última fase.

Nas comparações entre os grupos, o teste $U$ de Mann-Whitney encontrou diferenças estatisticamente significantes no primeiro ( $Z$ ajustado $=2,18, p=0,03$ ) e no segundo ( $Z$ ajustado=-1,97, $p=0,05$ ) blocos de tentativas da fase de adaptação, indicando menor erro para o CA36. Para o último bloco de tentativas da fase de estabilização foi encontrado $Z$ ajustado $=0,55, p=0,58$; para o terceiro bloco da fase de adaptação foi encontrado $Z$ ajustado=0,04, $p=0,97$; e para o quarto bloco da fase de adaptação foi encontrado $Z$ ajustado=0,00, $p=1,00$.

Em síntese, os resultados do erro de execução mostram que houve uma diminuição da quantidade de execuções erradas na fase de estabilização em todos os grupos. E, com as modificações na tarefa (fase de adaptação), os grupos diminuíram a quantidade de execuções erradas, mas o CA36 apresentou menor quantidade de erros.

\subsection{Síntese dos resultados}

Como se pôde observar na análise dos resultados, o grupo que teve variabilidade de nove elementos manteve a precisão e a consistência do desempenho durante a fase de estabilização; enquanto o grupo com trinta e seis variações piorou o seu desempenho nessas medidas. Quanto à direção do desempenho, pode-se inferir que ambos os grupos tiveram a tendência a atrasar a resposta durante a prática constante e durante a prática variada aleatória eles passaram a adiantar a resposta. Ambos os grupos diminuíram quantidade de execuções erradas na fase de estabilização.

Na fase de adaptação, o grupo com nove variações foi mais preciso do que o grupo trinta e seis, no terceiro bloco de tentativas. Contudo, o grupo cuja prática envolveu trinta e seis variações cometeu menos erros de execução do que o grupo 
com nove variações, nos dois primeiros blocos de tentativas dessa fase. Os grupos apresentaram o mesmo nível de variabilidade e continuaram a adiantar a resposta.

O fato de cada grupo ter apresentado melhor desempenho em uma medida não permite conclusões a favor de o processo adaptativo ter sido melhor para um ou para o outro grupo. Dessa forma, mais uma vez poderia ser sugerido que a diversificação conseguida com a variação que envolveu a combinação de três velocidades do estímulo visual e três seqüências de toques teria sido suficiente para dar conta da perturbação.

De igual surpresa, já que esses resultados contrariam as expectativas construídas com a revisão de literatura, foi o fato de os grupos não terem sido perturbados com a modificação na tarefa. De acordo com a literatura (CORRÊA, 2001; TANI, 1995; UGRINOWITSCH, 2003) e com as explicações adotadas nos experimentos anteriores, esperava-se que os grupos não somente fossem perturbados, como apresentassem diferenças entre eles. Isso porque os autores acima descritos mostraram a existência de uma hierarquia relacionada à modificação de diferentes aspectos da tarefa, como segue: a modificação na velocidade do estímulo visual e na seqüência de toques em conjunto envolve um nível superior de perturbação comparado com aquele gerado pela modificação apenas na seqüência de toques, por sua vez, implica em superior perturbação em comparação com a modificação na velocidade do estímulo visual.

Em conclusão, os resultados do presente experimento mostraram similares efeitos da prática aleatória com nove e com trinta e seis variações, após a prática constante. Da mesma forma que nos experimentos 1 e 2, pode-se concluir que, nesse experimento, o aumento na quantidade de elementos manipulados na prática aleatória (de nove para trinta e seis elementos) não implicou em aumento significativo da diversificação ao ponto de causar melhor adaptação.

\section{DISCUSSÃO GERAL E CONCLUSÃO}

O objetivo dessa dissertação foi investigar os efeitos da quantidade de elementos manipulados na prática variada aleatória, após a prática constante, no processo adaptativo de aprendizagem motora. Foi questionado se a diversificação de 
habilidades motoras adquirida via diferentes quantidades de variações na prática aleatória, após a prática constante, afetaria o processo adaptativo, sendo que se esperava que a resposta fosse "sim". Ou seja, a hipótese foi de melhor adaptação dos grupos cuja prática variada que envolvesse maior variabilidade em termos da quantidade.

Essa hipótese baseou-se na proposição de que a prática variada após a formação da estrutura da habilidade com a prática constante promoveria a diversificação da mesma (BARROS, 2006; CORRÊA, 2001; 2007; CORRÊA et al. 2006; 2007; FIALHO, 2007; MASSIGLI et al., 2004; PAROLI, 2004; WALTER et al., 2008). Segundo CORREAA (2001), a introdução de variação nos componentes da habilidade faz com que aumente o leque de interações na habilidade sem que a mesma perca a identidade. Assim, pensou-se que a maior quantidade de variabilidade implicaria em uma habilidade mais diversificada e, como conseqüência, com maior capacidade de adaptação.

Era esperada melhor adaptação da habilidade mais diversificada em virtude do entendimento de que a maior diversificação implicava em maior redundância. Ou seja, maior disponibilidade de recursos para a adaptação (CORRÊA et al., 2003; TANI, 1995).

O fato é que os resultados dos três experimentos mostraram que as crianças que aprenderam com menor quantidade de variabilidade se adaptaram igualmente àquelas que tiveram maior quantidade de variabilidade. Dessa forma, com relação ao objetivo do presente estudo, esses resultados permitem concluir que os efeitos das diferentes quantidades de variabilidade na prática aleatória, após a prática constante, no processo adaptativo de aprendizagem motora foram semelhantes.

Essa conclusão possibilita o pensamento da existência de uma quantidade "ótima" de elementos variados na prática aleatória, ou seja, de diversificação. Conclusões nessa direção foram feitas por CORRÊA (2007), CORRÊA et al. (2006; 2007) e MASSIGLI et al. (2004). No caso de CORRÊA (2007), a conclusão foi feita no sentido de existir uma quantidade ótima de prática aleatória após a prática constante. $\mathrm{E}$, os demais autores concluíram em relação à existência de uma quantidade ótima de prática constante anteriormente à prática aleatória. 
No presente trabalho, a quantidade ótima seria de três velocidades do estímulo visual, três padrões seqüenciais de resposta e, quando da combinação desses aspectos, a quantidade ótima seria de nove. Entende-se a quantidade mínima como "ótima" porque ela foi suficiente para promover a adaptação sem a necessidade de mais prática. Em outras palavras, é ótima porque envolveu menor gasto de tempo, energia e informação. De uma forma simples, a quantidade mínima variada pode ser entendida como ótima por que não faz sentido variar muitos elementos se, ao variar poucos, o mesmo estado é alcançado.

A consideração dessas conclusões induzem a perguntas de crucial importância para o entendimento da aprendizagem de habilidades motoras e, por conseguinte, dos seres humanos: por que o ser humano lidaria com níveis ou quantidades ótimas? Como ele faria isso? Logicamente, repostas a essas perguntas necessitam de, no mínimo, reflexões e especulações mais aprofundadas. Contudo, alguns insights poderiam ser construídos a partir de lógicas de raciocínio clássicas na área de Comportamento Motor como, por exemplo, aquela relativa a, a partir de certa fase de desenvolvimento não se aprender nada absolutamente novo ou, ainda, àquela de o ser humano ter capacidade limitada de armazenamento (SCHMIDT, 1975).

Nesse último caso e restrito ao presente trabalho, poderia ser dito que se a quantidade de variabilidade ótima fosse infinita, a pergunta surgiria: qual sistema comportaria tudo isso? Na verdade, as explicações para as perguntas feitas acima podem se remeter ao próprio referencial teórico no qual essa dissertação se fundamenta: o de processo adaptativo de aprendizagem motora. Conforme colocado anteriormente, esse processo permite entender que a aprendizagem envolve contínua reorganização de habilidades já adquiridas.

Com base nesse pensamento, poderia ser sugerido que as quantidades mínimas são ótimas por que o ser humano reorganiza a redundância adquirida em sucessivas adaptações.

A partir dos resultados do presente estudo sugere-se, também, certa cautela em relação em relação à assunção de hierarquia na adaptação em função dos aspectos manipulados (velocidade do estímulo visual, seqüência de toques e ambos os aspectos em conjunto). Isso porque em conformidade com a literatura (CORREA, 
2001, TANI, 1995; UGRINOWITSCH, 2003) foi verificada hierarquia apenas entre os dois primeiros aspectos.

Uma limitação da presente pesquisa foi não ter utilizado medidas relativas ao padrão de movimento. Essas medidas poderiam dar informações sobre como ocorreu a adaptação. De acordo com o modelo teórico do processo adaptativo em aprendizagem motora a adaptação pode ocorrer via modificação de parâmetros, via alteração de alguns componentes da habilidade, ou ainda, formando-se uma nova estrutura (TANI, 1995). Em estudos anteriores, apesar de não terem sido encontradas diferenças quanto ao desempenho, foram encontradas diferenças relativas ao padrão de movimento (CORRÊA, 2001; 2007; FIALHO, 2007). Essa limitação poderia ser colocada em termos de perspectiva de investigação.

Finalizando, os resultados do presente estudo permitem concluir que os efeitos das diferentes quantidades de variabilidade na prática aleatória, após a prática constante, no processo adaptativo de aprendizagem motora foram semelhantes.

\section{REFERÊNCIAS BIBLIOGRÁFICAS}

ADAMS, J.A. A closed-loop theory of motor learning. Journal of Motor Behavior, v.3, n.2, p. 111-149, 1971.

BARROS, J.A.C. Estrutura de prática e processo adaptativo em aprendizagem motora: efeitos da especificidade da tarefa. 2006. Dissertação (Mestrado) - Escola de Educação Física e Esporte, Universidade de São Paulo, São Paulo, 2006.

BENDA, R.N. Variabilidade e processo adaptativo na aquisição de habilidades motoras. 2001. Tese (Doutorado) - Escola de Educação Física e Esporte, Universidade de São Paulo, São Paulo, 2001.

CATTUZZO, M.T. O ciclo instabilidade-estabilidade-instabilidade no processo adaptativo em aprendizagem motora. 2007. Tese (Doutorado) - Escola de Educação Física e Esporte, Universidade de São Paulo, São Paulo, 2007. 
CHOSHI, K. Aprendizagem motora como um problema mal-definido. Revista Paulista de Educação Física, São Paulo, supl.3, p. 17-23, 2000.

CORREA, U.C. Estrutura de prática e processo adaptativo na aquisição de habilidades motoras. 2001. Tese (Doutorado) - Escola de Educação Física e Esporte, Universidade de São Paulo, São Paulo, 2001.

CORREAA, U.C. A prática constante-variada e a aquisição de habilidades motoras: efeitos da quantidade e do tipo de prática variada. 2007. Tese (LivreDocência) - Escola de Educação Física e Esporte, Universidade de São Paulo, São Paulo, 2007.

CORREAA, U.C.; BARROS, J.A.C.; MASSIGLI, M.; GONÇALVES, L.A.; TANI, G. A prática constante-aleatória e o processo adaptativo de aprendizagem motora: efeitos da quantidade de prática constante. Revista Brasileira de Educação Física e Esporte, São Paulo, v.21, n.4, p.301-14, 2007.

CORRÊA, U.C.; BENDA, R.N.; MEIRA JÚNIOR, C.M.; TANI, G. Practice schedule and adaptive process in the acquisition of a manual force control task. Journal of Human Movement Studies, v.44, p.121-138, 2003.

CORREAA, U.C.; BENDA, R.N.; TANI, G. Estrutura de prática e processo adaptativo na aprendizagem do arremesso de dardo de salão. Revista Brasileira de Ciências do Esporte, v.22, n.2, p.69-84, 2001.

CORRÊA, U.C.; GONÇALVES, L.A.; BARROS, J.A.C.; MASSIGLI, M. Prática constante-aleatória e aprendizagem motora: efeitos da quantidade de prática constante e da manipulação de exigências motoras da tarefa. Brazilian Journal of Motor Behavior, v.1, n.1, p. 41-52, 2006. 
CORREAA, U.C.; TANI, G. Aparelho de timing coincidente em tarefas complexas. P.I. $\mathrm{n}^{\circ}$ 0.403.433-4 de 03/08/2004. Revista da Propriedade Industrial, São Paulo, RPI n. 1763, p. $178,2004$.

CORREAA, U.C.; TANI, G. Estrutura de prática e processo adaptativo em aprendizagem motora: por uma nova abordagem da prática. In: G. TANI (Ed.) Comportamento Motor: Aprendizagem e Desenvolvimento. Rio de Janeiro: Guanabara Koogan, p.141-161, 2005.

DORON, R.; PAROT, F. Dicionário de psicologia. São Paulo: Ática, 1998.

FIALHO, J.V.A.P. A prática constante-aleatória: efeitos da manipulação do aspecto da habilidade e o tipo de perturbação no processo adaptativo em aprendizagem motora. 2007. Dissertação (Mestrado) - Escola de Educação Física, Fisioterapia e Terapia Ocupacional, Universidade Federal de Minas Gerais, Belo Horizonte, 2007.

GENTILE. A.M. A working model of skill acquisition with application to teaching. Quest, v.17, p.3-23, 1972.

MANOEL, E.J. Adaptação e desenvolvimento motor. In: G. TANI (Ed.), Comportamento Motor: Aprendizagem e Desenvolvimento. Rio de Janeiro: Guanabara Koogan, p.71-81, 2005.

MASSIGLI, M.; GONÇALVES, L.A.; BARROS, J.A.C.; SOUZA JR.; CORRÊA, U.C. O efeito de diferentes quantidades de prática constante-aleatória no processo adaptativo na aquisição de habilidades motoras: manipulação de exigências perceptivas da tarefa. In: CONGRESSO INTERNACIONAL DE EDUCAÇÃO FÍSICA, 19.; CIBGRESSO DE FISIOTERAPIA DO MERCOSUL; CONGRESSO CINETÍFICO DA FIEP, Foz do Iguaçu. Anais. 2004. p.131. 
MEIRA JÚNIOR., C.M. Conhecimento de resultados no processo adaptativo em aprendizagem motora. 2005. Tese (Doutorado) - Escola de Educação Física e Esporte, Universidade de São Paulo, São Paulo, 2005.

NEWELL, K.M.; SLFIKIN, A.B. The nature of movement variability. In: J.P. PIEK (Ed.), Motor behavior and human skill: a multidisciplinary approach. Champaign, Illinois: Human Kinetics, 1998.

NICOLIS, G.; PRIGOGINE, I. Exploring complexity. New York: Freeman, 1989.

PAROLI, R. Efeito da estrutura de prática na aquisição de uma habilidade motora. 2004. Dissertação (Mestrado) - Escola de Educação Física e Esporte, Universidade de São Paulo, São Paulo, 2004.

PINHEIRO, J.P.; CORRÊA, U. C. Estrutura de prática na aquisição de uma tarefa de timing coincidente com desaceleração do estímulo visual. Revista Portuguesa de Ciências do Desporto, v.7, n.3, 2007.

SCHMIDT, R.A. A schema theory of discrete motor skill learning. Psychological Review, v.82, n.4, p.225-60, 1975.

TANI, G. Educação física na pré-escola e nas quatro primeiras séries do ensino de $1^{\circ}$ grau: uma abordagem de desenvolvimento I. Kinesis. V.3, n.1, p. 19-41, 1987.

TANI, G. Variabilidade de resposta e processo adaptativo em aprendizagem motora. 1989. Tese (Livre Docência) - Escola de Educação Física, Universidade de São Paulo, São Paulo, 1989.

TANI, G. Hierarchical organization of human motor behavior. Sheffield, University of Sheffield, 1995. (Relatório final de atividades de Pós-doutorado). 
TANI, G. Variabilidade e programação motora. In: A.C. AMADIO \& V.J. BARBANTI (Orgs.), A biodinâmica do movimento humano e suas relações interdisciplinares. São Paulo: Estação Liberdade, 2000a.

TANI, G. Processo adaptativo em aprendizagem motora: o papel da variabilidade. Revista Paulista de Educação Física. Suplemento 3, p. 55-61, 2000b.

TANI, G. Comportamento motor: aprendizagem e desenvolvimento. Rio de Janeiro: Guanabara-Koogan, 2005.

TANI, G. Comportamento motor e sua relação com a Educação Física. Brazilian Journal of Motor Behavior, v. 1, n. 1, p. 20-31, 2006.

TANI, G.; MANOEL, E.J.; KOKUBUN, E.; PROENÇA, J.E. Educação física escolar: Fundamentos de uma abordagem desenvolvimentista. São Paulo: EPU/EDUSP, 1988.

TANI, G.; MEIRA JÚNIOR., C.M.; GOMES, F.R.F. Freqüência, precisão e localização temporal de conhecimento de resultados e o processo adaptativo na aquisição de uma habilidade motora de controle da força manual. Revista Portuguesa de Ciências do Desporto, v. 5, n.1, p. 59-68, 2005.

TERTULIANO, I.W.; SOUZA JÚNIOR, O.P.; SILVA FILHO, A.S.; CORREAA, U.C. Estrutura de prática e freqüência de feedback extrínseco na aprendizagem de habilidades motoras. Revista Brasileira de Educação Física e Esporte, São Paulo, v.22, n.2, p.103-118, 2008.

UGRINOWITSCH, H. Efeito do nível de estabilização e do tipo de perturbação no processo adaptativo em aprendizagem motora. 2003. Tese (Doutorado) - Escola de Educação Física e Esporte, Universidade de São Paulo, São Paulo, 2003. 
UGRINOWITSCH, H.; CORREAA, U.C.; TANI, G. Perturbação perceptiva e processo adaptativo na aprendizagem de uma tarefa de timing coincidente. Revista Brasileira de Educação Física e Esporte, São Paulo, v. 19, n. 4, p. 277-284, 2005.

UGRINOWITSCH, H.; TANI, G. Efeitos do tipo de perturbação e do nível de estabilização no processo adaptativo em aprendizagem motora. In: G. TANI (Ed.) Comportamento Motor: Aprendizagem e Desenvolvimento. Rio de Janeiro: Guanabara Koogan, p.162-172, 2005.

UGRINOWIITSCH, H.; TERTULIANO, I.W.; COCA, A.A.; PEREIRA, F.A.S.; GIMENEZ, R. Freqüência de feedback como um fator de incerteza na aprendizagem de uma tarefa de preensão. Revista Brasileira de Ciência e Movimento, v.11. n.2, p. 41-7, 2003.

WALTER, C.; BASTOS, F.H.; ARAUJO, U.O.; SILVA, J.A.O.; CORRÊA, U.C. Estrutura de prática e liberdade de escolha na aprendizagem de habilidades motoras. Revista Portuguesa de Ciências do Desporto, Porto, v.8, n.3, 2008. 


\begin{abstract}
ANEXOS
ANEXO I - Termo de consentimento livre e esclarecido.
ESCOLA DE EDUCAÇÃO FÍSICA E ESPORTE DA UNIVERSIDADE DE SÃO PAULO Comitê de Ética em Pesquisa

TERMO DE CONSENTIMENTO LIVRE E ESCLARECIDO
\end{abstract}

\title{
I - DADOS DE IDENTIFICAÇÃO DO SUJEITO DA PESQUISA OU RESPONSÁVEL LEGAL
}

1. NOME DO INDIVÍDUO:

Documento de identidade $\mathrm{N}^{\mathrm{o}}$ :

Data de nascimento:

Endereço:

Bairro:

Cidade:

Sexo: $\square \mathrm{M} \quad \square \mathrm{F}$

Telefone:

CEP:

APTO

2. RESPONSÁVEL LEGAL:

Natureza (grau de parentesco, tutor, curador, etc.)

Documento de identidade $\mathrm{N}^{\circ}$ :

Sexo: $\square \mathrm{M} \quad \square \mathrm{F}$

Data de nascimento:

Endereço:

Bairro:

Cidade:

$\mathrm{N}^{\circ}$

APTO

Telefone:

\section{II - DADOS SOBRE A PESQUISA CIENTÍFICA}

1. Título do Projeto de Pesquisa

A prática constante-aleatória e a diversificação de habilidades motoras

2. Pesquisador Responsável

Prof. Dr. Umberto Cesar Corrêa

3. Cargo/Função

Professor Associado

4. Avaliação do risco da pesquisa:

RISCO MÍNIMO $\bigotimes \quad$ RISCO BAIXO $\square \quad$ RISCO MÉDIO $\square \quad$ RISCO MAIOR (probabilidade de que o indivíduo sofra algum dano como conseqüência imediata ou tardia do estudo)

5. Duração da Pesquisa

30 minutos 
ANEXO I - Termo de consentimento livre e esclarecido (cont.).

\section{III - EXPLICAÇÕES DO PESQUISADOR AO INDIVÍDUO OU SEU REPRESENTANTE LEGAL SOBRE A PESQUISA, DE FORMA CLARA E SIMPLES, CONSIGNANDO:}

A diversificação de habilidade motoras refere-se ao aumento no número de elementos do comportamento motor. Ela pode facilitar a adaptação a novas situações e também o desenvolvimento de novas habilidades motoras. Assim, o objetivo do presente trabalho é investigar os efeitos da quantidade de elementos na prática variada, após a prática constante, na aprendizagem de uma habilidade motora. Será solicitada a realização de uma tarefa motora que consiste em executar cinco toques com os dedos da mão em uma seqüência pré-determinada de modo que o último toque coincida com o acendimento de uma luz. Serão realizadas tentativas de prática constante até o alcance de um critério. Depois, será solicitada a realização de tentativas de forma variada, com mudança da velocidade do estímulo, da seqüência de toques ou de ambas. Não são esperados desconfortos ou riscos. A coleta de dados será feita no Laboratório de Comportamento Motor da Escola de Educação Física e Esporte da USP. O indivíduo que participar da pesquisa terá como benefício principal o desenvolvimento de sua habilidade de timing, requisito necessário em uma série de habilidades motoras que envolvem "tempo de bola" como, por exemplo: chute no futebol, rebatida no tênis, cortada do voleibol, entre outras. A procedência dos participantes será de cursos para comunidade oferecidos pela Escola de Educação Física e Esporte de USP.

\section{IV - ESCLARECIMENTOS DADOS PELO PESQUISADOR SOBRE GARANTIAS DO SUJEITO DA PESQUISA:}

- A criança e seu responsável podem, em qualquer momento, ter a informação que desejarem a respeito de procedimentos, eventuais riscos e benefícios relacionados à pesquisa;

- A criança e seu responsável têm a liberdade de retirar seu consentimento e de deixar de participar do estudo, sem nenhum prejuízo;

- Nenhuma informação a respeito da identidade da criança ou do responsável serão tornadas públicas;

- Será providenciada assistência por eventuais danos à saúde decorrentes da pesquisa.

$V$ - INFORMAÇÕES DE NOMES, ENDEREÇOS E TELEFONES DOS RESPONSÁVEIS PELO ACOMPANHAMENTO DA PESQUISA, PARA CONTATO EM CASO DE INTERCORRÊNCIAS CLÍNICAS E REAÇÕES ADVERSAS.

Pesquisador responsável: Umberto Cesar Corrêa; Av. Prof. Mello Moraes, 65; (11) 30913135.

Pesquisador gerente: João de Paula Pinheiro; Av. Prof. Mello Moraes, 65; (11) 30913135.

\section{VI. - OBSERVAÇÕES COMPLEMENTARES}

\section{VII - CONSENTIMENTO PÓS-ESCLARECIDO}

Declaro que, após convenientemente esclarecido pelo pesquisador e ter entendido o que me foi explicado, consinto em participar do presente Projeto de Pesquisa.

São Paulo, de de 20 
ANEXO I - Termo de consentimento livre e esclarecido (cont.).

\section{INSTRUÇÕES PARA PREENCHIMENTO \\ (Resolução Conselho Nacional de Saúde 196, de 10 outubro 1996)}

1. Este termo conterá o registro das informações que o pesquisador fornecerá ao sujeito da pesquisa, em linguagem clara e acessível, evitando-se vocábulos técnicos não compatíveis com o grau de conhecimento do interlocutor.

2. A avaliação do grau de risco deve ser minuciosa, levando em conta qualquer possibilidade de intervenção e de dano à integridade física do sujeito da pesquisa.

3. O formulário poderá ser preenchido em letra de forma legível, datilografia ou meios eletrônicos.

4. Este termo deverá ser elaborado em duas vias, ficando uma via em poder do paciente ou seu representante legal e outra deverá ser juntada ao prontuário do paciente.

5. A via do Termo de Consentimento Livre e Esclarecido submetida à análise do Comitê de Ética em Pesquisa - CEP deverá ser idêntica àquela que será fornecida ao sujeito da pesquisa. 
ANEXO II - Média do erro absoluto (EA) em milissegundos, dos participantes dos dois grupos do experimento 1 [CA3 (1) e CA6 (2)], no primeiro bloco de tentativas de prática constante (Co1) e nos quatro blocos de tentativas de prática aleatória (Aleat) da fase de estabilização, e nos quatro blocos de tentativas da fase de adaptação (Adap).

\begin{tabular}{ccccccccccc}
\hline & & \multicolumn{10}{c}{ Erro Absoluto } \\
\cline { 2 - 11 } Sujeito & Grupo & Co1 & Aleat1 & Aleat2 & Aleat3 & Aleat4 & Adap1 & Adap2 & Adap3 & Adap4 \\
\hline 1 & 1 & 126,5 & 148,3 & 147,3 & 219,3 & 180,5 & 99,9 & 63,8 & 36,1 & 74,0 \\
2 & 1 & 1266,0 & 85,3 & 138,7 & 190,3 & 107,8 & 396,6 & 266,0 & 183,1 & 210,3 \\
3 & 1 & 259,1 & 106,7 & 108,2 & 112,9 & 75,9 & 54,0 & 69,4 & 66,7 & 58,0 \\
4 & 1 & 130,3 & 117,1 & 123,3 & 178,7 & 86,8 & 155,8 & 166,5 & 154,3 & 123,3 \\
5 & 1 & 288,5 & 190,2 & 105,0 & 360,1 & 189,5 & 161,0 & 167,7 & 91,8 & 79,8 \\
6 & 1 & 274,0 & 118,0 & 434,2 & 133,3 & 128,1 & 164,4 & 67,0 & 106,9 & 135,9 \\
7 & 1 & 843,5 & 175,3 & 135,8 & 208,6 & 74,5 & 208,1 & 195,8 & 167,1 & 183,0 \\
8 & 1 & 415,0 & 660,8 & 163,9 & 217,6 & 230,9 & 167,9 & 60,0 & 104,6 & 80,1 \\
9 & 1 & 111,4 & 114,5 & 75,9 & 60,0 & 46,0 & 134,6 & 81,9 & 48,4 & 109,0 \\
10 & 1 & 386,6 & 119,4 & 317,3 & 172,4 & 132,4 & 142,8 & 163,6 & 85,8 & 74,9 \\
11 & 1 & 506,2 & 86,7 & 163,6 & 122,2 & 158,7 & 99,0 & 93,9 & 79,0 & 47,4 \\
1 & 2 & 400,0 & 98,3 & 117,6 & 138,8 & 87,0 & 225,4 & 275,6 & 137,0 & 233,0 \\
2 & 2 & 258,3 & 171,1 & 90,0 & 146,9 & 210,9 & 318,7 & 392,9 & 460,4 & 321,5 \\
3 & 2 & 48,9 & 56,4 & 62,9 & 87,5 & 84,7 & 118,0 & 83,8 & 101,4 & 113,0 \\
4 & 2 & 422,5 & 129,6 & 142,0 & 212,3 & 93,3 & 52,3 & 145,0 & 137,2 & 158,3 \\
5 & 2 & 165,7 & 146,0 & 154,2 & 139,8 & 108,8 & 219,8 & 191,3 & 175,3 & 241,7 \\
6 & 2 & 887,0 & 130,5 & 196,4 & 110,0 & 157,8 & 282,4 & 259,5 & 270,8 & 291,0 \\
7 & 2 & 276,6 & 161,3 & 149,3 & 169,4 & 119,7 & 205,4 & 85,1 & 137,3 & 117,6 \\
8 & 2 & & 181,3 & 151,6 & 525,0 & 289,3 & 137,3 & 179,0 & 277,7 & 93,8 \\
9 & 2 & 510,0 & 77,0 & 332,8 & 80,8 & 40,5 & 75,4 & 87,8 & 86,0 & 97,9 \\
10 & 2 & 224,7 & 155,4 & 191,0 & 158,1 & 181,0 & 108,8 & 91,0 & 102,0 & 140,3 \\
11 & 2 & 61,0 & 101,7 & 43,7 & 115,2 & 88,8 & 79,4 & 172,6 & 80,6 & 110,8 \\
\hline
\end{tabular}


ANEXO III - Média do erro variável (EV) em milissegundos, dos participantes dos dois grupos do experimento 1 [CA3 (1) e CA6 (2)], no primeiro bloco de tentativas de prática constante (Co1) e nos quatro blocos de tentativas de prática aleatória (Aleat) da fase de estabilização, e nos quatro blocos de tentativas da fase de adaptação (Adap).

\begin{tabular}{ccccccccccc}
\hline & & \multicolumn{10}{c}{ Erro Variável } \\
\cline { 2 - 11 } Sujeito & Grupo & Co1 & Aleat1 & Aleat2 & Aleat3 & Aleat4 & Adap1 & Adap2 & Adap3 & Adap4 \\
\hline 1 & 1 & 99,7 & 125,8 & 158,5 & 163,2 & 168,3 & 84,2 & 83,7 & 39,8 & 88,4 \\
2 & 1 & 558,9 & 101,4 & 129,2 & 213,0 & 127,5 & 142,7 & 101,4 & 130,7 & 147,0 \\
3 & 1 & 228,7 & 147,0 & 133,3 & 138,3 & 70,8 & 68,6 & 76,8 & 87,0 & 63,7 \\
4 & 1 & 182,1 & 155,1 & 180,1 & 220,0 & 93,0 & 130,4 & 109,5 & 111,8 & 96,3 \\
5 & 1 & 253,6 & 192,9 & 136,8 & 491,9 & 224,3 & 227,2 & 238,8 & 56,4 & 58,0 \\
6 & 1 & 99,3 & 168,9 & 398,6 & 147,7 & 117,0 & 216,6 & 77,7 & 93,4 & 174,4 \\
7 & 1 & 304,8 & 192,1 & 119,9 & 205,0 & 67,1 & 246,8 & 256,7 & 165,4 & 139,0 \\
8 & 1 & 120,2 & 1139,5 & 150,9 & 237,5 & 183,6 & 161,4 & 76,5 & 115,8 & 134,3 \\
9 & 1 & 137,2 & 135,5 & 79,0 & 83,3 & 56,7 & 173,7 & 59,4 & 48,3 & 34,0 \\
10 & 1 & 264,3 & 136,7 & 324,5 & 196,5 & 131,8 & 123,0 & 145,6 & 60,7 & 49,4 \\
11 & 1 & 463,4 & 102,7 & 213,5 & 104,3 & 207,2 & 123,8 & 63,4 & 62,8 & 43,9 \\
1 & 2 & & 82,7 & 154,9 & 150,2 & 69,1 & 150,4 & 141,6 & 88,9 & 70,9 \\
2 & 2 & 277,0 & 217,9 & 144,6 & 167,5 & 238,2 & 147,5 & 236,9 & 95,1 & 224,7 \\
3 & 2 & 82,5 & 68,0 & 70,9 & 97,8 & 80,9 & 85,5 & 92,6 & 46,6 & 88,8 \\
4 & 2 & 152,9 & 90,6 & 153,8 & 131,5 & 141,2 & 69,5 & 199,2 & 94,1 & 172,1 \\
5 & 2 & 216,8 & 163,7 & 149,5 & 187,8 & 130,2 & 183,3 & 102,8 & 192,8 & 82,6 \\
6 & 2 & 130,1 & 175,6 & 224,9 & 174,4 & 186,0 & 359,3 & 101,3 & 56,7 & 130,6 \\
7 & 2 & 296,6 & 207,2 & 190,5 & 195,7 & 136,4 & 206,0 & 99,5 & 130,4 & 95,3 \\
8 & 2 & & 218,2 & 80,8 & 754,1 & 498,6 & 163,8 & 218,9 & 309,9 & 139,7 \\
9 & 2 & 760,7 & 85,7 & 752,6 & 111,7 & 48,7 & 42,5 & 40,3 & 76,2 & 58,5 \\
10 & 2 & 253,5 & 236,5 & 244,3 & 195,7 & 316,9 & 163,4 & 111,9 & 121,6 & 195,0 \\
11 & 2 & 76,6 & 115,2 & 54,7 & 153,8 & 131,2 & 89,6 & 153,9 & 58,0 & 75,0 \\
\hline
\end{tabular}


ANEXO IV - Média do erro constante (EC) em milissegundos, dos participantes dos dois grupos do experimento 1 [CA3 (1) e CA6 (2)], no primeiro bloco de tentativas de prática constante (Co1) e nos quatro blocos de tentativas de prática aleatória (Aleat) da fase de estabilização, e nos quatro blocos de tentativas da fase de adaptação (Adap).

\begin{tabular}{cccccccccccc}
\hline & & \multicolumn{10}{c}{ Erro Constante } \\
\cline { 2 - 6 } & Grupo & Co1 & Aleat1 & Aleat2 & Aleat3 & Aleat4 & Adap1 & Adap2 & Adap3 & Adap4 \\
\hline 1 & 1 & 126,5 & 128,5 & 121,3 & 181,3 & 132,5 & $-92,6$ & 22,4 & $-6,6$ & $-56,0$ \\
2 & 1 & 1266,0 & $-32,8$ & 91,3 & 156,0 & $-4,3$ & $-396,6$ & $-266,0$ & $-172,0$ & $-206,6$ \\
3 & 1 & 217,4 & 61,6 & 82,7 & 71,4 & 71,6 & $-31,0$ & $-48,9$ & $-25,6$ & 34,0 \\
4 & 1 & 106,9 & $-23,1$ & 24,4 & $-35,0$ & $-45,0$ & $-133,0$ & $-162,3$ & $-144,5$ & $-116,8$ \\
5 & 1 & 288,5 & 107,8 & 91,0 & 260,3 & 76,8 & 131,3 & 49,1 & $-91,8$ & $-79,6$ \\
6 & 1 & 274,0 & 38,3 & 409,0 & 57,0 & 91,3 & $-115,6$ & $-26,5$ & $-94,9$ & $-16,7$ \\
7 & 1 & 843,5 & 114,2 & 96,3 & 185,7 & 56,2 & $-101,9$ & $-58,5$ & $-102,9$ & $-172,5$ \\
8 & 1 & 415,0 & 628,8 & 158,1 & 195,1 & 204,9 & $-113,9$ & 11,3 & 88,3 & 18,8 \\
9 & 1 & 16,3 & $-60,5$ & $-51,7$ & 13,3 & $-32,9$ & $-129,9$ & $-81,9$ & $-35,1$ & $-109,0$ \\
10 & 1 & 386,6 & 9,7 & 317,3 & 136,2 & 77,1 & $-142,8$ & $-142,7$ & $-82,5$ & $-71,3$ \\
11 & 1 & 506,2 & 8,7 & 67,3 & 120,2 & 17,3 & $-0,4$ & $-90,1$ & $-79,0$ & $-47,0$ \\
1 & 2 & 400,0 & 98,3 & 0,1 & 74,8 & $-87,0$ & $-208,6$ & $-258,7$ & $-137,0$ & $-233,0$ \\
2 & 2 & 247,0 & 32,3 & $-0,3$ & 128,9 & $-65,7$ & $-318,7$ & $-381,7$ & $-460,4$ & $-321,5$ \\
3 & 2 & 3,7 & $-7,8$ & $-40,1$ & $-73,2$ & $-68,1$ & $-118,0$ & $-39,8$ & $-101,4$ & $-89,6$ \\
4 & 2 & 422,5 & 129,6 & 114,0 & 205,3 & 53,3 & $-0,1$ & $-20,8$ & $-129,0$ & $-67,8$ \\
5 & 2 & 146,0 & 28,7 & $-104,6$ & $-18,5$ & 59,3 & $-201,8$ & $-191,3$ & $-86,7$ & $-241,7$ \\
6 & 2 & 887,0 & $-63,5$ & 49,0 & 69,2 & $-42,8$ & $-63,6$ & $-259,5$ & $-270,8$ & $-289,9$ \\
7 & 2 & 241,1 & 38,2 & $-8,0$ & $-55,4$ & $-90,6$ & $-167,4$ & $-85,1$ & $-132,0$ & $-101,3$ \\
8 & 2 & & 76,5 & 151,6 & 511,6 & 200,7 & $-33,6$ & 30,3 & 119,7 & $-16,7$ \\
9 & 2 & 510,0 & $-34,0$ & 287,4 & $-31,0$ & $-23,0$ & $-75,4$ & $-87,8$ & $-86,0$ & $-94,6$ \\
10 & 2 & 224,7 & 84,4 & 115,9 & 46,4 & 81,0 & 44,1 & $-42,3$ & $-25,3$ & $-26,1$ \\
11 & 2 & $-41,7$ & 46,7 & $-15,7$ & 10,1 & 1,4 & $-54,3$ & $-165,9$ & $-80,6$ & $-110,8$ \\
\hline
\end{tabular}


ANEXO V - Mediana do erro de execução (EE), dos participantes dos dois grupos do experimento 1 [CA3 (1) e CA6 (2)], no primeiro bloco de tentativas de prática constante (Co1) e nos quatro blocos de tentativas de prática aleatória (Aleat) da fase de estabilização, e nos quatro blocos de tentativas da fase de adaptação (Adap).

\begin{tabular}{cccccccccccc}
\hline & & \multicolumn{10}{c}{ Erro de Execução } \\
\cline { 2 - 11 } Sujeito & Grupo & Co1 & Aleat1 & Aleat2 & Aleat3 & Aleat4 & Adap1 & Adap2 & Adap3 & Adap4 \\
\hline 1 & 1 & 4,0 & 0,0 & 2,0 & 3,0 & 4,0 & 0,0 & 0,0 & 0,0 & 0,0 \\
2 & 1 & 6,0 & 5,0 & 2,0 & 2,0 & 4,0 & 4,0 & 0,0 & 2,0 & 2,0 \\
3 & 1 & 2,0 & 2,0 & 0,0 & 2,0 & 1,0 & 1,0 & 1,0 & 0,0 & 2,0 \\
4 & 1 & 2,0 & 1,0 & 0,0 & 1,0 & 0,0 & 1,0 & 1,0 & 1,0 & 0,0 \\
5 & 1 & 4,0 & 0,0 & 0,0 & 0,0 & 1,0 & 2,0 & 2,0 & 0,0 & 0,0 \\
6 & 1 & 2,0 & 0,0 & 2,0 & 3,0 & 2,0 & 1,0 & 5,0 & 2,0 & 2,0 \\
7 & 1 & 5,0 & 0,0 & 0,0 & 0,0 & 3,0 & 0,0 & 1,0 & 1,0 & 0,0 \\
8 & 1 & 7,0 & 1,0 & 2,0 & 0,0 & 2,0 & 0,0 & 0,0 & 0,0 & 0,0 \\
9 & 1 & 2,0 & 1,0 & 0,0 & 1,0 & 0,0 & 1,0 & 0,0 & 0,0 & 1,0 \\
10 & 1 & 4,0 & 0,0 & 0,0 & 0,0 & 0,0 & 0,0 & 0,0 & 1,0 & 0,0 \\
11 & 1 & 4,0 & 2,0 & 2,0 & 2,0 & 3,0 & 2,0 & 1,0 & 3,0 & 4,0 \\
1 & 2 & 7,0 & 3,0 & 0,0 & 4,0 & 3,0 & 1,0 & 0,0 & 2,0 & 1,0 \\
2 & 2 & 0,0 & 0,0 & 0,0 & 1,0 & 0,0 & 0,0 & 1,0 & 0,0 & 3,0 \\
3 & 2 & 1,0 & 0,0 & 0,0 & 0,0 & 0,0 & 1,0 & 0,0 & 0,0 & 1,0 \\
4 & 2 & 4,0 & 2,0 & 2,0 & 1,0 & 0,0 & 0,0 & 0,0 & 0,0 & 0,0 \\
5 & 2 & 2,0 & 3,0 & 3,0 & 2,0 & 4,0 & 3,0 & 4,0 & 2,0 & 0,0 \\
6 & 2 & 6,0 & 1,0 & 1,0 & 2,0 & 1,0 & 3,0 & 1,0 & 0,0 & 1,0 \\
7 & 2 & 2,0 & 0,0 & 1,0 & 0,0 & 0,0 & 1,0 & 1,0 & 0,0 & 0,0 \\
8 & 2 & 7,0 & 1,0 & 2,0 & 2,0 & 2,0 & 2,0 & 2,0 & 6,0 & 0,0 \\
9 & 2 & 5,0 & 3,0 & 0,0 & 1,0 & 1,0 & 0,0 & 1,0 & 1,0 & 1,0 \\
10 & 2 & 2,0 & 1,0 & 0,0 & 1,0 & 0,0 & 0,0 & 0,0 & 0,0 & 0,0 \\
11 & 2 & 6,0 & 3,0 & 2,0 & 0,0 & 0,0 & 0,0 & 1,0 & 0,0 & 0,0 \\
\hline & & & & & & & & & &
\end{tabular}


ANEXO VI - Média do erro absoluto (EA) em milissegundos, dos participantes dos dois grupos do experimento 2 [CA3 (1) e CA6 (2)], no primeiro bloco de tentativas de prática constante (Co1) e nos quatro blocos de tentativas de prática aleatória (Aleat) da fase de estabilização, e nos quatro blocos de tentativas da fase de adaptação (Adap).

\begin{tabular}{ccccccccccc}
\hline & & \multicolumn{10}{c}{ Erro Absoluto } \\
\cline { 2 - 11 } Sujeito & Grupo & Co1 & Aleat1 & Aleat2 & Aleat3 & Aleat4 & Adap1 & Adap2 & Adap3 & Adap4 \\
\hline 1 & 1 & 386,8 & 140,4 & 247,7 & 131,2 & 92,2 & 182,5 & 307,0 & 438,3 & 302,0 \\
2 & 1 & 694,0 & 119,1 & 99,8 & 121,8 & 45,0 & 133,0 & 139,3 & 86,5 & 67,4 \\
3 & 1 & 207,3 & 129,6 & 77,3 & 58,6 & 102,9 & 102,6 & 103,8 & 125,1 & 52,2 \\
4 & 1 & 52,5 & 57,8 & 94,1 & 54,5 & 80,1 & 118,4 & 72,9 & 24,3 & 86,6 \\
5 & 1 & 396,0 & 144,8 & 95,3 & 74,1 & 119,0 & 159,0 & 515,3 & 601,8 & 245,0 \\
6 & 1 & 179,6 & 126,0 & 35,8 & 184,7 & 42,4 & 43,0 & 71,1 & 85,2 & 85,6 \\
7 & 1 & 147,5 & 65,9 & 177,7 & 74,8 & 84,1 & 97,5 & 85,8 & 72,4 & 55,3 \\
8 & 1 & 792,4 & 85,5 & 34,3 & 75,0 & 80,3 & 63,4 & 27,6 & 54,4 & 57,8 \\
9 & 1 & 186,5 & 76,6 & 177,8 & 45,4 & 60,9 & 82,2 & 57,7 & 22,9 & 27,9 \\
10 & 1 & 694,0 & 38,0 & 178,8 & 307,7 & 181,5 & 202,0 & 144,5 & 208,6 & 205,2 \\
11 & 1 & 1,0 & 66,3 & 249,5 & 45,0 & 111,5 & 275,5 & 147,1 & 204,0 & 78,4 \\
1 & 2 & 663,5 & 560,5 & 127,8 & 169,5 & 40,3 & 740,3 & 598,5 & 382,3 & 204,5 \\
2 & 2 & & 75,7 & 19,0 & 202,5 & 55,5 & 157,6 & 326,5 & 235,5 & 126,5 \\
3 & 2 & 246,7 & 134,0 & 123,8 & 60,9 & 89,4 & 77,2 & 115,2 & 84,4 & 86,0 \\
4 & 2 & 89,6 & 585,0 & 898,8 & 1392,5 & 1443,0 & 223,8 & 219,2 & 72,8 & 236,0 \\
5 & 2 & 306,0 & 159,7 & 121,3 & 98,9 & 118,2 & 209,8 & 34,0 & 76,7 & 70,7 \\
6 & 2 & 482,0 & 45,0 & 303,3 & 185,4 & 122,0 & 143,2 & 177,0 & 108,0 & 73,6 \\
7 & 2 & 229,0 & 95,0 & 124,6 & 82,0 & 54,3 & 80,6 & 56,5 & 38,7 & 72,4 \\
8 & 2 & 107,6 & 1104,0 & 18,0 & 918,0 & 305,8 & 50,6 & 49,1 & 74,1 & 120,2 \\
9 & 2 & 183,0 & 124,2 & 66,0 & 72,8 & 84,5 & 80,6 & 58,8 & 53,7 & 48,6 \\
10 & 2 & 1234,6 & 2262,1 & 2317,3 & 1898,3 & 1376,5 & 207,6 & 118,0 & 123,7 & 190,8 \\
11 & 2 & 24,0 & 50,3 & 37,5 & 38,1 & 81,7 & 39,8 & 52,3 & 32,1 & 86,2 \\
\hline
\end{tabular}


ANEXO VII - Média do erro variável (EV) em milissegundos, dos participantes dos dois grupos do experimento 2 [CA3 (1) e CA6 (2)], no primeiro bloco de tentativas de prática constante (Co1) e nos quatro blocos de tentativas de prática aleatória (Aleat) da fase de estabilização, e nos quatro blocos de tentativas da fase de adaptação (Adap).

\begin{tabular}{ccccccccccc}
\hline & & \multicolumn{10}{c}{ Erro Variável } \\
\cline { 2 - 11 } Sujeito & Grupo & Co1 & Aleat1 & Aleat2 & Aleat3 & Aleat4 & Adap1 & Adap2 & Adap3 & Adap4 \\
\hline 1 & 1 & 102,2 & 105,9 & 190,9 & 115,2 & 59,9 & 115,9 & 172,5 & 175,8 & 57,6 \\
2 & 1 & 584,1 & 104,6 & 66,3 & 131,8 & 68,9 & 131,3 & 103,7 & 38,9 & 73,5 \\
3 & 1 & 194,5 & 173,5 & 103,1 & 71,6 & 120,8 & 96,7 & 21,4 & 40,2 & 50,7 \\
4 & 1 & 60,1 & 71,3 & 128,2 & 59,1 & 113,0 & 139,7 & 90,0 & 34,0 & 82,1 \\
5 & 1 & 178,8 & 133,1 & 81,6 & 118,1 & 199,2 & & 586,0 & 821,4 & 170,3 \\
6 & 1 & 115,6 & 143,6 & 49,3 & 254,6 & 58,1 & 48,3 & 80,9 & 97,4 & 137,1 \\
7 & 1 & 222,8 & 53,6 & 249,9 & 72,5 & 95,5 & 124,6 & 110,1 & 85,3 & 54,2 \\
8 & 1 & 181,0 & 56,0 & 46,3 & 101,4 & 75,1 & 32,3 & 32,7 & 60,0 & 83,2 \\
9 & 1 & 248,8 & 112,2 & 294,2 & 42,1 & 72,3 & 91,0 & 65,7 & 22,3 & 37,0 \\
10 & 1 & 606,7 & & 197,6 & 91,8 & 167,2 & 56,7 & 119,7 & 37,7 & 83,0 \\
11 & 1 & & 92,5 & 352,8 & & 95,0 & 184,2 & 79,3 & 107,7 & 98,4 \\
1 & 2 & 485,8 & 758,7 & 104,4 & 9,2 & 33,5 & 219,8 & 152,0 & 115,5 & 211,0 \\
2 & 2 & & 110,5 & 4,2 & 65,8 & 78,5 & 172,6 & 458,9 & 95,5 & 81,3 \\
3 & 2 & 257,9 & 155,3 & 22,8 & 66,0 & 104,9 & 75,4 & 130,4 & 95,2 & 82,5 \\
4 & 2 & 103,7 & 471,5 & 596,9 & 673,8 & & 68,2 & 185,6 & 78,2 & 375,9 \\
5 & 2 & 230,3 & 182,0 & 84,0 & 106,4 & 79,5 & 136,9 & 43,5 & 65,1 & 99,5 \\
6 & 2 & 226,7 & & 98,0 & 145,6 & 97,6 & 114,9 & 97,1 & 107,1 & 90,0 \\
7 & 2 & & 104,1 & 108,1 & 99,4 & 48,7 & 105,2 & 64,3 & 45,4 & 95,4 \\
8 & 2 & 146,5 & 1561,3 & & 1102,3 & 445,0 & 50,2 & 62,1 & 97,0 & 151,6 \\
9 & 2 & 188,5 & 152,7 & 84,9 & 91,6 & 84,3 & 123,6 & 71,9 & 55,0 & 48,8 \\
10 & 2 & 240,9 & 766,0 & 1420,7 & 1098,6 & 1656,7 & 104,1 & 166,6 & 74,8 & 214,4 \\
11 & 2 & 24,3 & 58,3 & 55,8 & 35,1 & 39,9 & 44,3 & 57,0 & 39,6 & 62,6 \\
\hline
\end{tabular}


ANEXO VIII - Média do erro constante (EC) em milissegundos, dos participantes dos dois grupos do experimento 2 [CA3 (1) e CA6 (2)], no primeiro bloco de tentativas de prática constante (Co1) e nos quatro blocos de tentativas de prática aleatória (Aleat) da fase de estabilização, e nos quatro blocos de tentativas da fase de adaptação (Adap).

\begin{tabular}{ccccccccccc}
\hline & & \multicolumn{10}{c}{ Erro Constante } \\
\cline { 2 - 11 } Sujeito & Grupo & Co1 & Aleat1 & Aleat2 & Aleat3 & Aleat4 & Adap1 & Adap2 & Adap3 & Adap4 \\
\hline 1 & 1 & 386,8 & 135,6 & 247,7 & 122,3 & 92,2 & 182,5 & 307,0 & 438,3 & 302,0 \\
2 & 1 & 694,0 & 116,9 & 99,8 & 121,8 & 40,2 & 104,3 & 139,3 & 86,5 & 57,0 \\
3 & 1 & $-140,3$ & $-23,2$ & 27,0 & 9,9 & 59,9 & $-58,2$ & $-103,8$ & $-125,1$ & $-52,2$ \\
4 & 1 & $-52,5$ & 48,2 & $-2,8$ & $-45,8$ & $-10,7$ & 13,3 & 65,1 & 7,0 & 60,1 \\
5 & 1 & 396,0 & 130,2 & 86,4 & 67,9 & 99,0 & 159,0 & 515,3 & 579,4 & 245,0 \\
6 & 1 & 173,1 & 71,7 & $-0,8$ & 157,3 & 5,6 & 18,7 & $-30,1$ & 53,9 & 17,4 \\
7 & 1 & 88,0 & $-63,6$ & 41,1 & $-51,0$ & $-52,1$ & $-13,5$ & $-32,3$ & $-49,6$ & $-42,3$ \\
8 & 1 & 792,4 & $-80,0$ & 17,7 & 28,3 & $-62,5$ & $-63,4$ & 9,1 & $-28,7$ & $-12,0$ \\
9 & 1 & 112,0 & 16,6 & 83,8 & $-42,6$ & 36,6 & $-36,2$ & $-8,0$ & $-17,6$ & $-12,6$ \\
10 & 1 & 694,0 & $-38,0$ & 144,3 & 307,7 & 181,5 & 202,0 & 144,5 & 208,6 & 205,2 \\
11 & 1 & $-1,0$ & $-47,0$ & 238,5 & 45,0 & 97,5 & 275,5 & 147,1 & 204,0 & 18,4 \\
1 & 2 & 663,5 & 560,5 & 127,8 & 169,5 & 37,3 & 740,3 & 598,5 & 382,3 & 204,5 \\
2 & 2 & & 27,0 & $-19,0$ & 202,5 & 13,5 & 157,6 & 326,5 & 235,5 & 126,5 \\
3 & 2 & 246,7 & 109,0 & 123,8 & 56,9 & 64,0 & 77,2 & 35,5 & 39,6 & 81,3 \\
4 & 2 & 86,0 & 585,0 & 898,8 & 1392,5 & 1443,0 & 223,8 & 219,2 & 59,2 & 232,0 \\
5 & 2 & 306,0 & 151,4 & 121,3 & 52,3 & 116,2 & 209,8 & $-12,4$ & 63,3 & 22,2 \\
6 & 2 & 482,0 & 45,0 & 303,3 & 152,2 & 122,0 & 137,2 & 177,0 & 90,5 & 42,9 \\
7 & 2 & 229,0 & 88,5 & 102,6 & 30,0 & 54,3 & 13,1 & $-15,5$ & 9,3 & 44,0 \\
8 & 2 & 71,2 & 1030,0 & 18,0 & 900,0 & 262,3 & 42,9 & 9,9 & 73,6 & 96,9 \\
9 & 2 & 169,0 & 120,6 & 29,0 & 1,8 & 67,5 & 38,3 & $-1,0$ & $-32,3$ & $-32,6$ \\
10 & 2 & 1234,6 & 2262,1 & 2317,3 & 1898,3 & 928,8 & 207,6 & 105,4 & 123,7 & 190,8 \\
11 & 2 & 16,0 & 39,7 & 31,5 & 37,9 & 81,7 & 24,5 & 36,0 & 3,6 & 86,2 \\
\hline
\end{tabular}


ANEXO IX - Mediana do erro de execução (EE), dos participantes dos dois grupos do experimento 2 [CA3 (1) e CA6 (2)], no primeiro bloco de tentativas de prática constante (Co1) e nos quatro blocos de tentativas de prática aleatória (Aleat) da fase de estabilização, e nos quatro blocos de tentativas da fase de adaptação (Adap).

\begin{tabular}{cccccccccccc}
\hline & & \multicolumn{10}{c}{ Erro de Execução } \\
\cline { 2 - 10 } Sujeito & Grupo & Co1 & Aleat1 & Aleat2 & Aleat3 & Aleat4 & Adap1 & Adap2 & Adap3 & Adap4 \\
\hline 1 & 1 & 5,0 & 2,0 & 3,0 & 0,0 & 4,0 & 5,0 & 7,0 & 6,0 & 4,0 \\
2 & 1 & 7,0 & 2,0 & 0,0 & 1,0 & 0,0 & 2,0 & 2,0 & 3,0 & 0,0 \\
3 & 1 & 2,0 & 3,0 & 0,0 & 0,0 & 1,0 & 1,0 & 0,0 & 1,0 & 0,0 \\
4 & 1 & 4,0 & 1,0 & 0,0 & 0,0 & 0,0 & 2,0 & 2,0 & 3,0 & 1,0 \\
5 & 1 & 1,0 & 3,0 & 2,0 & 0,0 & 3,0 & 8,0 & 5,0 & 4,0 & 4,0 \\
6 & 1 & 1,0 & 2,0 & 3,0 & 1,0 & 1,0 & 3,0 & 1,0 & 0,0 & 1,0 \\
7 & 1 & 5,0 & 1,0 & 2,0 & 1,0 & 2,0 & 3,0 & 1,0 & 2,0 & 1,0 \\
8 & 1 & 4,0 & 1,0 & 2,0 & 1,0 & 1,0 & 0,0 & 0,0 & 0,0 & 1,0 \\
9 & 1 & 1,0 & 0,0 & 1,0 & 2,0 & 1,0 & 3,0 & 2,0 & 1,0 & 0,0 \\
10 & 1 & 7,0 & 8,0 & 5,0 & 6,0 & 3,0 & 6,0 & 1,0 & 4,0 & 4,0 \\
11 & 1 & 8,0 & 6,0 & 6,0 & 8,0 & 1,0 & 5,0 & 2,0 & 4,0 & 1,0 \\
1 & 2 & 6,0 & 7,0 & 3,0 & 6,0 & 4,0 & 6,0 & 7,0 & 5,0 & 1,0 \\
2 & 2 & 9,0 & 5,0 & 7,0 & 7,0 & 6,0 & 4,0 & 7,0 & 7,0 & 6,0 \\
3 & 2 & 6,0 & 3,0 & 2,0 & 1,0 & 2,0 & 3,0 & 2,0 & 2,0 & 1,0 \\
4 & 2 & 3,0 & 4,0 & 3,0 & 3,0 & 3,0 & 2,0 & 0,0 & 0,0 & 1,0 \\
5 & 2 & 4,0 & 2,0 & 3,0 & 2,0 & 4,0 & 4,0 & 0,0 & 2,0 & 0,0 \\
6 & 2 & 5,0 & 8,0 & 4,0 & 4,0 & 5,0 & 3,0 & 1,0 & 1,0 & 0,0 \\
7 & 2 & 6,0 & 5,0 & 1,0 & 3,0 & 5,0 & 2,0 & 1,0 & 2,0 & 0,0 \\
8 & 2 & 4,0 & 7,0 & 8,0 & 3,0 & 5,0 & 0,0 & 0,0 & 1,0 & 0,0 \\
9 & 2 & 6,0 & 4,0 & 3,0 & 4,0 & 5,0 & 2,0 & 1,0 & 3,0 & 1,0 \\
10 & 2 & 4,0 & 2,0 & 1,0 & 1,0 & 3,0 & 2,0 & 2,0 & 3,0 & 3,0 \\
11 & 2 & 0,0 & 2,0 & 2,0 & 1,0 & 1,0 & 0,0 & 1,0 & 1,0 & 2,0 \\
\hline
\end{tabular}


ANEXO X - Média do erro absoluto (EA) em milissegundos, dos participantes dos dois grupos do experimento 3 [CA9 (1) e CA36 (2)], no primeiro bloco de tentativas de prática constante (Co1) e nos quatro blocos de tentativas de prática aleatória (Aleat) da fase de estabilização, e nos quatro blocos de tentativas da fase de adaptação (Adap).

\begin{tabular}{ccccccccccc}
\hline & & \multicolumn{10}{c}{ Erro Absoluto } \\
\cline { 2 - 11 } Sujeito & Grupo & Co1 & Aleat1 & Aleat2 & Aleat3 & Aleat4 & Adap1 & Adap2 & Adap3 & Adap4 \\
\hline 1 & 1 & 564,1 & 207,1 & 421,4 & 330,4 & 193,1 & 243,6 & 208,0 & 212,9 & 155,2 \\
2 & 1 & 139,8 & 839,1 & 601,4 & 400,4 & 490,8 & 544,7 & 701,4 & 463,8 & 309,3 \\
3 & 1 & 295,6 & 250,0 & 103,1 & 227,4 & 329,9 & 929,3 & 525,4 & 383,9 & 205,8 \\
4 & 1 & 1446,3 & 964,2 & 554,4 & 215,1 & 807,0 & 1090,1 & 890,8 & 502,0 & 151,0 \\
5 & 1 & & 1116,8 & 726,9 & 520,0 & 614,0 & 1457,9 & 1052,8 & 366,8 & 762,2 \\
6 & 1 & 51,4 & 156,0 & 438,1 & 196,4 & 54,0 & 277,6 & 309,8 & 291,1 & 109,6 \\
7 & 1 & 482,0 & 631,5 & 216,6 & 227,1 & 171,3 & 277,3 & 878,4 & 448,9 & 309,0 \\
8 & 1 & 1505,8 & 468,0 & 872,0 & 595,4 & 716,1 & 525,2 & 454,6 & 459,4 & 317,7 \\
9 & 1 & 88,0 & 308,1 & 66,8 & 602,8 & 367,6 & 483,9 & 701,7 & 69,7 & 66,7 \\
10 & 1 & 241,6 & 326,3 & 752,5 & 316,8 & 430,9 & 299,9 & 496,6 & 50,3 & 460,2 \\
11 & 1 & 145,8 & 106,2 & 377,3 & 209,8 & 236,0 & 277,6 & 72,9 & 296,1 & 461,1 \\
1 & 2 & 346,4 & 937,3 & 1179,6 & 737,8 & 421,4 & 558,9 & 161,0 & 724,4 & 96,8 \\
2 & 2 & 433,7 & 694,9 & 485,9 & 726,0 & 787,6 & 1440,0 & 1078,6 & 1255,6 & 883,3 \\
3 & 2 & 110,8 & 673,8 & 331,0 & 288,0 & 54,7 & 270,9 & 585,9 & 901,6 & 588,3 \\
4 & 2 & 225,3 & 742,7 & 755,9 & 620,4 & 545,4 & 73,9 & 245,0 & 1242,4 & 858,8 \\
5 & 2 & 951,5 & 963,9 & 580,7 & 747,3 & 893,1 & 785,9 & 297,1 & 683,7 & 73,6 \\
6 & 2 & 240,5 & 1438,6 & 522,1 & 541,4 & 687,6 & 627,8 & 566,4 & 609,8 & 568,6 \\
7 & 2 & 382,3 & 1016,9 & 463,3 & 753,6 & 926,8 & 830,2 & 219,2 & 768,9 & 382,0 \\
8 & 2 & 94,8 & 567,4 & 40,9 & 407,6 & 52,6 & 266,1 & 32,9 & 29,7 & 42,1 \\
9 & 2 & 314,0 & 1243,9 & 1129,6 & 1172,0 & 1109,1 & 726,8 & 93,9 & 851,9 & 358,0 \\
10 & 2 & 25,0 & 467,4 & 471,6 & 433,1 & 265,2 & 60,8 & 98,1 & 140,7 & 143,9 \\
11 & 2 & 802,4 & 984,6 & 855,8 & 416,3 & 272,0 & 505,6 & 65,4 & 55,9 & 38,8 \\
\hline
\end{tabular}


ANEXO XI - Média do erro variável (EV) em milissegundos, dos participantes dos dois grupos do experimento 3 [CA9 (1) e CA36 (2)], no primeiro bloco de tentativas de prática constante (Co1) e nos quatro blocos de tentativas de prática aleatória (Aleat) da fase de estabilização, e nos quatro blocos de tentativas da fase de adaptação (Adap).

\begin{tabular}{ccccccccccc}
\hline & & \multicolumn{10}{c}{ Erro Variável } \\
\cline { 2 - 10 } Sujeito & Grupo & Co1 & Aleat1 & Aleat2 & Aleat3 & Aleat4 & Adap1 & Adap2 & Adap3 & Adap4 \\
\hline 1 & 1 & 468,8 & 191,9 & 659,8 & 505,5 & 134,9 & 80,6 & 41,5 & 49,5 & 48,9 \\
2 & 1 & 204,8 & 745,7 & 850,9 & 558,6 & 805,4 & 853,7 & 944,1 & 819,3 & 642,1 \\
3 & 1 & 261,4 & 456,1 & 120,5 & 413,7 & 600,6 & 853,0 & 798,2 & 642,5 & 187,7 \\
4 & 1 & 461,6 & 821,8 & 846,7 & 222,3 & 1066,7 & 1055,1 & 889,1 & 865,5 & 188,3 \\
5 & 1 & & 1301,3 & 967,0 & 737,2 & 883,6 & 867,2 & 931,5 & 576,0 & 831,2 \\
6 & 1 & 58,4 & 177,8 & 698,1 & 384,7 & 60,1 & 581,7 & 572,3 & 577,0 & 45,3 \\
7 & 1 & & 843,2 & 236,8 & 200,9 & 193,6 & 608,7 & 1014,7 & 795,0 & 610,1 \\
8 & 1 & 1675,2 & 709,9 & 850,5 & 806,4 & 832,5 & 746,7 & 788,7 & 777,9 & 609,2 \\
9 & 1 & & 561,4 & 80,6 & 611,0 & 542,7 & 769,8 & 843,5 & 63,9 & 52,6 \\
10 & 1 & 189,5 & 489,2 & 788,6 & 531,1 & 717,6 & 595,8 & 845,3 & 74,9 & 775,0 \\
11 & 1 & 169,9 & 156,2 & 599,0 & 370,6 & 524,4 & 596,8 & 91,1 & 588,9 & 773,1 \\
1 & 2 & 277,2 & 1084,0 & 1146,8 & 937,8 & 655,4 & 824,7 & 63,8 & 827,6 & 70,2 \\
2 & 2 & 335,6 & 903,1 & 761,8 & 832,8 & 862,3 & 822,9 & 884,4 & 852,7 & 893,4 \\
3 & 2 & 65,7 & 687,0 & 579,8 & 558,0 & 70,9 & 186,2 & 706,1 & 881,3 & 707,1 \\
4 & 2 & 295,6 & 643,9 & 783,7 & 684,3 & 698,6 & 78,4 & 599,5 & 897,2 & 956,7 \\
5 & 2 & 500,0 & 1105,0 & 749,8 & 794,8 & 972,1 & 962,8 & 595,6 & 880,4 & 89,5 \\
6 & 2 & 179,6 & 973,6 & 764,0 & 691,5 & 767,3 & 851,7 & 884,4 & 784,6 & 723,0 \\
7 & 2 & 141,6 & 802,2 & 725,8 & 984,3 & 747,8 & 970,7 & 174,9 & 795,8 & 562,0 \\
8 & 2 & 104,0 & 705,8 & 52,5 & 664,4 & 67,0 & 625,8 & 41,1 & 34,2 & 53,2 \\
9 & 2 & 408,6 & 660,2 & 1314,5 & 1342,3 & 1253,5 & 1060,4 & 123,1 & 946,5 & 647,6 \\
10 & 2 & 35,7 & 662,1 & 702,8 & 691,1 & 544,4 & 64,6 & 108,3 & 185,1 & 137,7 \\
11 & 2 & 403,2 & 1132,5 & 914,4 & 585,9 & 454,6 & 779,5 & 76,5 & 61,3 & 51,5 \\
\hline
\end{tabular}


ANEXO XII - Média do erro constante (EC) em milissegundos, dos participantes dos dois grupos do experimento 3 [CA9 (1) e CA36 (2)], no primeiro bloco de tentativas de prática constante (Co1) e nos quatro blocos de tentativas de prática aleatória (Aleat) da fase de estabilização, e nos quatro blocos de tentativas da fase de adaptação (Adap).

\begin{tabular}{|c|c|c|c|c|c|c|c|c|c|c|}
\hline \multicolumn{11}{|c|}{ Erro Constante } \\
\hline Sujeito & Grupo & Co1 & Aleat1 & Aleat2 & Aleat3 & Aleat4 & Adap1 & Adap2 & Adap3 & Adap4 \\
\hline 1 & 1 & 564,1 & 168,0 & 37,4 & 43,1 & 193,1 & $-243,6$ & $-208,0$ & $-212,9$ & $-155,2$ \\
\hline 2 & 1 & 15,4 & $-768,6$ & $-156,6$ & $-220,9$ & 40,0 & $-54,7$ & $-590,3$ & $-388,9$ & $-188,4$ \\
\hline 3 & 1 & 295,6 & $-60,3$ & 63,1 & $-106,8$ & $-102,1$ & $-929,3$ & $-448,3$ & $-246,1$ & $-174,7$ \\
\hline 4 & 1 & 1446,3 & $-827,8$ & $-216,9$ & 88,0 & $-249,0$ & $-937,2$ & $-890,8$ & $-320,4$ & $-25,0$ \\
\hline 5 & 1 & & $-163,2$ & $-333,6$ & $-318,3$ & $-277,7$ & 1389,2 & 1040,3 & $-341,0$ & $-730,9$ \\
\hline 6 & 1 & $-22,1$ & $-30,7$ & $-413,9$ & $-155,8$ & $-40,6$ & $-277,6$ & $-309,8$ & $-291,1$ & $-109,6$ \\
\hline 7 & 1 & 482,0 & $-328,5$ & 194,1 & 172,9 & 120,8 & $-224,0$ & $-765,8$ & $-424,9$ & $-231,4$ \\
\hline 8 & 1 & 1475,8 & $-129,3$ & $-689,1$ & $-357,0$ & $-493,9$ & $-521,4$ & $-437,4$ & $-454,3$ & $-247,0$ \\
\hline 9 & 1 & $-88,0$ & $-90,8$ & 51,3 & $-582,8$ & $-359,6$ & $-473,0$ & $-701,7$ & $-66,3$ & $-62,2$ \\
\hline 10 & 1 & 221,2 & $-38,8$ & $-626,8$ & $-224,8$ & $-381,4$ & $-287,2$ & $-359,9$ & $-11,9$ & $-459,3$ \\
\hline 11 & 1 & 124,5 & $-35,1$ & $-323,1$ & $-191,1$ & $-165,3$ & $-257,3$ & $-8,7$ & $-276,3$ & $-461,1$ \\
\hline 1 & 2 & 346,4 & $-406,7$ & $-716,4$ & $-270,3$ & $-237,2$ & $-426,2$ & $-161,0$ & $-724,4$ & $-96,8$ \\
\hline 2 & 2 & 433,7 & $-441,6$ & $-370,9$ & $-492,7$ & $-556,4$ & $\stackrel{-}{1410,0}$ & 1078,6 & 1255,6 & $-883,3$ \\
\hline 3 & 2 & $-110,8$ & $-662,0$ & $-259,8$ & $-207,4$ & $-27,3$ & $-268,2$ & $-585,9$ & $-901,6$ & $-588,3$ \\
\hline 4 & 2 & 196,7 & $-742,7$ & $-741,9$ & $-587,1$ & $-528,6$ & $-59,9$ & $-232,6$ & 1226,7 & $-818,8$ \\
\hline 5 & 2 & 951,5 & $-418,1$ & 193,6 & 387,3 & $-402,9$ & $-603,7$ & $-262,7$ & $-656,3$ & $-47,3$ \\
\hline 6 & 2 & 240,5 & 1121,4 & $-288,6$ & $-492,4$ & $-577,1$ & 113,8 & $-290,4$ & $-504,7$ & $-568,6$ \\
\hline 7 & 2 & 382,3 & $-950,9$ & $-333,6$ & $-206,4$ & $-804,8$ & $-619,8$ & $-157,4$ & $-768,9$ & $-358,2$ \\
\hline 8 & 2 & 41,8 & $-530,6$ & 21,6 & $-195,3$ & 13,6 & $-186,6$ & $-24,4$ & $-21,7$ & $-18,6$ \\
\hline 9 & 2 & 314,0 & 1169,9 & $-430,4$ & $-268,0$ & 255,8 & $-99,0$ & 16,1 & $-828,1$ & $-182,4$ \\
\hline 10 & 2 & 4,7 & 138,9 & $-110,7$ & $-217,3$ & $-143,0$ & $-42,6$ & $-97,0$ & $-4,4$ & $-136,3$ \\
\hline 11 & 2 & 802,4 & $-359,4$ & $-735,8$ & $-272,1$ & $-29,1$ & $-470,4$ & $-37,0$ & $-48,6$ & $-24,3$ \\
\hline
\end{tabular}


ANEXO XIII - Mediana do erro de execução (EE), dos participantes dos dois grupos do experimento 3 [CA9 (1) e CA36 (2)], no primeiro bloco de tentativas de prática constante (Co1) e nos quatro blocos de tentativas de prática aleatória (Aleat) da fase de estabilização, e nos quatro blocos de tentativas da fase de adaptação (Adap).

\begin{tabular}{cccccccccccc}
\hline & & \multicolumn{10}{c}{ Erro de Execução } \\
\cline { 2 - 11 } Sujeito & Grupo & Co1 & Aleat1 & Aleat2 & Aleat3 & Aleat4 & Adap1 & Adap2 & Adap3 & Adap4 \\
\hline 1 & 1 & 2,0 & 2,0 & 1,0 & 1,0 & 0,0 & 0,0 & 0,0 & 0,0 & 0,0 \\
2 & 1 & 3,0 & 5,0 & 1,0 & 1,0 & 2,0 & 2,0 & 1,0 & 2,0 & 1,0 \\
3 & 1 & 1,0 & 1,0 & 0,0 & 0,0 & 0,0 & 3,0 & 2,0 & 0,0 & 0,0 \\
4 & 1 & 5,0 & 7,0 & 3,0 & 0,0 & 3,0 & 5,0 & 4,0 & 2,0 & 0,0 \\
5 & 1 & 6,0 & 4,0 & 2,0 & 2,0 & 3,0 & 6,0 & 1,0 & 0,0 & 1,0 \\
6 & 1 & 1,0 & 3,0 & 3,0 & 1,0 & 2,0 & 0,0 & 0,0 & 0,0 & 0,0 \\
7 & 1 & 7,0 & 3,0 & 0,0 & 1,0 & 0,0 & 0,0 & 0,0 & 0,0 & 0,0 \\
8 & 1 & 4,0 & 2,0 & 6,0 & 3,0 & 4,0 & 2,0 & 2,0 & 2,0 & 1,0 \\
9 & 1 & 7,0 & 1,0 & 1,0 & 5,0 & 4,0 & 2,0 & 3,0 & 0,0 & 0,0 \\
10 & 1 & 4,0 & 2,0 & 5,0 & 2,0 & 3,0 & 1,0 & 2,0 & 0,0 & 2,0 \\
11 & 1 & 2,0 & 0,0 & 1,0 & 0,0 & 1,0 & 0,0 & 0,0 & 1,0 & 2,0 \\
1 & 2 & 1,0 & 3,0 & 5,0 & 3,0 & 1,0 & 2,0 & 0,0 & 2,0 & 0,0 \\
2 & 2 & 1,0 & 4,0 & 1,0 & 2,0 & 2,0 & 2,0 & 1,0 & 3,0 & 1,0 \\
3 & 2 & 3,0 & 3,0 & 1,0 & 1,0 & 0,0 & 0,0 & 0,0 & 1,0 & 0,0 \\
4 & 2 & 5,0 & 2,0 & 2,0 & 2,0 & 0,0 & 0,0 & 0,0 & 2,0 & 2,0 \\
5 & 2 & 4,0 & 4,0 & 1,0 & 2,0 & 5,0 & 1,0 & 0,0 & 3,0 & 0,0 \\
6 & 2 & 1,0 & 4,0 & 1,0 & 4,0 & 3,0 & 1,0 & 2,0 & 2,0 & 2,0 \\
7 & 2 & 4,0 & 4,0 & 1,0 & 2,0 & 3,0 & 2,0 & 0,0 & 2,0 & 1,0 \\
8 & 2 & 5,0 & 4,0 & 0,0 & 2,0 & 1,0 & 1,0 & 0,0 & 0,0 & 0,0 \\
9 & 2 & 3,0 & 8,0 & 4,0 & 5,0 & 3,0 & 2,0 & 0,0 & 4,0 & 1,0 \\
10 & 2 & 2,0 & 2,0 & 1,0 & 2,0 & 1,0 & 0,0 & 0,0 & 0,0 & 0,0 \\
11 & 2 & 4,0 & 4,0 & 5,0 & 2,0 & 1,0 & 2,0 & 0,0 & 0,0 & 0,0 \\
\hline
\end{tabular}

